\title{
A QUANTITATIVE ASSESSMENT OF THE EFFECT OF FIRST CONTRACT ARBITRATION ON BARGAINING RELATIONSHIPS
}

\author{
A Thesis \\ Presented to the Faculty of the Graduate School \\ of Cornell University \\ In Partial Fulfillment of the Requirements for the Degree of \\ Master of Science
}

by

Bradley Richard Weinberg

January 2013 
(C) 2013 Bradley Weinberg 


\begin{abstract}
First contract arbitration (FCA), the Canadian labor law that allows the union or the employer to apply to the provincial labor board for assistance in settling an agreement in first contract situations, was originally created with four goals in mind: (1) to end first contract work stoppages, (2) to allow newly certified unions to obtain a first agreement, (3) to foster enduring bargaining relationships, and (4) to deter further misconduct. This study seeks to enter the debate concerning the latter two by examining the effect of FCA provisions on two scaled measures of decertification, which are used as proxies for measuring bargaining relationships. This is undertaken using Time-Series Cross-Sectional (TSCS) analysis with data from nine Canadian provinces over a four decade time period. It finds that the presence of an FCA provision correlates with 23 to 32 percent less decertifications, depending on the measure of decertification employed, in provinces with an FCA provision than in those without one. Furthermore, it examines the different types of FCA which shows that the automatic and fault forms of FCA correlate with 32 to 44 percent and 26-31 percent less decertifications respectively, depending on the measure, than in those provinces without a provision. Although this analysis cannot investigate whether FCA fosters lengthy bargaining relationships, it represents a preliminary attempt to assess this goal by showing that less decertifications take place in the provinces that provide access to FCA than those that do not, which implies that there are more bargaining relationships on aggregate. Furthermore, this study represents the first to undertake an investigation of this goal of FCA using a multi-jurisdictional quantitative approach that incorporates the whole of the industrial relations arena of the provinces included, meaning both bargaining units who accessed the FCA system and those that did not. Thus, it is the first to incorporate both the direct and indirect (deterrent) effects of FCA in measuring this outcome.
\end{abstract}




\section{BIOGRAPHICAL SKETCH}

Bradley R. Weinberg was born and raised in Central New York where he attended Marcellus High School and then Hobart College. He graduated magna cum laude from Hobart in 2008 with a Bachelor's Degree in Economics. After Hobart, Brad went to Geneva, Switzerland to work at the International Labor Organization (ILO) of the United Nations where he initially served as an Intern and then as an Industrial Relations Research Officer. Upon his return to the United States, Brad enrolled in the M.S./Ph.D. program at the New York State School of Industrial and Labor Relations at Cornell University. 
To my parents, Stu and Sherry 


\section{ACKNOWLEDGEMENTS}

First and foremost, I would like to express my earnest thanks to my committee members: Alex Colvin, Chris Riddell and Sam Kleiner. Thank you all for your insightful, thoughtprovoking, and critical comments which I am confident vastly improved the quality of this thesis with each subsequent draft. I would especially like to thank Alex for serving as my graduate committee chair and academic advisor. Alex has not only been integral at every step of this thesis process, from the selection of the initial idea to its current composition, but more generally in helping to steer me in a direction that makes me confident moving forward in my graduate and academic life.

I would like to thank the staff at the National Archives in Ottawa for helping me to obtain the majority of the documents from which I was able to build this data set. I must also acknowledge the help that I received from all of the people at the various provincial labor boards who responded to my requests for additional data, some of which from decades ago, and for answering any and all queries concerning that data.

Thank you to my parents, Stu and Sherry, for the constant support and encouragement that you have provided me in all of my endeavors. Any success that I am able to obtain is in large part due to the work ethic that you instilled in me and it is for this reason that I dedicate this thesis to you.

And last, but certainly not least, thank you Chantal. Thank you for playing the role of expert translator when I needed help understanding the various articles and documents written in French and for assisting me in corresponding with Quebec's Commission des Relations du Travail. While both of those were extremely helpful, I want to thank you most of all for your love, your care and your companionship for which I believe that I am truly fortunate. 


\section{TABLE OF CONTENTS}

Biographical Sketch........................................................... iii

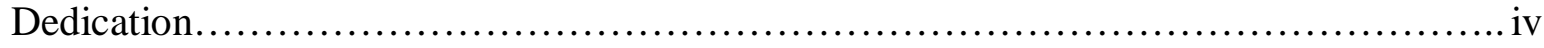

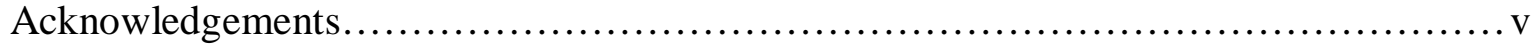

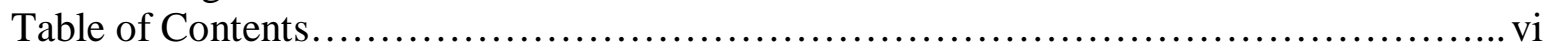

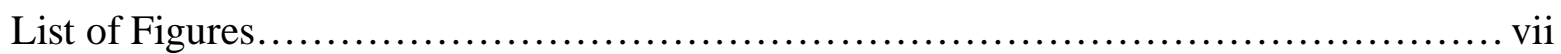

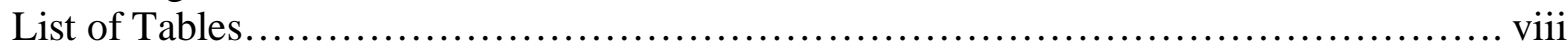

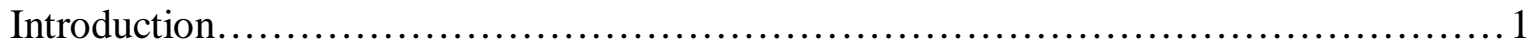

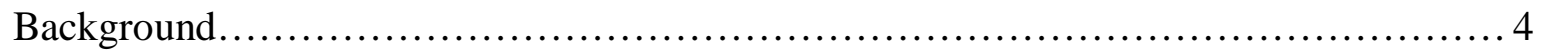

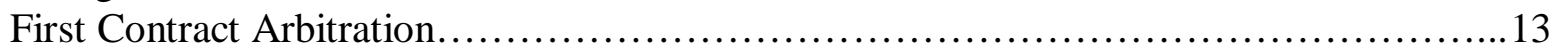

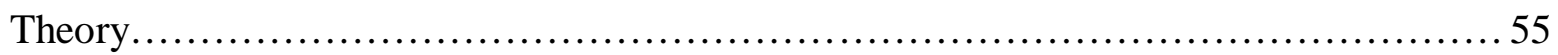

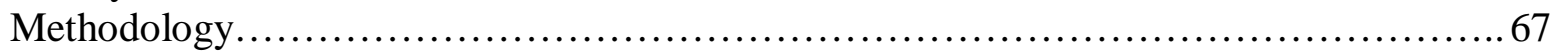

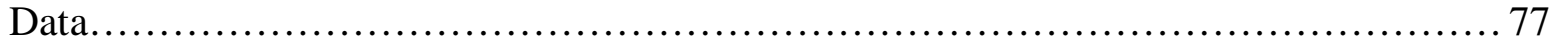

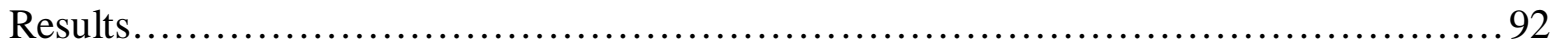

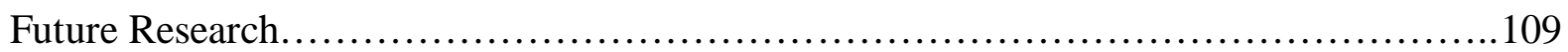

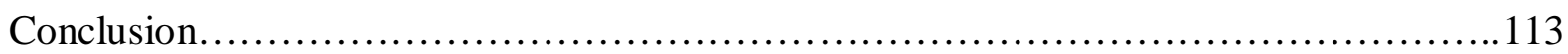

Appendices..................................................................... 115

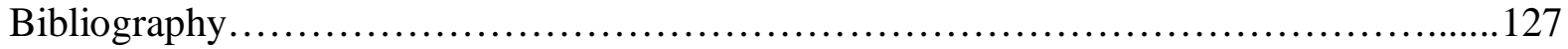




\section{LIST OF FIGURES}

Figure 1: Timeline of Types of FCA Found in the Canadian Provinces..................... 14

Figure 2: Timeline of FCA and Mandatory Representation Vote Legislation

in the Canadian Provinces....................................................... 90 


\section{LIST OF TABLES}

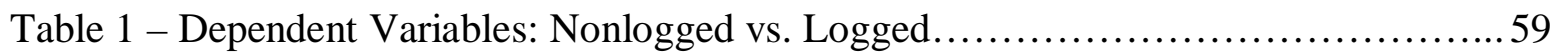

Table 2 - Regression Results for Model 1 ......................................... 94

Table 3 - Informal Test of the Exogeneity of First Contract Arbitration Provisions.........99

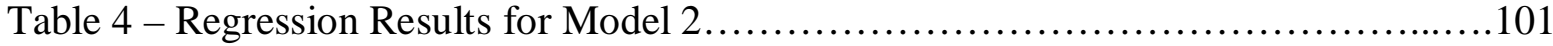




\section{Introduction}

The most recent attempt at labor law reform in the United States, the Employee Free Choice Act (EFCA, Bill H.R.1409.IH), sought to amend the National Labor Relations Act (NLRA) by instituting three reforms: a card-check mechanism for union certification, first contract arbitration (FCA), and strengthened penalties for violating the NLRA. The focus of this thesis is the second of these reforms which intended to address the problem that newly certified bargaining units have in securing a first collective bargaining agreement in the United States. Advocates of FCA claim that it will allow employees who have voted to unionize the opportunity to participate in meaningful collective bargaining that will result in a contract, even in the face of a determinedly anti-union employer. Furthermore, it is claimed that the presence of a collective bargaining agreement will stabilize the new bargaining relationship such that it may be developed and maintained in the long-term. Opponents of FCA, on the other hand, claim that it will hinder free collective bargaining and that the imposition of a contract will not result in a long term bargaining relationship between management and labor because the agreement was not produced voluntarily.

This study seeks to preliminarily test this debate to see whether FCA can result in the development of lasting bargaining relationships by examining the effect that it has on various measures of the decertification rate. Since EFCA failed to pass the Senate in 2009 due to a filibuster, there is no first contract arbitration in the private sector of the United States and thus, no U.S. data for which I could test this relationship. However, FCA has been present in a number of Canadian provinces for decades, as well as the Canadian federal jurisdiction, and thus, this study uses time-series, provincial-level aggregated data from nine Canadian provinces for 
the period 1970 to 2010 to contribute to and better inform the debate about first contract arbitration that is taking place in both countries.

Although there is a moderate amount of existing literature concerning first contract arbitration in Canada, there are a number of deficiencies in this area of research, some of which this study seeks to address. The majority of studies restrict their analysis to only those cases in which the union or employer applies or receives access to the FCA process, which results in the absence of measure of any deterrent effects that FCA might (and is intended to) produce. This is a potentially drastic oversight in that other studies have shown that the FCA machinery is rarely accessed such that its effectiveness may heavily rely on the deterrence of employer misconduct (Rose 2006; Johnson 2010). By including the totality of the industrial relations system of the provinces encompassed in this study, the results account for the existence of any deterrence of employer misconduct in first contract situations where the FCA machinery is not utilized. Such an approach will hopefully provide a more accurate depiction of the outcomes of FCA since it comprises both the direct and indirect effects of such legislation. Johnson (2010) and Riddell (forthcoming) are the only other studies to undertake such an analysis that may account for this deterrence by being inclusive of the entirety of the industrial relations systems. However, both of those studies investigated different goals of FCA, whereas this study represents the first concerning the aim of fostering bargaining relationships.

Furthermore, many of the studies focus on only one province or type of FCA and do not use rigorous statistical analysis to try to isolate the influence of FCA in the presence of extraneous factors. The lone exception to this, Johnson (2010), as mentioned above, examines a different goal of FCA, but that article does not investigate the effect of the different types of FCA. Whereas this study, like Johnson (2010), looks at the aggregate effect of FCA in the 
presence of any type of FCA versus its absence, this study is the first to model the different types of FCA under such an analysis. Thus, this is the first study that allows for the comparison of each type of FCA against a base case of a province that lacks an FCA provision. This is performed through time-series cross-sectional analysis (TSCS) using Ordinary Least Squares (OLS) estimates with Panel Corrected Standard Errors (PCSEs) on a dataset that contains four decades of data from nine Canadian provinces. Although limitations of the data disallow me from fully investigating the goal of fostering enduring bargaining relationships, the investigation of the effect of FCA provisions on decertifications allows one to see whether FCA correlates with more or less bargaining relationships, on aggregate, in the presence of such provisions versus its absence. Thus, this represents only a preliminary inquiry into whether FCA is satisfying its goal of fostering lengthy bargaining relationships, but it is the first to use rigorous statistical analysis with a multi-jurisdictional dataset to undertake that inquiry. 


\section{Background}

A survey of existing empirical studies shows that newly certified unions in the United States often have great difficulty securing a first contract (Weiler 1984; Cooke 1985; Pavy 1994; Bronfenbrenner 1994, 1996, 2009; Ferguson 2008; see Appendix 1 for a summary). For example, Weiler (1984) found that the success rate of unions obtaining a first contract decreased from 86 percent in 1955 to 78 percent in 1970, which further declined to 63 percent by 1980 . Cooke (1985) found from a sample of 118 cases of union certification that took place between 1979 and 1980 that between 22 and 23 percent of those cases had not resulted in a first agreement within two years. Pavy (1994), using survey results from the AFL-CIO's Industrial Union Department, found a similar downward trend as Weiler (1984) in that 22 percent of unions who won certification in 1970 did not gain a contract, which increased to 39 and 35 percent of unions that won certification in 1982 and 1987 respectively. Bronfenbrenner $(1994,1996)$ found an 80 percent first contract win rate from a sample of 100 units, but she believed that this win rate was higher than those found by others due to the inclusion of only large bargaining units. Bronfenbrenner highlights how dire the situation is when one looks at the overall process from the petition for certification to the agreement of a first contract in that only 27 percent of workers who voted for a union in a certification election ended up being covered by a collective agreement. In her more recent study, using NLRB data from 1999 to 2003, Bronfenbrenner (2009) found that 52 percent of the unions that won certification during this period were without a first contract within a year, which subsequently fell to 37 percent within two years and 30 percent within three years. Further, she found that 25 percent had not achieved a first contract more than three years after the union had been certified. Likewise, Ferguson (2008), using National Labor Relations Board and Federal Mediation and Conciliation data for 1999-2004, 
found that only 56 percent of unions who won certification during this time period also won a contract within two years. Like Bronfenbrenner, Ferguson also takes a look at the sequential failure of unions to gain a contract and found that only one-seventh of unions that file an election petition with the NLRB achieve a contract within one year following certification. Lastly, Johnson (2010) found that newly certified private sector unions failed to achieve a contract within two years following certification 30 to 45 percent of the time during the period 1996 to 2004.

Although the bulk of the first contact literature has focused on the United States, some similar work has been performed on Canada, which due to its similar industrial relations system and many shared labor laws faced similar problems in the past (and still does today). From a random sample of 150 Ontario Labour Relations Board non-construction certifications from April 1, 1980 to March 30, 1981, Solomon (1984) found that 86.6\% of those certifications resulted in successful bargains. In a similar article on the Canada Labour Code of the federal jurisdiction, Solomon (1985) found that $83.1 \%$ of all unions certified during the 1979 and 1980 calendar years were successful in obtaining first agreements. These rates show a higher first contract success rate than the U.S. studies, but neither of Solomon's articles provided a time frame of how long it took the negotiations to produce a collective agreement. Forrest (1986) finds a largely similar rate as Solomon (1984) for the province of Ontario in that she finds that approximately one in seven newly certified unions failed to achieve a contract during the 1970s, and that she finds this rate deteriorates to one in five in industries in which compulsory arbitration was unavailable. A more recent article by Riddell (forthcoming) shows that this situation has worsened in the province of Ontario since the work of Solomon and Forrest in the 1980s. He finds that only $60 \%$ of newly certified unions achieve a first contract within a two 
year window for the period 1995-1998. In comparison to Ferguson's (2008) assessment in the US, he finds that only 38 percent of unions who initially apply for a certification election actually obtain a first contract. He believes this to be quite surprising in that this failure occurs in a context that includes labor laws such as snap elections and first contract arbitration. The difference between his finding and Ferguson's is not a difference between the certification and first contract success rates, but rather it is due to the withdrawal rate in the process. Riddell argues that Ontario provides the best comparison to the United States of any of the Canadian provinces, but recognizes that it is likely that the success rates may be higher in other provinces. This is very likely to be true in light of the fact that his period of study (1995-1998) took place under one of the most anti-union provincial governments in Canada, the Progressive Conservative Harris government (Godard 2003).

This failure to obtain a first contract can occur for a number of reasons, including the need to create a contract from scratch, the nascence of the bargaining relationship, a hangover of ill will due to a contentious certification campaign, inexperienced negotiators, unrealistic expectations about what can be accomplished through collective bargaining, and in many cases, employer anti-unionism (Johnson 2010). Much of the above literature highlights the effect that employer opposition has on the achievement of first contracts. Cooke (1984) estimates that the filing of an unfair labor practice (ULP) charge during the contract negotiations results in a 32 to 35 percent drop in the contract success rate compared to those negotiations where no such ULP was filed. Similarly, Bronfenbrenner (1994) found a 25 to 50 percent drop depending upon the tactics used by the employer and Ferguson (2008) found a cumulative decrease of 30 percent in the contract success rate with the presence of ULPs. 
Likewise, the Canadian literature finds a similar correlation between employer misconduct and the achievement of a first collective agreement. Both Solomon (1985) and Forrest (1986) found an adverse effect of unfair labor practices on first contract rates, although neither of them measured the magnitude of such a decrease. Bentham (2002) surveyed employers to measure the effects of employer actions during organizing and bargaining campaigns and she found that the effects of employer responses to unionization were more pronounced at later stages in the process. This is very likely due to the accelerated certification laws found in Canada, which may limit the effect of employer opposition prior to certification and shift it to the later stages. In one of her models, she found that if the employer committed an unfair labor practice during the organizing drive, then this decreased the chance of obtaining an agreement by 14 percentage points, increased the chances of "serious bargaining difficulties" by 30 to 35 percentage points and lastly, increased the likelihood of decertification during the first couple of months following the post-certification moratorium or the expiration of an agreement by 46 to 57 percentage points. In her other model, the effect of an unfair labor practice charge was associated with a 22 percentage point decline in the achievement of a first contract. This resulted in a decrease from over nine out of ten newly certified unions obtaining an agreement to just over two out of three. Furthermore, she found that even the "innocuous" act of hiring a lawyer, or a consultant, resulted in a greater likelihood of needing outside assistance in obtaining a contract, as well as a greater chance of early decertification. Bentham's labeling this action as innocuous seems rather naïve as the existence and use of consulting and law firms for anti-union activity in Canada was documented decades earlier (Muthuchidambaram 1980) and has also been documented in the U.S. (Logan 2002). More recently, in a study of Ontario, Riddell 
(forthcoming) found that the existence of unfair labor practice charges against the employer correlated with a 17 percentage point decrease in the likelihood of obtaining a first contract. Many of the unfair labor practice charges in the American context are section 8(a)5 violations of the National Labor Relations Act, which places a duty on the employer to bargain in good faith with the union that the employees have certified to be their representative. The number of 8(a)5 violations increased by almost eight times over the period 1955 to 1980 , which as mentioned above, occurred within the context of a declining first-contract success rate (Weiler 1984). This duty to bargain in good faith, however, does not mean that a collective agreement must be settled nor does it outlaw "hard bargaining" in which an employer is taking strong stances on the issues being negotiated. That being said, it is very difficult to distinguish between hard bargaining and bad faith bargaining, otherwise known as surface bargaining, which combined with the weakness of the penalties for flouting the National Labor Relations Act (NLRA), means that an employer who is determined to keep his operations nonunion can successfully inhibit a union from reaching a first contract and may even be able to rid itself of the union altogether.

After a union is certified under the NLRA, there is a one year moratorium before the process of decertification can be undertaken in that bargaining unit. If an employer wants to rid itself of the newly certified union, then it can participate in a number of different bargaining strategies to prolong the negotiation process beyond that which is necessary to decertify. These strategies include technical refusals to bargain in which the employer appeals the outcomes of the election as a way to delay bargaining; defiant bargaining in which the employer openly refuses to bargain with the union; evasive bargaining in which the employer opposes issues viewed as essential to the union and extends the bargaining process through infrequent 
scheduling; and finally, peremptory bargaining in which the employer presents unclear proposals that the union are unlikely to accept (Hurd 1996). Note that the latter two may fall within the purview of the law as hard bargaining and if a case is made before the Labor Board then the Board would decide, in the context of the employer's overall conduct, whether they would constitute a violation of good-faith bargaining. Nonetheless, the goal of all of these strategies remains to prolong the bargaining process because the longer employers can effectively frustrate unions' attempts to secure a contract, the greater the likelihood that the workers will decertify the union since they will be paying dues without receiving all of the benefits of unionization (such as a say in creating their terms and conditions of employment through collective bargaining, work under a union contract, access to a grievance system, etc.). As Paul Weiler noted, "Even if all workers were able to make a genuinely uncoerced choice about union representation, however, the battle would be only half over. Winning an NLRB-sponsored election gives the union no more than the right to sit across the bargaining table from the employer. Only after the union achieves a first contract will it be established within the plant and will its members truly be able to judge the value of collective bargaining in the day-to-day lives" (Weiler 1984, p. 352).

Therefore, it is due to this employer intransigence, which one author estimates to be twice as high in first contract as in non-first contract situations (Rose 2006), from which the calls for first contract arbitration in the Employee Free Choice Act emanated in the United States.

Even though the system of industrial relations in Canada is provincial (as opposed to national in the U.S), Canadian labor law is originally based upon the NLRA, also known as the Wagner Act, such that it also adheres to the same model of a free system of collective bargaining with the duty to bargain in good faith as is found in the United States. Thus, many researchers have used Canada as a comparison to the United States due to the similarities in their systems of 
industrial relations, but also due to the similarities in their economies, labor markets and institutions (Martinello 2002). These similarities mean that an analysis of Canadian data may be able to inform the policy of both countries (Johnson 2010), which is what I hope to accomplish with the analysis of FCA in this study.

As has already been shown above, employer intransigence affects the Canadian system of industrial relations as much as the American system. Furthermore, previous research shows that Canadian management share the same anti-union sentiments as their American counterparts (see Taras 1997 for a review) and that like their American brethren, the cease and desist orders that were levied against Canadian employers for flouting labor law in the past failed to deter employers from further misconduct (Backhouse 1980). Additionally, the same difficulty of determining whether the bargaining strategy employed by employers constituted hard bargaining or bad-faith bargaining was present in the Canadian context (Patterson 1990). Thus, this background of intransigent employers who obstinately resisted unionization produced a number of caustic strikes in the 1970s and 1980s which prompted provinces such as British Columbia and Ontario to pass FCA provisions to avoid the cost that such occurrences inflicted not only on the parties involved, but society at large (Weiler 1980, Backhouse 1980). However, unlike in the United States, the provincial jurisdiction of labor law and the parliamentary system in Canada has allowed for much more experimentation with new and innovative labor laws, including first contract arbitration, such that legislation that is enacted in one province often spreads to the others. This difference in labor law between the U.S. and Canada is one of the possible explanations that others studies have used to explain the difference in industrial relations outcomes between the two countries. Similarly, it is this difference, specifically first contract arbitration, amongst all of the similarities listed above, that I argue results in improved 
outcomes concerning decertifications, and thus bargaining relationships, in Canada compared to the United States. However, despite all of the similarities in the first contract setting and the use of the United States and Canada as the backdrop of a quasi-natural experiment in many previous articles, the comparison between the two is not perfect. Other differences exist between the industrial relations systems of Canada and the U.S., including more governmental intervention in work stoppages through back to work legislation and more social unionism in the former than the latter to name a few (see Godard 2003 for a review of such explanations). Thus, it is these similarities (and differences) between the United States and Canada which makes for an interesting comparison in that the use of Canadian data to assess the effectiveness of FCA, and its different forms may not only answer questions about the policy within the country in which they are found, but that the findings may perhaps be applied to the debate proceeding in the American industrial relations context too.

\section{Summary}

First contract arbitration was initially passed in a number of the Canadian provinces to address some of the highly-publicized, caustic work stoppages that plagued the provinces during the 1970s and 1980s. Although the avoidance of such strikes remains one of the goals of this public policy, the recent calls for FCA in the United States stem mainly from research describing the struggles of newly certified unions to achieve a first contract (see Appendix 1 for a tabular summary of this research). This vein of research highlights that these struggles have persisted for decades and that the success rate of obtaining a first contract has increasingly deteriorated in the most recent decades. Such studies place this finding in a context in which employer opposition to unionization has increased, as signified by the increase in unfair labor practice 
complaints (ULPs) over the course of this time period, and shown that such ULPs, as a proxy for employer opposition, can have drastic effects on the chances of a newly certified union being able to achieve a collective agreement within a timely manner, if at all. This research extends to the Canadian industrial relations system as articles on the same subject of employer opposition and first contracts have produced similar, if slightly more favorable, findings. First contract arbitration is viewed as a remedy to counteract the actions of an obstinate employer and has been employed in a number of Canadian provinces as early as the 1970s. Due to the similarities of the industrial relations systems of Canada and the United States, the assessment of the FCA policies in Canada that is undertaken in this study is hopefully applicable in both countries. The next section explains what first contract arbitration is and elaborates on the different types of FCA that are found in Canada before reviewing the existing literature to survey whether these provisions have been successful at meeting the goals upon which they were enacted. 


\section{First Contract Arbitration}

First contract arbitration, depending upon its form (detailed below), provides an avenue for workers (or management in some cases) to apply for arbitration under a number of circumstances. Once an application for FCA is accepted, all forms of self-help (i.e. strikes or lock-outs) must cease and an arbitrator, or the labor board whose jurisdiction the application falls under, can impose the terms and conditions of the collective agreement that the parties are unable to settle. This imposed agreement may be for a duration of one to three years depending on the jurisdiction. Currently, nine out of the eleven jurisdictions in Canada have FCA provisions in their system of labor law. They include: British Columbia (1973), Quebec (1977), the Federal jurisdiction (1978), Manitoba (1982), Newfoundland (1985), Ontario (1986), Saskatchewan (1994), Prince Edward Island (1995) and, most recently, Nova Scotia (2011). The provinces that do not have FCA provisions are Alberta and New Brunswick. Although some of the provinces have shifted in the past among the types of FCA, no province has ever completely repealed FCA and despite initial reticence, FCA has largely become an accepted part of the industrial relations system in those provinces. There are four different types of FCA: "fault", "no fault", "automatic" and "mediation-intensive/mediation-arbitration". For a timeline of when the different types of FCA have been found in the Canadian provinces since 1973, see chart 1 below. 


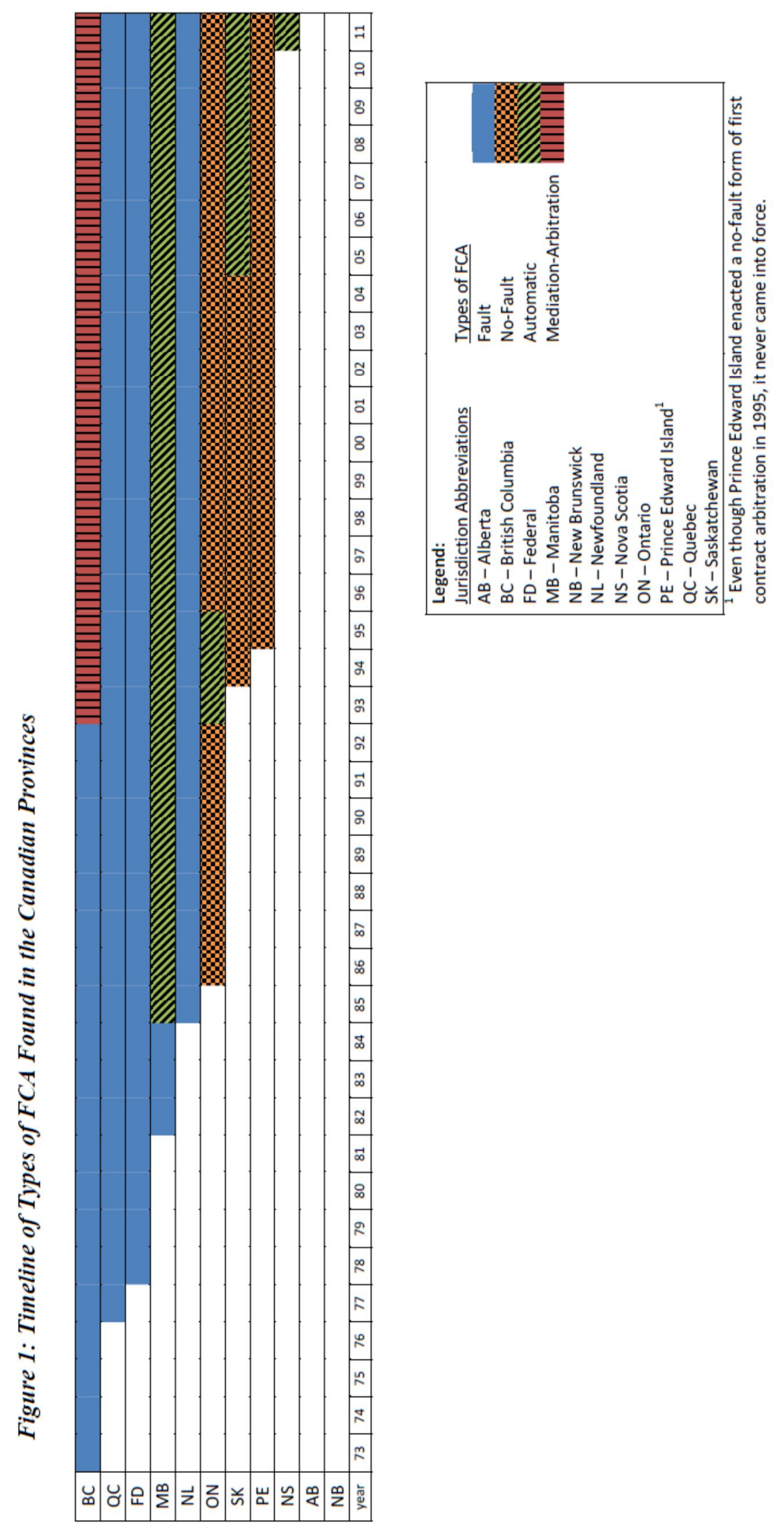




\section{i. Types of FCA:}

The "fault", also known as "exceptional remedy", model, as its name implies, seeks to establish that one of the parties has acted in bad faith and is responsible for the breakdown of bargaining. Thus, it is viewed as being accessible only as a remedy for unfair labor practices whose occurrence precludes the ability for constructive bargaining and settlement to take place. Therefore, this form has the most stringent criteria from which the parties may gain access since it must be proven that one of the parties committed such activity. Additionally, this form typically has a double screen mechanism by which the applicant applies to the Minister of Labour who then may refer the application to the Labour Board who subsequently decides whether or not to issue a direction to arbitration. This was the first form of FCA used in Canada and thus, was found in British Columbia from 1973 until they amended the provision in 1993. It was also found in Manitoba from 1982 to 1984 and is currently found in the Federal jurisdiction, Newfoundland and Quebec, although it differs slightly in Quebec and Newfoundland in that they only use a single-screen. Whereas the Minister of Labour performs this role in Quebec, recent amendments (May 2011) to the Newfoundland and Labrador Labour Relations Act eliminated the use of the Minister of Labour as a screen such that the Newfoundland and Labrador Labour Board is now the sole screen for FCA applications in that province.

The second type of FCA, "no-fault", places fewer restrictions on the requirements necessary to gain access to arbitration. This model recognizes that negotiations may breakdown regardless of whether bad-faith conduct took place and thus, seeks to move away from the use of arbitration as a punishment against one of the parties. Therefore, under this variation, if it is shown that one of the parties violated any one of a set of criteria as set out in the provision, which doesn't necessarily amount to bad-faith (e.g. hard bargaining), then the Labour Board may 
provide a direction to arbitration. For example, under the Ontario Labour Relations Act, the Ontario Labour Relations Board reviews all applications to determine whether bargaining failed due to the violation of any of the criteria set out in section 43 (then section 40) of the Labour Relations Act. These criteria include: “(a) the refusal of the employer to recognize the bargaining authority of the trade union; (b) the uncompromising nature of any bargaining position adopted by the respondent without reasonable justification; (c) the failure of the respondent to make reasonable or expeditious efforts to conclude a collective agreement; or (d) any other reason the Board considers relevant" (Ontario Labour Relations Act). As one can see from the example, this form of FCA is used in Ontario (except for the years 1993-1995) and it was also found in Saskatchewan from 1994 to 2005.

The third form of FCA, "automatic", provides the greatest ease of access in that it only requires that a sufficient amount of time elapse since certification and that the Labour Board believes that conciliation will not produce a settlement. Thus, there is no double-screen and there are no criteria that need to be shown to have been violated by either party in order for arbitration to commence. This form of FCA is currently used in Manitoba, Saskatchewan and Nova Scotia, but it was also used in Ontario for a brief period from 1993-1995. Prior to Manitoba's shift to the automatic model in 1985, it experimented with a system known as the 'Code of Employment', which mandated that any alteration in wages and benefits by the employer during negotiations be turned into a first contract for one year if requested by the union, and then the fault system after the enactment of FCA in 1982 (Mitchell 1992; Slinn and Hurd 2011).

The last type of FCA, "mediation-intensive" or "mediation-arbitration", seeks to use first contract arbitration not as a replacement for bargaining, but rather as a facilitator of it. Under 
this system, which is found only in British Columbia since 1993, an application is accepted if it can be shown that negotiations have broken down and a strike vote has passed. If this is the case, then a mediator is assigned to help the parties settle any outstanding issues in their negotiations for 20 days, at which point if the parties are unable to produce a settlement then the mediator gives a recommendation to the associate chair of the B.C. Labour Board. This recommendation can be for further mediation, arbitration or allowing the parties to resort to selfhelp. Like the no-fault form of FCA, the B.C. Labour Relations Board does adhere to a number of criteria in determining whether or not to give a direction to FCA.

In comparison, the section of the Employee Free Choice Act (EFCA) pertaining to first contract arbitration proposed an automatic form of FCA, such as is found in Manitoba, Saskatchewan and Nova Scotia. Under EFCA, either party could apply to the Federal Mediation and Conciliation Service (FMCS) for mediation and conciliation if an agreement was not produced within the first 90 days of bargaining. If no agreement was then produced after 30 days of mediation, FMCS could refer the case to an arbitration board that would settle the dispute with an agreement that would last two years. Although specific time frames were specified, the provisions allowed for additional time to be taken before the application and during the mediation phases if mutually agreed upon by the parties. Additionally, the duration of the imposed agreement could be altered based upon the mutual consent of the parties (Bill H.R.1409.IH). The only major difference between the model proposed in EFCA and the automatic FCA in the Canadian provinces was that the EFCA provision lacked the equivalent screening role performed by the Labour Boards. Thus, the Labour Boards can refuse to direct the case to arbitration, such as if it believes that a settlement can still be produced through 
conciliation, whereas under EFCA, an application would move directly to arbitration once the specified time period has elapsed.

\section{ii. The Goals of FCA:}

Perhaps the facts that (1) no FCA provision has ever been overturned in any of the provinces in which it is present, (2) that opponents in those provinces no longer seek to remove it from the law books, and (3) that it has become an accepted part of the industrial relations systems of those provinces, provides some evidence that first contract arbitration is a success. However, the absence of will to overturn any FCA provisions could also point to its lack of success if opponents believe them to be sufficiently ineffective that it does not warrant the effort of trying to have them repealed. Analyzing the success of first contract arbitration can be difficult because there are a number of ways in which success may be measured. For example, the number of first agreements produced in the process, the number of subsequent agreements, the quality of the agreements, and the number of first contract work stoppages evaded could all realistically be used as metrics for the success of first contract arbitration. However, it seems reasonable to judge the merits of FCA based upon the goals that were envisioned at its outset and whether or not these are met. As one can see from the descriptions of the types of FCA above, different models may encompass slightly different goals, but regardless of the type, there seem to be four goals that are paramount to these provisions. They include: (1) ending work stoppages, (2) allowing newly certified unions to obtain a first contract, (3) familiarizing the parties such that a lasting bargaining relationship may be developed, and (4) deterring misconduct that precludes the settlement of a first agreement and creation of a bargaining relationship. The following elaborates on each one of these goals and surveys the existing FCA literature to see 
whether FCA may be judged as a success or failure in light of them (for a tabular presentation of the following sections, see Appendix 2).

\section{End Work Stoppages}

As stated above, a number of the provinces initially passed FCA provisions because of the commonplace of first contract disputes. A strike wave prior to the election of the New Democratic Party government in British Columbia and a bitter, protracted strike in a Sandringham, B.C. hospital precipitated the passage of FCA in British Columbia, while the Fleck Manufacturing strike in Ontario preceded that province's decision to pass FCA (Backhouse 1980, pp. 501-502). Paul Weiler (1980), one of the authors of the B.C. provision, saw FCA as "a sharp surgical instrument for lancing those running sores in the body of industrial relations" and believed that if FCA was successful at stopping such disputes then for this reason alone, it "is a sufficient justification for it" (Weiler 1980, p. 53). In his book, Weiler (1980) highlights how the Sandringham Hospital and Fleck Manufactuing disputes brought the first contract struggle into the public eye in their respective provinces and produced a conversation about how to handle such situations, but he does not attempt to quantify the number of first contract strikes that were taking place in B.C. around the passage of its FCA provision. Thus, the pervasiveness of such disputes cannot be extrapolated, but in highlighting the success of the FCA provision in preventing first contract disputes, he implies that the problem was more general than the highly publicized disputes used to illustrate it. Furthermore, in her article on the Fleck Manufacturing Stike in Ontario, Backhouse (1980) interviewed Professor Weiler who stated that "[c]learly the problem of the acrimonious first contract dispute had been around for some time" and even estimated that 99 percent of bitter, protracted strikes were in first contract situations. 
The strikes that Weiler referred to in the interview were the ones in which the parties were incapable of bargaining due to the non-acceptance of collective bargaining, usually by the employer (Backhouse 1980, pp. 502-505). Thus, although it is difficult to say how many of the work stoppages actually took place in the first contract setting, it appears that the problem was large enough to warrant legislative attention.

According to Weiler (1980), FCA was successful in this regard in that the types of disputes that led to its passage ceased to occur in all but a few cases in those sectors of British Columbia that fell under the purview of the legislation (to which he acknowledged that there will always be a few). Indeed, Weiler (1980) further highlights FCA's effectiveness by acknowledging that bitter work stoppages continued in B.C., but largely in those sectors that were covered by the Federal jurisdiction, which at the time of those strikes, was without its own FCA provision (Weiler 1980, p. 54). Cleveland (1982) came to the same conclusion as Weiler (1980) in her study, which analyzed the effects of the British Columbia FCA provision during the slightly longer time frame of 1974 to 1979, although she concedes that a causal relationship cannot be drawn from the evidence.

In terms of first contract disputes, the union tends to be at a disadvantage since by the time at which the negotiations have devolved to the point of breakdown, substantial time may have passed and union support may have waned. Thus, it may be difficult for some unions to obtain the necessary support for a strike that can sufficiently push the employer to participate in meaningful bargaining. Due to this, critics believe that FCA legislation only helps labor, but the evidence from a number of studies show otherwise. It was found that in the early years of the legislation in Manitoba, employers applied for FCA more often than unions because they wanted to avoid a costly work stoppage (Mitchell 1992). However, this seems to have changed more 
recently as only four applications for FCA, one of which was applied for jointly with the union, were made by management in Manitoba since 1992 (Slinn and Hurd 2011). Thus, in contradiction to the complaints of critics, it may actually be employers that benefit from FCA, and not labor, in this regard in that they may use the legislation to avoid costly disputes in which the union has sufficient support to force the employer to participate in meaningful bargaining. Also, there may actually be a further incentive for employers to access the legislation as arbitrators do not intend to break new ground or include innovative provisions (discussed below) in imposed agreements which may allow employers to evade agreements more favorable to the union in such situations where the union is powerful. However, since FCA can only be accessed in first contract situations, both sides may resort to self-help in the second round of negotiations and thus, the more powerful party may be able to make gains in subsequent rounds of negotiation. It has also been shown that employers comprise a substantial amount of the applications to FCA in other provinces too; one-third of the applications in British Columbia and one-sixth of them in Quebec originate from employers. One study found that employers accounted for 38 out of the 116 applications (32.76\%) for FCA during 2001 to 2008 in B.C. (Slinn and Hurd 2011, p. 62), while another found that employers account for 31 percent (Vipond 2010, p. 30). In fact, the mediation-intensive form of FCA in British Columbia actually bolsters this ability of employers to evade strikes for a number of reasons. As stated above, in order to obtain access to the FCA provision in B.C., the unions must show majority support in a strike ballot. Additionally, the union is required to give the employer a 72-hour notice before commencing a strike. The combination of these two allows the employer to assess the support the union has from the membership and gives the employer sufficient time to apply for FCA if he believes it to be in his best interest (Ibid). 
Actual empirical assessment of the effect of FCA on work stoppages is relatively sparse. In her study of British Columbia, O'Brien (2001) found that there were 50 first contract disputes during the period 1993 to 2000 in which 31 of them used the FCA process. In 16 of those cases, the application was filed following the start of the work stoppage and a first contract was concluded in all of them except for one. In contrast though, the other 15 strikes occurred after the application for FCA, presumably when there was a direction to further self-help, and only one-third of these eventually resulted in a contract (O'Brien 2001, p. 77). Thus, it seems that in the B.C. context, FCA is somewhat successful at ending work stoppages. In a more recent article by Johnson (2010), the effect of FCA was assessed with data that covered ten jurisdictions over the time period 1976 to 2005. She found that FCA was statistically significant and negative across all of her models and that the presence of FCA was associated with a 65 percent reduction in first contract work stoppages in the "Private and Quasi-Public" sectors and a 50 percent reduction in the "Private Sector" (Johnson 2010, pp. 592-593). Even though she finds a reduction in the occurrence of work stoppages, Johnson finds that it has no effect on the duration of first agreement work stoppages, which she attributes to the infrequency with which applications for FCA occur (p. 602).

\section{Summary/Analysis}

The alleviation of corrosive work stoppages in the first contract setting was the initial reason that FCA was passed by a number of jurisdictions, but it is a relatively sparse area of research concerning the assessment of FCA provisions. Indeed, Weiler (1980), one of the authors of the B.C. provision, provides some anecdotal evidence that this goal of ending first contract work stoppages was being satisfied and Cleveland (1982) and O'Brien (2001) provide 
some rudimentary empirical support to Weiler's observation in B.C. However, there is only one study (to my knowledge), Johnson (2010), that employs rigorous statistical analysis concerning this goal. It includes ten jurisdictions over a thirty year period and finds that FCA lessens the incidence of first contract work stoppages by up to 50 to 65 percent, depending upon if one includes the public sector. Although slightly tangential to this goal, some authors have addressed the criticism set forth by opponents of FCA who claim that it only benefits unions by ending work stoppages in which the union does not have the economic power to win it on its own. Indeed, newly certified unions are often more vulnerable in first contract situations in that it may be difficult to muster the support necessary to pass a strike vote, walk out, and stay out for a period long enough to win when an employer protracts the bargaining stage through his opposition. Certainly, FCA is meant to address this issue and thus, does benefit labor in this regard. However, studies from a number of jurisdictions found that although unions do file the majority of applications, employers also file a substantial portion of applications to avoid work stoppages when facing a powerful union. Thus, it would appear that the critics of FCA are wrong in that the policy can benefit both sides of the bargaining table. Lastly, even though some may view it is a hindrance to the side with more economic power in a dispute, the fact that FCA may only be applied in the first contract setting means that any losses for the more powerful side during this initial round may be recouped in subsequent rounds of bargaining.

\section{Securing a First Agreement}

Perhaps the most obvious goal of FCA legislation, as recounted by the background evidence above, is to ensure that the cases that access the FCA process result in a collective agreement, whether it be produced voluntarily or imposed. Almost all of the empirical articles 
on FCA produce some statistics as to the results of those who enter the process and these tend to vary depending upon the type of FCA that is at work in the province. For example, with the mediation-intensive form of FCA found in British Columbia, one would expect to find a higher frequency of voluntary agreements with the intensified focus on mediation and conciliation in operation. The findings of the existing studies, by province, are reported below:

\section{a. British Columbia:}

Using the time period 1974 to 1979 , Cleveland (1982) found that of the twenty-eight applications that were granted access to B.C.'s Section 70 FCA provision, four (14.29 percent) of the cases did not conclude with a first agreement. Of those that did conclude with a first agreement, eleven (45.83 percent) were arbitrated by the B.C. Labour Board, while the other 13 (54.16 percent) were settled voluntarily by the parties involved (p. 99). O'Brien (2001) found that 178 of 263 (67.68 percent) applications for the FCA process from 1993 to 2000 were settled without a direction to arbitration. Of those applications, 111 reached a settlement through mediation and 67 produced a settlement based on the mediator's recommendations, of which 20 of these used voluntary arbitration to reach that settlement. Of the 85 applications that were not settled, 25 were directed to arbitration (pp. 60-70). Studying a later period in B.C. (2001 to 2008), Slinn and Hurd (2011) found a lower settlement rate than O'Brien (2001) in that of the 116 applications that were filed during the time period under study, 65 cases (56.03 percent) were settled outright, with 10 of those settlements accepting the mediator's recommendations. The outcomes of those that were not settled outright included 8 cases ( 6.90 percent) in which the parties agreed to accept mediation/arbitration or acceptance of the mediator's recommendations; 10 cases ( 8.62 percent) settled through mediation/arbitration, 12 cases (10.34 percent) directed to exercise self-help; 6 cases ( 5.17 percent) had the application withdrawn, 3 cases (2.59 percent) in 
which the union was decertified during the process; 2 cases (1.72 percent) in which the business changed ownership or closed during the process; 2 cases (1.72 percent) in which the FCA application was overturned due to invalid strike votes and 8 cases (6.90 percent) in which the Board (1 case) or an arbitrator (7 cases) imposed the first collective agreement (Slinn and Hurd 2011, pp. 63-64).

In a study encompassing the entire period in which British Columbia used the mediationintensive model, and thus both of the periods under study in the two above articles, Vipond (2010) found that 88.4 percent of those in her sample obtained a first collective agreement. Of the respective outcomes possible under the B.C. FCA model, she found that the cases that involved acceptance of the mediator's recommendations (97.4 percent), voluntary arbitration (95.5 percent), and mediation (88.5 percent) produced the best chances of obtaining a first agreement, while the direction to self-help (74.3 percent) or arbitration (85.7 percent) produced fewer first agreements. All of her findings are based upon a survey of employers who participated in the FCA process from 1993 to 2009, which produced a sample of 302 cases (out of a population of 407; a response rate of 74 percent). Incorporating those cases that were not included in her sample, she concluded that at least 75 percent of those who used the FCA process in B.C. obtained a first collective agreement (Vipond 2010, pp. 40-41).

\section{b. Manitoba:}

Korpesho (1986), who at the time of writing was the Chairman of the Manitoba Labour Relations Board (MLB), observed that of the 21 referrals or applications that had been made to the MLB from the passage of the provision through 1985, 1 (4.7 percent) was rejected, 2 (9.5 percent) were withdrawn, 6 (28.6 percent) resulted in the voluntary settlement of an agreement, 11 (52.4 percent) resulted in the imposition of an agreement by the MLB and 1 (4.7 percent) was 
still before the courts (p. 52). Meanwhile, looking at a slightly longer time frame, Sexton (1987a) found that of the 25 applications that the MLB received, 1 (4.0 percent) was rejected, 2 (8.0 percent) were withdrawn, 8 (32.0 percent) resulted in the conclusion of a voluntary agreement, 11 (44.0 percent) resulted in an imposed agreement, 1 (4.0 percent) had yet to be determined by the Board and 1 (4.0 percent) was facing a court decision. A number of later studies found that the Manitoba Labour Board (MLB) received 93 applications for FCA from 1982 to 1991 . Of these, 48 (51.5 percent) were settled voluntarily, 37 (39.8 percent) had a first contract imposed by the MLB, 3 (3.22 percent) were withdrawn by the parties, and 2 (2.15 percent) had yet to be determined (Mitchell 1992, p. 324; Haywood 1993). Another study on the same time period later amended the above statistics such that only 47 (52.2 percent) were settled voluntarily, 39 (43.3 percent) were imposed by the MLB, 3 (3.3 percent) were withdrawn by the parties and 1 (1.1 percent) was refused to be seen by the MLB (Black and Hosea 1994, pp. 36, 39). In a more recent study, Slinn and Hurd (2011) found that of the 47 FCA applications that were filed between 2001 and 2008, 21 (44.7 percent) resulted in the voluntary settlement of the agreement by the parties, 21 (44.7 percent) resulted in the imposition of an agreement by the MLB, and 5 (10.6 percent) were withdrawn by the parties (Slinn and Hurd 2011, pp. 68-69).

\section{c. Ontario:}

Haywood (1993) also looked at Ontario from 1986 to 1991, in which 147 applications were made to the Ontario Labour Relations Board (OLRB), 48 of which were directed to arbitration. Of those applications, 16 (33.3 percent) cases were settled by the parties voluntarily, 9 (18.8 percent) resulted in the imposition of a contract by the OLRB, and 20 (41.7 percent) were settled using private arbitration (Haywood 1993). Riddell (forthcoming) examined the period from 1991 to 1998, which included the period in which Ontario enacted the automatic form of 
arbitration under an NDP government from 1993 to 1995. Thus in this article, the author was not only able to assess the outcomes during the period under study, but also make a comparison between the no-fault form of arbitration in Ontario that prevailed from 1991 to 1993 and 1995 to 1998 against the automatic form of the aforementioned years. He found that the first contract success rate in Ontario for 1995 to 1998, which included all first contracts, both under and outside of the FCA process, was between 60 and 70 percent, which was a decrease from the 80 percent that Forrest (1986) found for the 1970s. Furthermore, he found that the likelihood of settling a first contract was 10 to 12 percentage points higher under the automatic form of FCA in contrast to the no-fault form (Riddell, forthcoming, p. 5). Lastly, Slinn and Hurd (2011) examined the 70 applications that were filed with the OLRB during the period 2001 to 2009 and found that 8 (11.43 percent) were granted a direction to arbitration, 2 (2.86 percent) were dismissed, 38 (54.29 percent) were withdrawn by the parties, and 22 (31.43 percent) were not granted (adjourned sine die, terminated, or closed for other administrative purposes) (p. 66). The authors do not note whether any of the applications that did not have a collective agreement arbitrated resulted in the conclusion of a collective agreement.

\section{d. Quebec:}

The information on the FCA experience in Quebec is actually quite comprehensive as the Quebec government had commissioned a number of studies to report on the use of FCA in the province. One of those studies undertaken by the Ministry of Labour examined the first four years of FCA in Quebec from 1978-1981. During this time period, 135 applications were made for FCA of which 71 (52.6 percent) were granted, 34 (25.0 percent) were refused, 4 (3.0 percent) were still under ministerial review, and 26 (19.3 percent) resulted in agreements without a ruling for arbitration. Of those that were accepted, 15 (21.1 percent) were still ongoing, 33 (46.5 
percent) had an award imposed, 9 (12.7 percent) resulted in agreements before arbitration, 5 (7.0 percent) ended with the decision not to intervene, 3 (4.2 percent) resulted in agreements during arbitration, 3 (4.2 percent) concluded with the decertification of the union, 1 (1.4 percent) concluded with the withdrawal by the union, and 3 ( 4.2 percent) concluded with the closure of the business. Of the applications that were refused, 13 (38.2 percent) resulted in the decertification of the union, 6 (17.6 percent) concluded with the closure of the business, 6 (17.6 percent) concluded with the withdrawal of representation rights by the union, 3 ( 8.8 percent) ended because the union was no longer in operation, 1 (2.9 percent) resulted in the parties agreement to use voluntary arbitration, 1 (2.9 percent) resulted in an agreement, and 2 (5.9 percent) were denied for other reasons (Girard and St-Onge 1982, p. 35).

Looking at the period 1978 to 1984 , Sexton examined the 376 applications that were made to the Minister of Labour and found that 205 (54.5 percent) were accepted, 165 (43.8 percent $)$ were refused, and 6 (1.5 percent) were still under consideration at the time of writing. Of those applications that were accepted, 88 ( 42.9 percent) resulted in the imposition of a contract, 63 (30.7 percent) resulted in a voluntary agreement completed during the process, 12 (5.9 percent) resulted in a decision not to intervene, 8 (3.9 percent) resulted in the decertification of the union, 13 (6.3 percent) ended with the withdrawal of the union, 8 (3.9 percent) concluded due to the closure of the business, and 1 ( 0.4 percent) ended with the arbitrator declaring the case to be outside of his jurisdiction (Sexton 1987b, p. 290).

Another more recent governmental study examined the period 1978 to 2001 in which 1031 applications were made for FCA with 541 (52.5 percent) being granted. The outcomes of those granted were: 43.1 percent having an agreement imposed, 39.9 percent in which the parties voluntarily settled an agreement, 6.1 percent in which the parties withdrew the application, 3.1 
percent in which the business closed, 2.6 percent in which the union was decertified, 2.5 percent were still undergoing arbitration, 2.2 percent in which it was decided not to intervene, and 0.4 percent were settled outside of the FCA process. The authors also examined the 487 applications that were not accepted by the Minister of Labour and the reasons why they were refused. Of those that were not granted, 52.8 percent were because the parties had already concluded an agreement, 18.9 percent were because the union was decertified, 7.0 percent was due to the closure of the business, 6.2 percent were withdrawn by the union, 6.2 percent decided to use voluntary arbitration, 0.4 percent were withdrawn by the employer, and 8.6 percent were unspecified (Marotte and Paré 2002, pp. 11, 14). Thus, the authors note that if one is to add (1) the number of applications that were accepted and had an agreement imposed or in which the parties settled and (2) the applications that were refused due to the conclusion of an agreement by the parties, then they estimate that 68.5 percent of the applications during this period resulted in a first agreement (p. 22).

Although the focus of their article is case studies concerning FCA applications by WalMart employees, Murray and Cuillerier (2009) merge the data from the period 2002 to 2008 with that of Marotte and Paré (2002) to cover a thirty year period from 1978 to 2008. The incorporation of this period increases the amount of applications to 1239 and they find that 86.4 percent of those cases whose access was granted resulted in either an award or a voluntary agreement. However, they find that this shrinks to 74.5 percent when the entire population of applicants, whether or not they were granted access to the FCA process, are considered (Murray and Cuillerier 2009, p. 83). Slinn and Hurd (2011) also examined the period 2002 to 2008, but did not integrate it with previous data and rather simply compared it to the Marotte and Paré (2002) findings. During this time period, 214 applications were made for access to the FCA 
process, of which 151 (70.6 percent) were granted, 57 (26.6 percent) were denied, and 8 (2.8 percent) were withdrawn before the Ministry of Labour made a ruling. Of those that were accepted, 80 (53.0 percent) had an agreement imposed, 57 (37.7 percent) resulted in an agreement settled voluntarily by the parties, 8 (5.3 percent) resulted in either decertification or union withdrawal of the application, and 6 (4.0 percent) had yet to receive the arbitration award. Of the 57 cases that were denied access to the FCA process, 38 (66.7 percent) resulted in a collective agreement, 10 (17.5) concluded with the revocation of union representation through decertification or withdrawal, and 9 (15.8 percent) were concluded for other unspecified reasons. Thus, in comparison to the findings of Marotte and Paré, Slinn and Hurd found that there were a higher percentage of contracts imposed in their period of study, but less concluded voluntarily. However, the percentage of applications that resulted in a first collective agreement was higher for both cases that were granted or denied access to the process in this latter period (Slinn and Hurd 2011, p. 71).

\section{Summary/Analysis}

Perhaps the most obvious goal of an FCA provision is to ensure that a newly certified union is able to obtain a first contract and thus, most articles pertaining to FCA assess this in some regard. As one can see from the above descriptions, the analysis of this goal is limited to four provinces, although luckily each province that is analyzed represents a different form of FCA. This allows one to make some preliminary comparisons between the mediation-arbitration (British Columbia; except for the Cleveland (1987) study when B.C. was still under the no fault system), automatic (Manitoba; except for those covering the years 1982 to 1985 when a fault system existed), no-fault (Ontario; except for Riddell (forthcoming) which additionally covered 
the three years under the automatic system) and fault (Quebec) variations of FCA and how well each results in the settlement of a collective agreement. Although some authors calculate a first contract success rate in their articles, the data presented in the studies does not always allow for a comparison of these rates as sometimes the rate is calculated for the entire population of first contract situations inside and outside of the FCA process, while others only calculate it for those cases that have either applied or been accepted to undergo the FCA process. However, I attempted to calculate the success rates, within the confines of the data they present, to see how they compare.

Despite some lower rates from the earlier studies that incorporate the three years in which Manitoba used a fault system of FCA, Manitoba clearly has the best record for successfully settling first contracts. Of those that applied to the FCA system, the contract success rate of the early to mid-1980s in Manitoba was estimated to be between 70-80 percent (Korpesho 1986, Sexton 1987a), but when studies added data from the mid-1980s through the early 1990s to this earlier data, then the contract success rate rose to above 90 percent (Haywood 1992, Mitchell 1992), with the data from one study indicating a success rate of 95.56 percent (Black and Hosea 1994)!

The one study covering the fault system that prevailed before 1993 in British Columbia produces a contract success rate of approximately 85 percent for those applications that were considered by the Board, and thus were approved by the Minister of Labour (Cleveland 1982). Later studies of the mediation-arbitration system of B.C. produce a lower rate with a percentage somewhere in the upper 70s, but this may not be comparable to the previous rate due to the exclusion of cases through the ministerial screen (O'Brien 2001, Vipond 2010). However, the 
most recent article by Slinn and Hurd (2011) shows that the success rate may be increasing in B.C. as they find it climbed to almost 84 percent for the period 2001-08.

The studies on Quebec show a steady rise in the contract success rate over the period of analysis, such that the success rate is now almost comparable to that of B.C.'s mediationarbitration system. While the study covering the first four years of FCA in Quebec indicates that there was a 54 percent success rate for those who applied to the FCA system, the incorporation of data into the 2000s raised the rate to between 69 and 75 percent (Girard and St-Onge 1982, Marotte and Paré 2002, Murray and Cuillerier 2009). When the initial years are dropped from the population, the success rate climbs into the mid-70s and the most recent article by Slinn and Hurd (2011) indicates that the success rate in the most recent period under study is approximately 82 percent. However, one must keep in mind that the fault system in Quebec is slightly different than the fault systems found in other provinces so that the success rate in Quebec may not be a good representative of the success rate one is likely to find under a fault system in another province.

Of the four provinces studied in this section, there is the least amount of information on Ontario as two of the three studies do not provide information on the results of the total pool of applications that would allow me to calculate a rate that is comparable to those above. However, the article by Riddell (forthcoming) is interesting in that it not only incorporates all first contract situations, regardless of if involves access to the FCA process, but also makes a comparison between the automatic and no-fault systems of Ontario during the 1990s. Not surprisingly given the above analysis, he finds that the likelihood of successfully obtaining a first contract in Ontario to be 10 to 12 percentage points higher in the former than the latter. However, when he examines the period 1995-1998 in which the anti-union Harris government was in power, he 
finds that the first contract success rate for obtaining an agreement within 2 years was only 60 percent.

Thus, as the above suggests, the automatic form of FCA seems to result in the most first contracts. Whereas the fault and mediation-arbitration systems do seem to produce contract success rates of over 80 percent for those who attempt to obtain access to the FCA system, this is about 10 percentage points less than the automatic system. Lastly, there is not enough information from Ontario to make a comparison between it and the other provinces; however, the article by Riddell allows us to compare types of FCA within Ontario for the likelihood of obtaining a first contract. It is worth highlighting that with the exception of Riddell (forthcoming), these rates only pertain to those who apply for access to the FCA system and therefore, neglect any deterrent effect that such a provision may have on the larger industrial relations arena. Thus, while the success rate of those who access the system is still an revealing piece of information, it may potentially be overlooking a key portion of the influence that an FCA provision might exert.

\section{Foster a Bargaining Relationship}

An AFL-CIO survey from 1979-1981 showed that employers with no previous union experience were much less likely to sign an initial collective bargaining agreement and to subsequently renew such agreements than employers who did have previous experience with unions at other locations of their business (McDonald Memorandum, cited in Weiler 1984, p. 354). Those who designed the FCA model in B.C. assumed what the above survey showed: that employers were resisting bargaining due to their inexperience in dealing with a union. Thus, Paul Weiler and his colleagues hoped that if a contract was imposed on an intransigent employer 
then this "trial marriage" would familiarize the parties with collective bargaining and would provide the groundwork for a lasting bargaining relationship. However, despite having this goal at the outset, Weiler became skeptical of it a few years after enactment since every case in which a contract was imposed resulted in decertification (Weiler 1980). McDonald (1987) came to the same conclusion based upon his analysis of the same period and stated that Weiler's “'trial marriage' concept of first contract arbitration generally ended in divorce" (McDonald 1987, p. 21). McDonald (1987) also analyzed the experience of the Federal jurisdiction, whose FCA provision was based upon that of the B.C. fault model, and concluded that the same problems found in B.C. plagued that jurisdiction too. He attributed these problems to a number of weaknesses in the fault model of FCA, including the potential political hijacking of the process due to the ministerial screen, the incentive for employer intransigence due to the low probability of access to the process, and the weakness of the imposed contracts in both content and length. However, Sexton (1987a) casts doubt on Weiler's skepticism about the FCA provision since his conclusions were based on only 12 cases. Both Sexton (1987a) and McDonald (1987) point to the experience of other provinces with greater access to FCA, such as Manitoba and Quebec (due to its single screen despite being a fault system), to highlight the potential that FCA may hold for fostering bargaining relationships.

Perhaps it was due to these recognized failings of the fault model that other provinces moved towards other forms of FCA. The no-fault model instituted in Ontario sought to move away from the punitive nature of the B.C. and Federal models since they produced a clear winner and loser in their decision and instead, sought to repair the defunct bargaining that may have been due to the parties' inexperience. This meant that imposing a contract resulted in a balancing act between providing the employer enough flexibility to maintain competitiveness, 
but also to provide the union with a collective agreement that was "sufficiently attractive to employees that they will think twice about decertifying the union" and "provid[e] the union with a fair opportunity to demonstrate the viability of collective bargaining" (McCormack 1991, pp. 246-247). Thus, arbitration decisions generally seek to create agreements that do not break any new ground and represent what the parties would have created had negotiations not broken down. However, the contract needs to be attractive enough for the employees to see the merit in collective bargaining, but not so overly attractive that either unions come to rely on the process, rather than actually bargain, or employers intensify their resistance so as to avoid the process (Ibid). This balancing act though proved to be difficult to accomplish as the imposed contracts during the nascent years of FCA in both Ontario and Quebec had been criticized for being too conservative, which resulted in dissatisfaction among those covered and had not laid the foundations for bargaining relationships to grow (McDonald 1987; Patterson 1991). Further, it was found that wages were the greatest issue during the negotiations for the renewals of collective agreements (Sexton 1987b), which suggests that unions may seek to make up for lost ground in later negotiations due to the propensity of arbitrators to be conservative on monetary provisions of imposed contracts.

A number of studies have tried to empirically examine whether first contract arbitration has been successful at meeting this goal. However, there are a number of difficulties with such an analysis, one of which is the availability of data and the other being what actually constitutes a lasting bargaining relationship. It is relatively easy to measure when a bargaining relationship fails and thus, many of the studies observe whether the cases resulted in decertifications. Some of the studies have examined the number of subsequent renewals that have been accomplished, which is a step in the right direction, but still begs the question of how many renewals does it 
take to say that there exists a lasting bargaining relationship. This constitutes a fertile area for future research and development on first contract arbitration. Thus, the following studies, also organized by province, provide a sizeable amount of preliminary evidence about whether FCA is satisfying its goal of creating lasting bargaining relationships.

\section{a. British Columbia:}

Using the settlement of a second agreement as the measure of a lasting bargaining relationship, Cleveland (1982) found that of the twenty four cases that initially concluded a collective agreement using the FCA provision from 1974-1979, fifteen concluded a second agreement and thus, could be constituted as producing a lasting bargaining relationship. Furthermore, six of those fifteen cases concluded subsequent agreements beyond the first two. Cleveland (1982) then analyzed how the cases faired based upon how the initial applications were disposed of by the B.C. Labour Board and she found that those applications that were settled achieved lasting bargaining relationships more than those that were granted and imposed. The majority ( six out of nine) of cases where only one agreement was settled were cases in which the Board granted the application and imposed an agreement. Only 5 out of the 11 cases in which the Labour Board imposed an agreement produced a second agreement, whereas only one of those cases resulted in a third (although another case had a third agreement still under negotiation at the conclusion of the study). On the other hand, eight (out of 11) of the cases in which the application was voluntarily settled by the parties resulted in a second agreement and four of those resulted in further agreements (Cleveland 1982, pp. 99-100). These findings led Cleveland (1982) to conclude that those cases in which the Board imposed an agreement on the parties did not result in lasting bargaining relationships, but those in which the parties were able to settle an initial contract on their own were reasonably successful at producing lasting 
bargaining relationships. Indeed, she hypothesized that there would be such a finding in that the settling of subsequent agreements seemed much more likely when the parties were successful at settling the first agreement and that employers who do settle the first agreements may have initially been opposed to the union due to inexperience with dealing with a union rather than for ideological reasons that may have led to continued resistance of collective bargaining. However, Cleveland (1982) shows that when the definition of a lasting bargaining relationship is more stringently measured by whether the case produced more than one agreement and the union is still actively certified, she found that the success rate of the settled cases, while still higher than those cases in which an agreement was imposed, was much lower (Ibid, pp. 127-128). Thus, due to the failure with which cases in which an agreement was imposed resulted in lasting bargaining relationships, Cleveland (1982) rejected Weiler's notion of a "trial marriage" in that the imposed agreement did not normalize the bargaining relationship because employers continued, or even in some cases increased, their resistance to the union and collective bargaining in their workplace (Ibid, p. 135).

For the period 1993-2000, O'Brien (2001) found that 25 percent of the applications for FCA resulted in decertification, of which 23 out of the 66 occurred during the process. She was able to obtain information on later outcomes from the British Columbia Labour Relations Board (BCLRB) or the parties involved in 36 cases that concluded with an agreement. Of these cases, she found that the agreements in 16 cases had yet to expire, second agreements were settled in 13 cases, and that further agreements were negotiated in 10 of these cases. Thus, O'Brien (2001) concluded that the evidence of whether FCA was producing enduring bargaining relationships was inconclusive, but that the chances could be improved if the imposed agreements were implemented in excess of the one year required by the statute (O'Brien, pp. 71-72, 75). 
While O'Brien (2001) was able to obtain information on renewals by contacting the parties involved, Slinn and Hurd (2011) used only the BCLRB, which tracks whether or not bargaining relationships between the parties are active, to examine the reasons why bargaining relationships ended during 2001 to 2008 . They found that of the 65 applications that produced a bargaining relationship through a settlement in the FCA process, 47 (72.3 percent) were still in existence while 18 were inactive due to business closure or decertification. In terms of the direction that was given in the FCA process, the bargaining relationship still existed in: every one of the 8 cases in which the parties agreed to accept mediation/arbitration or the mediator's recommendations, 12 out of the 18 cases that received a direction to arbitration/mediation or had an agreement imposed by the Board, and 9 out of the 12 cases in which the parties were directed to exercise their right to self-help. Of these 65 cases, 13 (20 percent) resulted in the decertification of the union. Furthermore, they found that there were 33 applications for decertification out of the 108 cases involved in the FCA process during this time period, 24 of which resulted in decertification (22.2 percent). However, the authors note that there was a very high general decertification rate in British Columbia during this time period, and thus, even though the decertification rate of those involved in the FCA process seems high, it is actually no higher than the general rate (Slinn and Hurd 2011, p. 65).

Vipond (2010) makes the most comprehensive attempt to analyze the long term effect that first contract arbitration has on fostering enduring bargaining relationships. As mentioned above, this researcher used a telephone survey to compile information on a sample of 331 cases that were granted access to FCA from 1993 to 2009 (out of a possible 407 cases) and found that 164 (49.5 percent) of those in her sample were still in the bargaining relationship by the end of 
her study (Vipond 2010, p. 42). However, she later states that 164 (now 51 percent $^{1}$ ) of her sample are still in bargaining relationships, while 123 (38 percent) of the cases in her sample resulted in union decertification and 37 cases (11 percent) resulted in business closure. Therefore, of those cases that were no longer in a bargaining relationship in her sample, 77 percent were due to decertification and 23 percent were due to business closure (Ibid, p. 44). Furthermore, she was able to compile information on the amount of relationships still in existence based upon the method of resolution in each of the cases in her sample. Thus bargaining relationships existed in: 86 (out of 193; 44.6 percent) of those cases that ended with a mediated settlement; 32 (out of 39; 82.1 percent) of those cases that accepted the mediator's recommendations; 8 (out of $18 ; 44.4$ percent) of those cases that agreed to voluntary arbitration; 11 (out of 17; 64.7 percent) of those cases in which arbitration was undertaken after one party refused the mediator's recommendations; 11 (out of $28 ; 39.3$ percent) of those cases that ended with arbitration; and 16 (out of 36; 44.4 percent) of those cases that allowed the parties to exercise their right to self-help (Vipond 2010, p. 42).

Using decertifications for the entire population of cases that accessed the FCA process during the time period, Vipond (2010) finds that 136 (out of the 407 cases; 33 percent) ultimately resulted in decertification. During this same time period, 1407 out of the 4244 (33.3 percent) certifications granted in the entirety of British Columbia resulted in decertification. Thus, she believes that this provides evidence that the FCA process works since the decertification to certification rate of those using the process is the same as those not, which she states likely would not have been the case without FCA since they represent "the worst of the worst" (Vipond 2010, pp. 46-47). However, while I believe that she is right that this may be counter to

\footnotetext{
${ }^{1}$ She inexplicably drops seven cases from her sample, which is why the percentage of cases still in bargaining relationships increases from 49.5 percent to 51 percent.
} 
expectations if these cases truly represent the worst of the worst (which they very well may be), I also believe that her conclusion is tenuous. The finding that the decertification rate for those who access FCA is the same as those who do not provides inconclusive evidence concerning the effectiveness of FCA in producing bargaining relationships. If 33.3 percent is the actual rate for the province, and one thinks of those who gain access to the FCA process as merely a sample, then statistical inference would predict that one would find the same rate (or at least one that is not statistically different than the overall decertification rate if the sample is representative of the overall population). Her assertion may be true if those who access FCA are fundamentally different than those who do not, and there is some evidence that those who apply for FCA represent smaller bargaining units than those who do not, but given the information that she presents she cannot make the conclusion that this evidence shows that bargaining relationships are being created. Therefore, I believe that one can only come to the conclusion that Vipond arrives at, if one can show that the FCA process results in a statistically significant lower decertification rate.

This article also examines the length of the bargaining relationship for those cases in the sample whose bargaining relationships ended during the period of analysis. ${ }^{2}$ Vipond (2010) finds that the overall average relationship from the resolution of the first agreement to the end of the bargaining relationship (either decertification or business closure) was 35.8 months and that it was longer for the cases that were resolved through mediation (average of 38.3 months) than those that were settled in either arbitration (29.2 months) or a direction to exercise self-help (32.2 months). She believes that this is very informative in that it constitutes an approximately three

\footnotetext{
${ }^{2}$ It is also rather perplexing as to why Vipond did not also examine the length of the bargaining relationship of those cases still in bargaining relationships in her sample. It seems that if she could have measured the length for those who are no longer in relationships, then she could have done the same for those still in relationships, which in my opinion, would have been just as, if not more, informative.
} 
year relationship between that parties that would not have occurred had there not been access to the FCA process (under the assumption that no parties in the FCA cases would have resolved their dispute irrespective of it). She continues to state:

"What is interesting, however, is that the numbers indicate that most unions are not being decertified right after the expirations of the 10-month freeze period or after the expiration of the term of the first collective bargaining agreement. This would suggest that the B.C. first contract model may have assisted the parties in repairing their bargaining relationships for some period of time..."

And later concludes:

“...by allowing mediators to issue recommendations, the B.C. first contract model resulted in enduring bargaining relationships for the cases in which both parties $(82.1 \%)$ or at least one party $(64.7 \%)$ accepted the mediator's recommendations. Further, the average length of the bargaining relationship for parties who are no longer in current bargaining relationships was roughly three years, which suggests that even the bargaining relationships that did not last were successful in achieving lengthy bargaining relationships" (Vipond 2010, p. 48).

Again, I believe that Vipond is severely overstepping her data, especially within the context of how she defines "enduring bargaining relationships" and "lengthy bargaining relationships". She defines "enduring bargaining relationships as "greater than 50\%", which really does not make any sense in that she is referencing the percentage amount that are still bargaining per a method of resolution, rather than making any reference to the length of the relationship (p. 59).

Furthermore, she does not measure the length of the relationships of those currently in bargaining relationships so she cannot conclude whether these cases are enduring or not. If the cases that are still in bargaining relationships are only the more recent ones then one would not necessarily conclude that FCA is actually producing lengthy bargaining relationships. Additionally, she defines "lengthy bargaining relationship" as "a relationship longer than the 12month freeze period" (p. 60). This hardly seems appropriate since her sample includes cases that resulted in a contract that presumably extended beyond the freeze period anyways (at least in the 
case of imposed contracts which are two years unless otherwise agreed by the parties). A more stringent definition, such as the renewal of the bargaining agreement, would be much more believable than the bargaining relationship extending beyond the freeze period, especially since the three year mean that she finds for those cases in which the bargaining relationship ended could encompass the length of the agreement (likely 2 years) and then a failed round of negotiating over a new agreement before subsequent decertification. Under her definitions, a union that won an arbitration award that imposed an agreement for two years and was unable to renew this agreement and subsequently decertified would constitute a "lengthy bargaining relationship". I think that this barely merits the title bargaining relationship, let alone one that is lengthy.

\section{b. Manitoba:}

Some early studies on Manitoba provided better evidence of success than those early studies examining British Columbia, but also need to be viewed with suspicion since they too suffer from small samples. Korpesho (1986) noted that four of the first seven cases in Manitoba in which a contract was imposed resulted in the renewal of the agreement, although one of those cases resulted in decertification upon the expiration of the second agreement. The other three cases of the aforementioned seven resulted in two decertifications and an inactive certification (Korpesho 1986, p. 53). Sexton (1987a), who examined the first few years following the enactment of the provision, found that in the 17 cases (out of 25 applications) in which the collective agreement had expired, 10 resulted in renewed agreements or were currently under negotiation (p. 514). Mitchell (1992) found that of the 80 FCA applications from 1983 to 1991, 14 resulted in decertifications, 25 of the agreements were still in effect, 9 were negotiating second agreements, 10 settled second agreements, 23 further agreements had been negotiated or 
settled, 6 of the cases were inactive, 4 resulted in the withdrawal by the parties, and 2 were still going through the process. Of the 37 agreements that were imposed by the MLB, 8 resulted in decertification, 7 of the first agreements had yet to expire, 6 cases were amidst negotiations for a second agreement, 5 concluded second agreements, 8 further agreements had been negotiated or settled, and 3 of the cases were no longer active (Mitchell 1992, p. 324).

Examining the period 1983 to 1991, Black and Hosea (1994) provide a bit more context to the Manitoba experience than Mitchell (1992). From the 90 applications for FCA in their period of study, they found that 21 (23.3 percent) resulted in decertification, 6 (6.7 percent) resulted in the closure of the business or the inactivity of the union, 59 (65.6 percent) had yet to expire or were amidst renegotiations, and 4 (4.4 percent) were inconclusive due to a lack of information. Therefore, they found that 23 percent of the overall applications to the FCA process resulted in decertification and that this was more probable in the cases in which a contract was imposed than when the parties settled an agreement voluntarily. In the former case, 12 out of 39 imposed contracts resulted in decertification (30.7 percent), whereas in the latter case, 7 out of the 47 cases in which an agreement was settled voluntarily resulted in decertification (14.9 percent). During this time period, there was a total of 66 decertifications in Manitoba (out of 111 applications), of which 20 (30.3 percent) of these decertifications were bargaining units that applied for FCA. The author's note that this may seem high, but they state that supporters of FCA believed that these units would never have been certified in the absence of the legislation. To say that they would not have been certified without first contract arbitration might be a reach since FCA does not play a role in the unit's certification. That being said, finding a higher decertification rate among those who attempt to gain access to the FCA process may not be surprising as their action to apply is likely the result of a breakdown in 
negotiations and, as the authors note, the units that apply for FCA tend to be smaller units which are already increasingly susceptible to decertification. However, FCA did not seem to have had an adverse effect on the overall decertification rate in Manitoba as the ratio of decertifications to certifications during 1983 to 1991 was 11.4 percent, which was lower than the 13.2 percent from 1974 to 1982 in its absence (Black and Hosea 1994, pp. 37, 40).

Slinn and Hurd (2011) found that 7 of the 11 cases for which the MLB imposed an agreement from 2001 to 2008 were still active, 10 of the 17 agreements that were voluntarily settled by the parties during this time period remained active, and that the 7 others had expired. Unfortunately, the authors were unable to find any information on whether those agreements that had expired during this time period were initially renewed or whether the bargaining relationship between the parties remained in existence (Slinn and Hurd 2011, p. 70).

\section{c. Ontario:}

The only study that looks at the subsequent outcomes in Ontario (to the best of my knowledge) is Slinn and Hurd (2011), who look at both the outcomes for those who received a direction to arbitration and those who applied to the FCA process. From 2001 to 2009, the first collective agreement was still active in four out of the eight agreements imposed by the OLRB during that time period. Of the other four imposed agreements, one (12.5 percent) resulted in the decertification of the union, while there was not enough information on the other three for the authors to make an assessment. That being said, the authors know that the unions in the latter three cases had not been decertified and that the Ministry of Labour's Office of Collective Bargaining (OCB) file had not been closed, which means that the business had not closed. Thus, the parties had likely failed to give the OCB the necessary information from which the authors could judge. The authors note that this decertification rate for imposed agreements is similar to 
the overall decertification to certification rate for the province during this period. Of the overall 70 applications that were made to the OLRB for access to the FCA process, 16 (22.9 percent) were subsequently decertified. Of these 16 decertifications, 1 occurred in the case of an imposed agreement, 9 occurred in cases where the application had been withdrawn, 5 occurred in cases in which the case was closed due to administrative reasons, sine die or terminated and 2 occurred in cases where the application was dismissed (Slinn and Hurd 2011, p. 67).

\section{d. Quebec:}

In the aforementioned study questioning Weiler for being too presumptuous, Sexton (1987b) examined the outcomes of the bargaining relationships beyond the imposition of a first agreement in Quebec from 1978 to 1984 . Of the 88 cases in which a contract was imposed, he was able to build a sample of 72 cases ( 81.8 percent) from which he found that the agreements in 49 (68.1 percent) of them had yet to come up for renewal, 16 (22.2 percent) were still in operation, 4 (5.6 percent) were in the midst of bargaining, 16 (22.2 percent) had resulted in or were in the process of decertification, and 10 (13.8 percent) resulted in the closure of the business. Of those cases, he found that the collective agreement had been renewed at least once in 23 cases, twice in 5 cases and three times in 4 cases. Of those in which there was at least one renewal, 17 out of the 23 did not use any third-party assistance by the Ministry of Labour in the renewal process. In surveying both parties involved in the renewal cases, Sexton (1987b) found that management tended to view the bargaining relationships more favorably than the unions, but both generally agreed that the relationship had improved over time (Sexton 1987b, pp. 290-291).

The Ministry of Labour study on FCA from 1978 to 2001, followed 218 of the FCA cases in which an agreement was settled throughout the years 1978-1998 and found that 103 (47.2 percent) of these cases settled a second collective agreement. Furthermore, 54 (24.8 percent) of 
these cases negotiated further agreements, the maximum of which were a number of cases that successively concluded five rounds of negotiations. Furthermore, they found that the renewal rate for collective agreements improved over the course of the time period under study. During the period 1978 to 1983 , the average renewal rate was less than 20 percent, while the average was approximately 25 percent during 1984 to 1989 and over 35 percent for the period 1990 to 1998 (Marotte and Paré 2002, p. 20).

\section{Summary/Analysis}

An assessment of the goal of whether not FCA facilitates the creation of lasting bargaining relationships is undertaken in many articles on FCA, but due to the lack of agreement on what constitutes a "lasting" bargaining relationship, the way in which this is measured varies across studies. Some use the number of decertifications as a measure since this is an easy way to discern whether the parties are still in a bargaining relationship, while others use the number of renewals of a collective agreement to a certain threshold as the measure of a bargaining relationship, or both. While this goal of FCA was initially viewed with skepticism based upon the results of the cases during the first few years of enactment in a number of provinces, as the use of FCA became more widespread and data became more available, the assessment of this goal improved. The provinces/systems analyzed in the existing literature is limited to the same four provinces listed under the previous goal and, as with above, this allows one to make some rudimentary comparisons across provinces/types of FCA.

The evidence from British Columbia varied over time leading those authors writing on earlier periods to state that FCA was a failure in this regard (Cleveland 1987) or inconclusive at best (O’Brien 2001). However, later studies, such as Vipond (2010) and Slinn and Hurd (2011), 
found more favorable outcomes in which bargaining relationships were active in more than half of the cases in the former and almost 75 percent in the latter. When the number of decertifications was used as a measure, these studies found that between 20 to 40 percent of the first contract cases that applied for the FCA system resulted in decertification. One finding that holds across all of these B.C. studies is that the bargaining relationship is more likely to be enduring if the initial contract is settled by the parties, rather than imposed by the relevant labor board. Indeed, this is hypothesized to be the case in that if the parties are able to settle the first agreement then it would seem that they would be more likely to settle subsequent agreements. Furthermore, if they are able to settle one voluntarily then it is more likely to be accepted than one that is forced upon them. Thus, the cases in which a settlement was produced voluntarily, through mediation, or through the mediator's recommendations tended to correlate with better subsequent outcomes.

The evidence from Manitoba is rather similar across studies which largely found that between 50 and 60 percent of the cases that accessed the FCA system were still active at the end of the period of analysis and the decertification rate for the total applications to the system ranged between 20 and 30 percent, a lower range than that found in the studies of B.C. While one study found that the decertification rate for those cases that accessed the FCA system was higher than the general decertification rate, the authors noted that the general rate for that time period was still lower than the previous time period when no FCA provision existed. Similar to British Columbia though, these studies, with the exception of the most recent study by Slinn and Hurd (2011), produced the same finding that the likelihood of maintaining the bargaining relationship increased in cases that were settled with a voluntary agreement than ones in which the agreement was imposed. 
The evidence for both Ontario and Quebec is much sparser than for the two above provinces, such that it is difficult to draw any conclusions based on the few studies that undertake this analysis. The lone study for Ontario by Slinn and Hurd (2011) looks at the outcomes of only those cases that received a direction to arbitration, a population of 8 , and find that the relationship is still active in 50 percent of them. They also look at the decertification rate for those unions who apply for access to the FCA process and find the rate to be about 23 percent, which was similar to the overall decertification rate for the province during 2001 to 2008. Using a sample of cases, Sexton (1987b) found a renewal rate of 32 percent and a decertification rate of 22 percent in Quebec. This former rate seems low in comparison to the other provinces, but it is not a measure of the number of cases that are still active, which is likely much higher, and could not be calculated due to discrepancies in the data that Sexton (1987b) reports. The other study on Quebec found that 47.2 percent of the cases that accessed the FCA system and concluded an agreement renewed that agreement. Furthermore, they found that the renewal rate for agreements improved over the course of the time period under analysis (Marotte and Paré 2002).

Thus, from these studies it appears that the automatic system of Manitoba may be the most successful at fostering bargaining relationships when one takes into account how many of the cases remained active and the magnitude of the decertification rate. Although British Columbia exhibited a higher decertification rate for unions that accessed the FCA system than those in Manitoba, the number of cases that remained active in the studies was roughly comparable. Such findings may be expected due to the ease of access granted in the automatic system of Manitoba and the focus on mediation in the mediation-arbitration system of British Columbia. However, as with the previous goal, the attempt to evaluate how effective FCA 
provisions are at fostering the creation of lasting bargaining relationships has thus far been restricted to only those first contract instances in which the union (or employer) sought access to the FCA system. As noted above, this is not an uninformative piece of information but does gloss over the impact that FCA provisions might have through a deterrent effect.

\section{Act as a Deterrent}

The final goal of FCA provisions, which has been alluded to in the previous sections, is that the possibility of having an agreement imposed upon the parties should act as a deterrent to bad-faith conduct and should encourage the voluntary settlement of first agreements. Thus, this contributes to the aforementioned balancing act of imposed agreements in that while such agreements cannot be too overly attractive to induce a reliance on the process by newly certified unions for obtaining an agreement, the impositions must be sufficiently attractive to deter employers from evading their duty to bargain in good faith with the union. The need to impose sufficiently attractive agreements to represent a deterrent has led opponents of FCA to complain that it will (1) result in overreliance on the procedure such that it will inhibit free collective bargaining and (2) that it will result in contracts that will be harmful to the businesses (Hoh 2010, p. 52).

Such a reliance on the FCA process, it is argued, may produce a chilling effect on negotiations in that the parties may posture for a favorable arbitral award rather than participate in meaningful collective bargaining. However the evidence does not substantiate the first argument as many researchers highlight that while FCA is available to approximately 80 percent of the Canadian workforce, it is very rarely accessed. Rose (2006) found that from 1974 to 2000, FCA applications represented only 5.9 percent of certification applications in those jurisdictions 
where the provisions existed and that contracts were imposed in only 1.4 percent of the certifications during this time period (p. 201). Johnson (2010) found that the application rate for FCA (as a percentage of the certifications granted in that jurisdiction during that year) averaged between 1.0 percent for the Federal jurisdiction and 17.0 percent in Manitoba, while the imposition rate averaged between 0.3 percent for the Federal jurisdiction and 8.0 percent in Manitoba (pp. 597, 599). Thus, there doesn't seem to be a reliance on FCA, or a chilling effect on negotiations, since the vast majority of first contracts are settled voluntarily. It appears that the parties would rather settle a contract on their own terms than face the uncertainty that accompanies having one imposed upon them. This has led many to conclude that FCA does not inhibit free collective bargaining, but rather encourages it (Friedman and Wozniak 1996; Voos 1997; Johnson 2010).

The evidence also seems to contradict the second argument of FCA opponents that, as noted above, the arbitrators do not try to impose agreements that contain breakthrough or innovative clauses. Comparisons of imposed and voluntary agreements have shown that imposed agreements tend to contain lower monetary provisions than voluntary awards (Voos 1997). In fact, the imposed contracts were initially viewed as too conservative as not to make collective bargaining attractive enough in a number of jurisdictions (McDonald 1987; Patterson 1990). Furthermore, a study of all 16 of the businesses that had agreements imposed upon them between 2001 and 2007 in Manitoba showed that 14 of them were still in operation in 2009. Although this represents a very small sample, the survival rate of these firms during this time period was higher than the overall business survival rate for 2005 to 2006, which was at the peak of a boom cycle in Canada (Eisenbrey and Eagan-Van Meter 2010, pp. 2-3). Lastly, employers represent a substantial proportion of the applications for FCA in a number of the provinces, 
which would be counterintuitive if employers actually believed that the process would put their businesses in danger of closure. Thus, it does not seem that the claim that arbitrators will impose unworkable agreements that will put the businesses they affect at risk warrants very much merit.

The above statistics about the infrequency with which the process is accessed and the rarity of imposed of contracts provides some preliminary evidence that FCA does not interfere with free collective bargaining nor hinder business, but there is no rigorous statistical analysis of the deterrence effect. Due to the rarity with which parties are granted access, as shown above, one might hypothesize that the majority of the impact of FCA provisions arises through deterrence. That being said, the existence of a deterrent effect cannot be separated from the other goals of FCA identified above as the provisions must attain some modicum of achievement of those goals if the threat of first contract arbitration is to credible enough to induce employers to cease resisting unions. As one author highlights, "if employers can be assumed to be familiar enough with policy and procedures of the Labour Board to be deterred from union avoidance tactics by the possibility of imposition of a first agreement, by the same token, they could be presumed to know about the poor track record of imposed agreements" and accept the imposition knowing that they will be able to rid themselves of the union upon the expiration of the agreement (Walker 1987, pp. 31-32). Thus, the identification of a deterrent effect and an analysis of the factors that play a role in its existence and magnitude would be vital information in the debate over the effectiveness of first contract arbitration.

Cleveland (1982) is one of the few studies that tries to empirically identify the deterrence effect of an FCA provision. Analyzing British Columbia from 1974-1979, she uses a number of different measures including (1) the percentage of all new bargaining units in the province that are unable to obtain a first agreement within eighteen months, (2) the amount of cases that access 
the FCA provisions that are able to achieve settlements (rather than impositions), and (3) the existence of highly publicized work disputes. She hypothesizes that a decrease in the first and third measures and an increase in the second could point toward a deterrence effect (Cleveland 1982, p. 49). Additionally, the first and third measures would incorporate a deterrence effect that extends to all newly certified unions, whether or not they accessed the FCA provision, whereas the second is confined to only those who accessed the system. In terms of her first measure, Cleveland (1982) found the percentage of newly certified unions unable to obtain an agreement within 18 months to be highly variable over the time period and concluded that there were too many factors influencing such a measure to identify a deterrent effect. However, she did find that the FCA provision provided a deterrent effect through her second measure in that the process gave the Labour Board an opportunity to mediate settlements that it did not have prior to the enactment of FCA. Furthermore, she found that the paucity of applications during her period of study may be due to a deterrence effect from the union's perspective in that one union representative that she interviewed stated that the union would rather accept a mediocre agreement that was settled voluntarily than one that was imposed since the latter indicated weakness to the employer (Ibid, pp. 137-138, 146). Lastly, she found that there was a decrease in her third measure over the period of study and concluded that FCA reduces the occurrence of highly contentious first agreement work stoppages (Ibid, p. 141).

Walker (1987) also tried to identify the deterrence effect in British Columbia from 1974 to mid-1983 by using one of the same measures as Cleveland: the percentage of newly certified bargaining units that were able to obtain first agreements within 18 months following certification. Walker (1987) ultimately found no discernible trend in the percentage, which led him to conclude that there was no such effect during this period (Walker 1987, p. 32). However, 
his elementary analysis does not account for the percentages in the years prior to 1974, and thus the passage of the B.C. FCA provision. If the percentage over the period that he observed was greater than the prior period when no FCA provision existed, then this would lend more evidence to the notion of a deterrence effect, although the decrease over the period that he sought to identify would indeed bolster such a finding. Furthermore, Walker (1987) notes that any deterrence effect that might have taken place during this period may have been negated by the anti-labor Social Credit government. Whereas Cleveland (1982) saw the scarcity of applications during this time period as due to deterrence against unions applying to the process, Walker (1987) highlights that the shortage of applications may be due to political capture through the ministerial screen by an unfriendly government (Ibid, p. 35).

In addition to the above empirical analyses, there is also some anecdotal evidence showing that FCA does indeed deter misconduct and promotes voluntary collective bargaining. In recounting the first couple of years in B.C. under the FCA provisions, Weiler (1980) argued that the deterrent effect was quite successful as the first contract work stoppages that plagued the province prior to the FCA provision diminished (Weiler 1980, p. 54). Whereas in Ontario, both representatives of management and labor felt that the threat of having an agreement imposed upon them by a third party was enough impetus to settle one on their own accord (Patterson 1990). Thus, the dearth of empirical work trying to measure or examine the deterrence effect of first contract arbitration presents another solid area for future research.

\section{Summary/Analysis}

The goal of deterring employer misconduct is perhaps the least studied of the four goals of first contract arbitration. In order for a deterrence effect to exist, the threat of having an 
agreement imposed must be credible and the imposed agreement must be attractive enough to demonstrate the value of collective bargaining to the affected employees. This has led to criticisms by opponents that imposed agreements will be harmful towards business and will hinder free collective bargaining since the parties will come to rely on FCA for favorable contracts, but the evidence shows that neither of these claims hold water.

The reason that the deterrence effect of FCA has been under studied to date is largely due to the restriction of analysis to only those cases by which the union or employer seeks access to the FCA machinery. Although Cleveland (1987) points out that the inclination for the parties to settle an agreement rather than have one imposed once they gain access to the FCA system is a form of deterrence, one would hope that the deterrence of FCA policies reaches beyond into the greater industrial relations arena. However, this can only be assessed by looking at the effect that the passage of an FCA provision has on all first contract cases both within and outside of the FCA process. Thus far, only Johnson (2010) and Riddell (forthcoming) have undertaken such analysis that incorporates the deterrent effect that FCA has on work stoppages and the first contract settlement rate respectively in the overall industrial relations arena. As mentioned above, the only way that the deterrence of an FCA provision can be effective is if the provision is successful with regard to one of the other goals. Thus, the findings of Johnson (2010) can be said to account for the deterrence effect with regard to the first goal of FCA, to end first contract work stoppages, whereas the findings of Riddell (forthcoming) accounts for the deterrence effect with respect to the second goal, to enable newly certified unions to obtain a first agreement. To date, there is no study that undertakes this same endeavor with respect to the third goal: to foster enduring bargaining relationships. It is this gap in the literature that this study seeks to fill and the following section elaborates on the theory driving this investigation. 


\section{Theory}

In surveying the existing literature on first contract arbitration, a number of articles highlighted the need for more research on the long-term outcomes of the process. For example, one of the articles stated that "it would be important to know whether these agreements form the basis for enduring collective bargaining relationships" (Friedman and Wozniak 1996, p. 160). More recent articles echo this sentiment, such as one that proclaimed that there is a "paucity of information" concerning such outcomes and that "[r]esearch assessing labour relations subsequent to achieving a first agreement would go a long way towards assessing what factors contribute to the establishment of enduring bargaining relationships" (Rose 2006, p. 214). Another article recognized that "there is altogether less information on what happens to these first-contract settlements beyond the first agreement" and that "the key test over the longer term will come in the ability to maintain and develop a bargaining relationship beyond the first agreement" (Murray and Cuillerier 2009, p. 96).

As shown above, some articles have attempted to provide a preliminary answer to the question over whether FCA contributes to lasting bargaining relationships. However, the approaches that have been undertaken thus far are lacking for a number of reasons. The first of which is that the vast majority of the articles have limited their samples to either those who have been granted access to the FCA process or those who have applied to the process. This approach completely omits the deterrence effect that proponents of FCA claim takes place and thus, by restricting the sample to only the small percentage of overall certifications that apply or participate in the process, these articles may severely understate the effect of FCA. Furthermore, those that had explicitly tried to identify the deterrence effect with regard to bargaining relationships and thus, examined beyond the sample of only those cases that sought access to the 
system, utilized very rudimentary analyses that were unable to control for the effect of other factors on their dependent variables. Furthermore, the majority of studies have focused on only one province, and even so on periods in which only one type of FCA prevailed. Therefore, they have only assessed the type of FCA that is operating during that period in that province and have not made any attempt to make rigorous statistical comparisons across types of FCA. Slinn and Hurd (2011) did analyze multiple provinces in their article, but did so individually and stated that such statistical analysis was precluded by the noncomparability of the data across the jurisdictions (p. 73). However, Johnson's (2010) article on the effect of FCA on first contract work stoppages shows that such multi-jurisdictional studies are possible.

Thus, this thesis contributes to this stream of literature on whether or not FCA can result in bargaining relationships by performing a multi-jurisdictional study of the effect of FCA on various decertification rates, as a proxy for bargaining relationships, in a similar fashion as Johnson (2010). The longer employers can effectively frustrate unions' attempts to secure a contract, the greater the likelihood that workers will decertify their unions since they will be paying dues but not receiving the benefits of unionization (collective bargaining, work under a union contract, etc.). This employer opposition precludes the establishment of a lasting bargaining relationship. However, if FCA is present then workers have an avenue to circumvent such staunch employer opposition and have the ability to secure a collective contract. This will provide workers with a better idea of what it is like to work under a collective bargaining agreement and this experience, although not a guarantee that the workers won't decertify, should lessen the likelihood of decertification. This assumption holds unless such an imposed contract is, as FCA opponents claim, substantially unsatisfactory that the workers will subsequently decertify anyways. Furthermore, due to the deterrence effect of the FCA provisions, even if the 
union does not access the FCA process, the employer may still be compelled to settle an agreement out of fear of having one imposed by a third party. Therefore, if the number of decertifications and the decertification rate decline following the passage of an FCA provision then one can assume that bargaining relationships are taking hold and this would contradict the claims of opponents of FCA since under their pretenses, one would expect an increase.

Furthermore, using the decertification rate of the entire province, including both those cases that access the system of FCA and those that do not, this measure will incorporate both the direct effects of such provisions and any indirect, deterrent effects. Thus, the preceding advances the following hypotheses:

$\mathrm{H}_{0}$ : First contract arbitration does not result in more bargaining relationships.

$\mathrm{H}_{\mathrm{a}}$ : First contract arbitration does result in more bargaining relationships.

Therefore, the decertification rate may be used as a measure for bargaining relationships, since it is clear that if a union is decertified then a bargaining relationship ceases to exist, and various measures of the decertification rate are used as the dependent variables in the following model

$$
Y_{i t}=\beta_{0}+\beta_{1} X_{i t}+\beta_{2} Z_{i t}+\beta_{3} W_{i t}+T_{t}+\alpha_{i}+\epsilon_{i t}
$$

where $Y_{i t}$ are variables that proxy for the existence of bargaining relationships for province $i$ in year $t$. I define the dependent variable using two measures that are intended to capture this relationship. The first uses the log number of decertifications divided by the provincial unionized workforce, while the second uses the log number of decertifications divided by the number of certifications. For Model (1), $X_{i t}$ is a dummy variable that measures the availability of first contract arbitration in province $i$ in year $t$. In Model (2), however, $X_{i t}$ is a vector of variables that measures the availability and the type of FCA that is available in province $i$ in year $t$. Thus, this model includes dummy variables for each of the fault, no-fault, automatic and mediation- 
arbitration forms of first contract arbitration. $Z_{i t}$ is a legal control dummy variable that measures the presence of mandatory representation vote legislation in province $i$ in year $t$. The vector $W_{i t}$ includes environmental control variables that may influence the number of decertifications that occur in province $i$ in year $t$. These include two dummy variables that measure whether a conservative or an anti-union government is in power in province $i$ in year $t$, which are meant to serve as a proxy for the overall climate towards organized labor in the province. It also includes the number of unfair labor practice complaints received in province $i$ in year $t$, which is meant to serve as a proxy for the level of employer opposition towards organized labor. Finally, the vector includes a number of variables that serve to measure the economic environment for organized labor, including the unemployment, employment, inflation, and provincial union density rates. $T_{t}$ represents variables that account for unobserved change over time, which depending upon the specification, takes the form of either a time trend or year fixed effects. $\beta_{0}$, $\alpha_{i}$, and $\varepsilon_{i t}$ are a constant term, province fixed effects and the error terms for province $i$ in year $t$ respectively. The following paragraphs provide an in-depth discussion of each of these variables and an elaboration on the reason for their inclusion in the above model.

As stated above the two dependent variables are the log number of decertifications granted divided by the size of the unionized workforce in the province and the log number of decertifications granted divided by the number of certification applications granted in the province in that same year. The two dependent variables are divided by the unionized workforce and the number of certification applications granted respectively to scale or weigh the values so that the larger provinces don't over influence the outcomes of the regressions and the natural log of these "rates" are taken since they are highly variable by themselves and this normalizes their distribution (see Table 1 below). 
Table 1 - Dependent Variables: Nonlogged vs. Logged

\begin{tabular}{|l|l|l|l|l|l|l|}
\hline Variable & $\mathrm{N}$ & Mean & P50 & St. Deviation & Skewness & Kurtosis \\
\hline Decertificatons/Union Workforce & 362 & 0.0921793 & 0.0640167 & 0.0930769 & 4.029924 & 32.02604 \\
\hline Log Decertifications/ Union Workforce & 357 & -2.699628 & -2.737609 & 0.8094381 & 0.0008034 & 3.126681 \\
\hline Decertifications/Certifications & 362 & 0.1907157 & 0.1300739 & 0.2258023 & 4.646155 & 37.37498 \\
\hline Log Decertifications/Certifications & 357 & -2.047525 & -2.014903 & 0.8980307 & -0.0773195 & 3.48127 \\
\hline
\end{tabular}

The main explanatory variables in the two models are those that measure first contract arbitration, all of which are dummy variables. In Model (1), the FCA variable takes the value 1 during the years when access to first contract arbitration is available in the province and 0 otherwise. The four FCA variables in Model (2) represent the fault, no-fault, automatic and mediation-arbitration systems of FCA respectively and take the value 1 when that form of FCA is available in that province for that year and 0 otherwise. As stated above, I expect the availability of FCA to result in a decrease in decertifications so I expect the coefficient $\beta_{1}$ to be negative. Thus, I also expect the coefficient for all of the types of first contract arbitration to be negative and the coefficients on the variables for the more accessible types of FCA, such as the automatic form, to be of greater magnitude.

The variable measuring the mandatory representation vote legislation is a legal dummy variable that takes the value 1 when there exists a provincial law that requires mandatory representation votes to obtain certification and 0 when no such law exists and unions can be certified through a majority (or supermajority) of signed union authorization cards. Previous research on mandatory representation vote legislation shows that it has an adverse effect on union certification success (Johnson 2002, Riddell 2004). This finding may be due to an increase in the opportunity and effectiveness of management opposition as a result of a longer certification process and heightened susceptibility to employer coercion under a vote regime. Indeed, one study estimated that management resistance was twice as effective in the presence of 
mandatory vote legislation as in its absence (Riddell 2004). While there are a number of studies examining the effect on certifications, there is less information on the effect that mandatory vote laws may have decertifications. If employer resistance is more frequent and effective under such laws then this may continue into later stages of the process beyond certification. Thus, one might expect the number of decertifications to be higher in the presence of such laws due to management opposition. Bentham (2002) found that the likelihood of early decertification increased by as much as 41 percentage points when a certification vote was required in a jurisdiction. She also found that of the 29 cases of early decertification in her sample, 65 percent of those cases involved a certification vote. Thus, it seems that employers are able to more effectively resist union organizing campaigns in a mandatory vote regime (as is also found by Riddell 2001) and that this resistance continues into the contract campaign when the union is able to successfully overcome such resistance at the certification stage. The presence of such legislation could also be indicative of a period of union weakness in which the political climate is unfavorable towards organized labor, which may embolden employers in their resistance. Alternatively, the number of decertifications could potentially decrease if the mandatory vote legislation leads to weaker bargaining units failing to obtain certification. Thus, only bargaining units with strong employee support might obtain certification, which might also reduce employer opposition in that the certification may be demonstrative of that support. Similarly, if unions are aware that certification is more difficult under mandatory vote legislation, then they might be more strategic in deciding where to spend their resources and organize, which might produce a similar result in that only strong bargaining units obtain certification.

Furthermore, rather than passing singular amendments that affect one section of the provincial labor code, such as certification or decertification, the provinces often enact labor law 
reform packages that affect numerous sections of the labor code. Therefore, this legal control dummy may incorporate the effects of other changes to the labor code, the most pertinent of which to this analysis, are those that affect the sections concerning decertification. Of the seven provinces included in this study that made the switch from card-check to mandatory representation votes (and back again for some), five of them simultaneously changed their decertification procedure in some fashion when they enacted the reform package that included mandatory votes. Thus, this variable may also accounts for changes in the threshold of support needed to induce a decertification election, the time for which a decertification application may be filed, and/or the length of the time bar after a successful decertification from which a trade union may reapply for certification if such changes were enacted at the same time as mandatory representation votes/card check. However, this is not always the case as some provinces have passed reforms of their decertification procedure through bills that did not affect the certification process. This will introduce some error into my analysis as such changes will be unaccounted for in the model, but these changes occur less frequently than those that accompany a larger law reform package. Thus, the mandatory vote legislation dummy may have a direct effect on the number of decertifications if the passage of the legislation coincides with changes that make it easier for unions to decertify. Consequently, it is unclear what effect a mandatory representation vote law will have on the number of decertifications and thus, the direction that the coefficient, $\beta_{2}$, on this variable will take is ambiguous. However, based upon the lessening of the decertification requirements that may accompany the passage of such laws and previous empirical findings concerning the effectiveness of employer opposition under mandatory vote regimes, it seems probable that this coefficient will be positive. 
Since I am using decertifications as a proxy for bargaining relationships, I also need to control for other factors that may influence the number of decertifications in the province. Thus, the remainder of the variables in the above models are control variables. The conservative variable is a dummy variable that takes on the value 1 when a provincial conservative party is the ruling party in the province and 0 otherwise. This variable is a proxy for the favorability of the climate in the province towards organized labor. It has been shown that the party in power, through its enactment of legislation, appointments to the Labour Relations Board, and its rhetoric either highlighting the positives or negatives of organized labor, can affect the certification and decertification activity within a province (Martinello 2000). Some of the main parties in Canadian politics include the New Democratic Party, which is a social-democratic party with ties to the Canadian labor movement, the Liberal party, which is more central, and the Progressive Conservatives, which are to the right of the political spectrum. Thus, one would expect decertification activity to rise amid a conservative government, to fall when a party such as the NDP is in power, and the effect to be ambiguous when a party such as the Liberal Party in is power. Therefore, the coefficient on this variable is predicted to be positive. The variable antiunion government is also a dummy variable that takes the value 1 when a provincial government that has been recognized as being resoundingly anti-union is in power and 0 otherwise. Thus, during the neoconservative years of the Social Credit government in British Columbia (19831991), the Harris government in Ontario (1995-2002 ${ }^{3}$ ) and the Saskatchewan Party in Saskatchewan (late 2007-the present), it is expected that the decertification rates will greatly increase due to more decertifications and less certifications in the province, a result that as has been shown in previous research (Martinello 1996, 2000). Therefore it is expected that the

\footnotetext{
${ }^{3}$ Harris actually stepped down from office in 2002, but since this took place within the first half of 2002 and thus did not comprise a majority of the year, the value of ANTIUNGOV is 0 for that year.
} 
coefficient on this variable will be positive and of greater magnitude than the coefficient for the conservative variable.

As in other studies, unfair labor practice charges (ULPs) are included in the models as a proxy for employer opposition and it is expected that the incidence of ULPs will have a positive impact on decertification activity. Thus, I expect the coefficient on this variable to be positive.

The continuous variables for the unemployment, employment and inflation rates are included to account for the economic environment. A positive change in the unemployment rate is expected to have a negative impact on the decertification rate since jobs will be scarcer and thus, workers are expected to be less likely to shed the protection that is provided by a union and a collective agreement. Contrastingly, a positive change in the employment rate is expected to have a positive impact on the amount of decertification activity because as jobs become less scarce, it is expected that the need for the employment security that accompanies a collective bargaining agreement is lessened. A positive change in the consumer price index is expected to have a negative impact on decertification activity since union members will be less likely to dispose of the protection of their real wages that a collective contract provides during periods of inflation. However, Anderson et al. (1980), in their study of decertifications in the United States, found the coefficients on the unemployment rate to be positive, the employment rate to be negative and the change of prices to be positive, which is counter to their original, and the above, hypotheses. In light of their findings, they hypothesize that the coefficients on the unemployment and employment rates may be due to workers leaving their jobs for others when there are other employment opportunities, rather than decertify, and that the coefficient on the change in the consumer price index may be due to the workers' perception that their union is unable to protect their wages during periods of high inflation. Thus, in conditions of high 
inflation, union members may become disillusioned with their union and be more likely to decertify. However, inflation was much more prevalent during the time period under analysis in Anderson et al.'s (1980) study and thus, this finding may not hold for the period of analysis in this thesis in which inflation has largely remained at low levels. Anderson et al. (1980) included the employment rate (lagged three periods) and the unemployment rate in their equation, but only the unemployment and employment rates in the current year are included in these models. Therefore, the sign of the coefficients for the change in the provincial unemployment rate, the provincial employment rate, and the change in the consumer price index are ambiguous based upon theory.

The variable provincial union density is a measure of the union density rate in the province and this is expected to have a negative effect on decertification activity if the "demonstration effect" prevails in which a higher union density rate indicates that unions are successful and thus, results in worker unwillingness to get rid of their union. Alternatively, the union density could positively affect the number of decertifications, if the union density level is high enough, such that "union saturation" exists. This concept hypothesizes that there is level of unionization in a province (or perhaps more so an industry) where the remaining unorganized units are the most difficult to organize, or at least more difficult than those already organized, and thus, unions place less effort and resources into organizing them. Furthermore, those remaining units may not want or demand unionization (or at least may, but to a lesser degree) because if the industry is sufficiently organized then they may already receive the benefits of unionization due to spill over into the unorganized portion of the industry in which nonunion employers may provide union wages and benefits as a price for remaining nonunion. Thus, if the unions do organize these units then they might not feel strongly enough about remaining 
unionized to withstand a decertification campaign (Cooke 1983, pp. 407-408). Anderson et al. (1980) finds that the demonstration effect prevails in their study in that a higher unionization rate correlates with less decertifications, but this is not necessarily going to hold for this study, so the sign of the coefficient on this variable, based on theory, is ambiguous.

Lastly, the variables time and time-squared represent a normal time tend and a quadratic time trend respectively, which are used to account for temporal change that takes place during the period under study. I intend to vary the way in which I account for time in the various specifications such that I will run regressions using solely the normal time trend, solely the quadratic time trend, both time trends and lastly, year fixed effects. The $\alpha_{i}$ above represents province fixed effects, which are included to account for any unobservable characteristics across the Canadian provinces that are not covered by the other regressors included in the models. Finally, $\varepsilon_{i t}$ represents the error term of the model.

\section{Summary}

Since first contract arbitration provides a way for unions to counteract the effects of staunch employer opposition and increases the chance that newly certified union members will experience work under a collective agreement, it is hypothesized that this will result in more bargaining relationships. This can be modeled using the decertification rate as a proxy for bargaining relationships since it is clear that the bargaining relationship ceases to exist when a union decertifies. The inclusion of a host of control variables, province fixed effects, and various measures used to account for temporal change in the models will hopefully allow me to isolate this effect to see whether the presence of such a provision, as hypothesized, results in a lower decertification rate. 
There are a number of shortcomings that must be recognized with this model however, the first of which is that decertifications or the decertification rate give no indication about the duration of the bargaining relationship. It only indicates whether or not, on aggregate, more bargaining relationships actually exist and therefore, does not answer the question of whether FCA produces "lasting" or "enduring" relationships. Such an answer is beyond the scope of this study, but is one that should be ascertained in future research. Secondly, a bargaining relationship may end for a variety of reasons, including the closure of the business or the change of ownership, and these cannot be accounted for in this model. Nevertheless, all of the above articles, except for one ${ }^{4}$, found that bargaining relationships ended due to decertification more than business closure/changing ownership when examining either the reason for the disposition of applications or the subsequent outcomes beyond the first contract. However, by using the overall decertification rate for the provinces, this allows me to account for any deterrence effects that FCA may have outside those who actually apply, which makes this approach a marked improvement over its predecessors and will hopefully give us a better indication of the overall effect that FCA has on fostering bargaining relationships. The next section elaborates on the methodology that I intend to use to undertake this examination of first contract arbitration.

\footnotetext{
${ }^{4}$ This study, Sexton (1987b), found the same number of business closures as decertifications when it examined the reasons for the disposition of FCA applications, but found that the number of decertifications exceeded the number of business closures when it looked at the subsequent outcomes beyond the first contract.
} 


\section{Methodology}

Due to the form of the data and the specifications outlined above, time-series crosssection (TSCS) analysis is used to investigate the effect that FCA has on decertifications as a proxy for bargaining relationships. TSCS data is similar to panel data in that there are repeated observations of entities over time, but it distinguishes itself from panel data in that the number of time periods in TSCS data is greater than the number of entities included in the set. Thus, while there can be $N$ units and $T$ time periods in both panel and TSCS data, $N$ is greater than $T$ in the former and $T$ is greater than $N$ in the latter. Therefore, the asymptotic properties of panel data reside in the assumption as $N \rightarrow \infty$ with a fixed $T$, whereas the asymptotic properties of TSCS data reside in the assumption as $T \rightarrow \infty$ with a fixed $N$. Thus in this context in which there are $N$ cross-sectional units $(i=1 \ldots \mathrm{N})$ observed over $T$ time periods $(t=1 \ldots \mathrm{T})$, the general framework for this type of regression takes the form:

$$
y_{i t}=X_{i t}^{\prime} \beta+\varepsilon_{i t}
$$

There is a total of $N \times T$ observations in this model. For TSCS data, formula (1) may be rewritten such that each of the components, except for $\beta$, represents vectors in which the equations for each of the units are stacked. In doing so, formula (1) transforms to look like:

$$
y_{i}=X_{i}^{\prime} \beta+\varepsilon_{i}, \quad i=1 \ldots n
$$

which may also be written:

$$
\left[\begin{array}{c}
y_{1} \\
y_{2} \\
\cdot \\
\cdot \\
y_{n}
\end{array}\right]=\left[\begin{array}{c}
X_{1} \\
X_{2} \\
\cdot \\
\cdot \\
X_{n}
\end{array}\right] \beta+\left[\begin{array}{c}
\varepsilon_{1} \\
\varepsilon_{2} \\
\cdot \\
\cdot \\
\varepsilon_{n}
\end{array}\right] .
$$

Under this framework, it is assumed that the regressions for each of the units may be pooled together such that $\beta_{1}=\beta_{2}=\ldots \beta_{n}$, which is why the $\beta$ term does not vary with the unit like the 
other terms in formulas (1) - (3). Thus, the dependent variable, $\mathrm{y}_{i}$, and the error term, $\varepsilon_{i}$, represent $1 \times T$ vectors and $\mathrm{X}_{i}$ represents a $k \times T$ matrix in which $k$ is the number of exogenous variables used to predict the dependent variable. Since the variables within $\mathrm{X}$ are exogenous, we can specify that the $E\left[e_{i} \mid X\right]=0$ and thus, by extension the $E[\varepsilon \mid X]=0$. Lastly, the variancecovariance matrix of this framework is an NT x NT matrix in which each element is specified by $E\left[e_{i} e_{j}^{\prime} \mid X\right]=\sigma_{i j} \Omega_{i j}$. Thus, this represents a block matrix in which the general regression model applies to each cross section along the block diagonal, but the structure of TSCS data introduces the cross-sectional covariates of the different units on the off diagonals (Greene 2003, pp. 32021).

Ordinary least squares (OLS) may be used to calculate the parameters of the above framework, however due to the complicated error structure of TSCS data, the use of OLS standard errors may be inappropriate. OLS is the best linear unbiased estimator when the errors are assumed to be "spherical", meaning that they exhibit homoskedasticity, or equal variance, and are independently and identically distributed such that they are not correlated over time (no serial correlation) or with each other (no spatial correlation) (Beck and Katz 1995, p. 636). These OLS standard errors may be found by taking the square root of the diagonal terms of the covariance matrix given by the formula $\operatorname{Cov}(\hat{\beta})=\left(X^{\prime} X\right)\left\{X^{\prime} \Omega X\right\}\left(X^{\prime} X\right)$, where the covariance matrix $\Omega$ is a constant multiplied by the identity matrix, producing equal variance within and across units and covariances equal to zero (Beck 2001, p. 278). However, while analysts assume that this error structure holds for each individual cross sectional unit, or each of the matrices in the diagonal of the block matrix described above, these assumptions are likely to be violated for the overall TSCS block matrix due to the presence of groupwise heteroskedasticity, contemporaneous correlation and/or serial correlation/autocorrelation. 
When the errors are homoskedastic in TSCS analysis, the diagonal elements of the variance-covariance matrix take the form such that $E\left[e_{i} e_{i}^{\prime} \mid\right]=\sigma_{i}^{2}=\sigma^{2}$, in which the lack of a subscript on the last term denotes that there is equal variance regardless of the unit. As mentioned above, this assumption is presumed within each cross sectional submatrix of the diagonal of the TSCS block matrix, however it is unlikely to hold across the different units. For example, in the context of this study, due to the disparity in the size of the various Canadian provinces, it is unlikely that a large province, such as Ontario, would exhibit the same variance in the measured variables as a small province, such as New Brunswick. Thus, if this is the case then the $\Omega$ matrix is no longer a constant multiplied by the identity matrix and the diagonal elements of the variance covariance matrix takes the form $E\left[e_{i} e_{i}^{\prime} \mid X\right]=\sigma_{i}^{2}$ in which each unit exhibits a different variance. This is known as panel or groupwise heteroskedasticity and violates the OLS assumption of constant variance, which renders the OLS standard errors as inappropriate (Beck and Katz 1995).

The multiplication of a constant by the identity matrix in the covariance matrix $\Omega$ ensures that all of the off-diagonal elements of the error structure are equal to zero in the variance covariance matrix of OLS estimation. This entails that $E\left[e_{i} e_{j}^{\prime} \mid X\right]=0$, when $i \neq j$ and satisfies the assumption of the independence of the error terms under the Gauss-Markov theorem. As aforementioned, this criterion is assumed to hold for each of the submatrices along the diagonal of the TSCS covariance block matrix, but it is unlikely to hold for the off diagonals which represent the covariates across different cross-sectional units. The intuition as to why this assumption is likely violated is quite easy to see, especially in the context of this study, in that one would find it difficult to argue that the Canadian provinces are self-contained such that events, such as economic shocks, that take place in one province does not affect the others. 
Public policies, including the growth of the Canadian healthcare system and the development of various labor laws, are great examples exhibiting this correlation between the provinces as public policies are enacted in individual provinces and then proliferate to the others. This cross-unit correlation is known as contemporaneous correlation or cross-sectional dependence and provides another reason why OLS standard errors may be inappropriate for assessing TSCS data (Beck and Katz 1995).

Lastly, as with any data in which there are repeated observations over time, the error terms may exhibit temporal dependence in which the error term in one period influences error terms in other periods. This is also relatively intuitive in that one would not expect measures such as the employment/unemployment rates to be independent over time, rather the magnitude of the rate in one period largely affects the magnitude of the rate in the next/subsequent period(s). Thus, the existence of serial correlation, as this is known, violates the assumption of identical and independently distributed errors of the Gauss-Markov theorem and necessitates the use of standard errors other than those produced by ordinary least squares.

Ordinary least squares is known to produces consistent estimates of parameters in TSCS models but, in the presence of groupwise herteroskedasticity, contemporaneous correlation and/or serial correlation, the OLS standard errors will be inaccurate (Beck and Katz 1995). The presence of these respective issues can be detected through a Wald test for groupwise heteroskedasticity or a Lagrange-Multiplier test for either autocorrelation or contemporaneous correlation based upon the residuals of OLS estimation. The existence of any of these issues necessitates a transformation of the structure of the covariance matrix, which is done by varying the $\Omega$ matrix, in order to produce accurate standard errors. The generalized least squares (GLS) estimator, $\hat{\beta}=\left[X^{\prime} \Omega^{-1} X\right]^{-1}\left[X^{\prime} \Omega^{-1} Y\right]$, is optimal for TSCS data and can produce accurate 
standard errors in the covariance matrix (denoted by the inverse matrix in the brackets of the estimator), but in order to perform this type of estimation, the error process, or the covariance matrix $\Omega$, needs to be known. In reality, the error process is never known and thus, the "feasible" generalized least squares (FGLS) estimator $\hat{\hat{\beta}}=\left[X^{\prime} \widehat{\Omega}^{-1} X\right]^{-1}\left[X^{\prime} \widehat{\Omega}^{-1} Y\right]$, in which the error process $\widehat{\Omega}$ is estimated, is often used in this context to produce standard errors (Greene 2003, pp. 321-322).

The use of FGLS to correct for contemporaneous correlation was first proposed by Park (1967), but this method has been called into question more recently by Beck and Katz (1995). As one can see, this method requires that $\widehat{\Omega}$ be invertible in order to perform FGLS and thus, $T$ must be greater than $N$, which as mentioned above is not a problem for TSCS data since that is the main characteristic of such data. FGLS has been shown to perform well in large samples, which in the case of TSCS data, entails data sets in which $T$ greatly exceeds $N$. Indeed, the greater the ratio of $T$ to $N$, the better the estimate of $\Omega$ and the estimator improves with the addition of more time periods. However, despite the suitable asymptotic properties of this method, problems may arise if the sample is not sufficiently large. As Beck and Katz explain: "[E]ven when $\mathrm{T}$ is greater than N, so that FGLS can be used, estimation of standard errors is problematic unless $\mathrm{T}$ is considerably larger than $\mathrm{N}$. Each element of the matrix of contemporaneous covariances of the errors is estimated using, on average, 2T/N observations. Many cross-national panel studies have ratios of $\mathrm{T}$ to $\mathrm{N}$ very close to 1 , so covariances are being estimated with only slightly more than two observations per estimate! Studies on the political economy of advanced industrial nations seldom have $\mathrm{T}$ to $\mathrm{N}$ ratios that exceed 3 ; thus the elements of the covariance matrix of the errors are estimated with, on average, six observations. Theory does not tell us how inaccurate the Parks method is in these cases, but we should be prepared to see highly overconfident Parks standard errors in the typical cross-national panel case." (p. 637)

Due to the estimation of parameters on so few observations, they believe that FGLS estimates in which $T$ is remotely close to $N$ vastly understates the variability of the estimated coefficients, which in turn produces unrealistically small standard errors. While researchers may find this 
appealing since smaller standard errors translates into more favorable $t$-statistics and confidence intervals, it also increases the chances of type 1 error in which a coefficient is found to be statistically significant when in actuality it is not. Indeed, they find that a number of articles using FGLS in political science, a field that often uses TSCS analysis due to cross-national comparisons, to have understated the magnitude of the standard errors of their estimation and thus, overstated the significance of the coefficients that they found. They further illustrate the adverse effects of using FGLS through the use of Monte Carlo simulations in which they vary the ratio between $T$ and $N$ and they find that the use of FGLS "may understate variability by between $50 \%$ and 300\% in practical research situations" (Beck and Katz 1995, p. 634). The authors attribute this discrepancy to the inconsistent estimation of the covariance matrix, which Maddala (1997) points out is inaccurate in that it is the inverse of the covariance matrix that is not consistently estimated when $N$ is similar to $T$, but notes that this doesn't affect the overall analysis performed by Beck and Katz (1995).

Therefore, in light of these problems with the FGLS estimation of TSCS data, Beck and Katz (1995) suggest that researchers use the consistent parameters obtained through OLS estimation, but replace the standard error obtained through OLS with panel-corrected standard errors (PCSEs) to more accurately estimate the variability of the OLS parameters. The PCSEs method of producing standard errors involves estimating $\Sigma$, which is the diagonal of the $N$ x $N$ matrix of contemporaneous covariances produced from the $N T$ x $N T$ covariance matrix $\Omega$, using the repeated information on the contemporaneous correlation of the errors produced from OLS estimation. This is performed by estimating each individual element of $\Sigma$ through the formula $\widehat{\Sigma}_{i j}=\frac{\sum_{t=1}^{T} e_{i t} e_{j t}}{T}$, and then aggregating each of these elements to form $\widehat{\Sigma}$. This is then used to transform $\Omega$ to $\widehat{\Omega}$ which is composed of $\widehat{\Sigma}$ along the block diagonal and zero on the off diagonals, 
thus correcting for both contemporaneous correlation and groupwise heteroskedasticity (Beck and Katz 1995, p. 638). The estimation of $\hat{\Sigma}$ is consistent because the residuals estimated by OLS are consistent, and similar to the FGLS estimation, the estimation of $\hat{\Sigma}$ improves as $T$ increases. If the OLS error process exhibits autocorrelation then this needs to be corrected prior to the estimation of the PCSEs, which Beck and Katz (1996) prescribes the use of a lagged dependent variable to correct the serial correlation. However, Maddala (1997) points out that PCSEs are incompatible with the use of a lagged dependent variable since the inclusion of a lagged dependent variable as a regressor results in inconsistent estimates and thus, an inconsistent estimate of $\widehat{\Sigma}$. Luckily, as described below, a Lagrange Multiplier test for the presence of autocorrelation on the OLS residuals of the models failed to reject the null hypothesis of no serial correlation. Therefore, I am able to avoid this situation and use the PCSE method to correct for the presence of groupwise heteroskedasticity and/or contemporaneous correlation.

Even though the data set used in this study exceeds the 3:1 ratio of time periods to units that Beck and Katz (1995) recommend if one is to use FGLS estimation for TSCS data, they show that the understatement of the variability of the parameters induced by the Parks method can persist even in such data sets. Using Monte Carlo simulations in which the units and time period were set at 10 and 40 respectively, which, excluding missing data, represents the same ratio as the data set used in this study, they found that the standard errors in such a situation were 30 percent overconfident and produced 95 percent confidence intervals that contained the true value of the coefficient only 87 percent of the time (Beck and Katz 1995, p. 639). Conversely, running Monte Carlo simulations on the same variations of $N$ and $T$ using OLS parameters with PCSEs always resulted in standard errors within 10 percent of the true variability of the 
coefficient and in many cases, were only off by a few percent (Ibid, p. 641). Thus, based on their results, I decided to use the more conservative PCSE method of calculating standard errors to analyze the data, which hopefully will provide a truer indication of whether first contract arbitration has a statistically significant effect on various measures of decertification, and thus, bargaining relationships by extension..$^{5}$

There is some debate as to whether or not researchers should include fixed unit effects in their analysis of TSCS data when using PCSEs, which as shown in the models in the previous section, I intend to include. The inclusion of province fixed effects allows me to avoid possible omitted variable bias due to any unobservable characteristics that may vary across the provinces and are not captured by the specified regressors. The concern raised by Beck (2001) is that fixed effects are perfectly collinear with any time-invariant variables, which forces their exclusion, and may be highly collinear with any variables that change slowly over time, which results in the fixed effects absorbing much of their explanatory power (p. 285). Beck suggests that researchers be conscious of this fact and possibly suffer the consequences of slight omitted variable bias if one is attempting to investigate such slowly changing variables. However, Garrett and Mitchell (1999) defend the use of country dummies in their cross-national study by arguing that "[i]f a regressor varies only little over time but greatly across countries, and if the inclusion of country dummies has a substantial effect on the direction, magnitude or statistical significance of the variable, the appropriate response is not to exclude the country dummies" (p. 20). They go on to state that the inclusion of such dummies should be viewed as "part of the underlying fabric of a country" that influences the dependent variable but is not captured by the other regressors (Ibid,

\footnotetext{
${ }^{5}$ Ideally, I would have like to have produced standard errors using both the Beck and Katz (1995) PCSE method and the Parks (1967) FGLS method to be able to compare the results. Unfortunately, balanced panels are necessary to run FGLS, which due to missing data from a number of provinces (detailed in the next section), I am unable to perform such a method. However, based upon the results presented in the Beck and Katz (1995) article, I feel comfortable performing just the PCSE method as it is the more conservative of the two methods.
} 
p. 20). Both articles, however, suggest using an $F$-test to determine whether or not fixed effects should be included in the model, which I performed on all of my specifications and determined that the province fixed effects should be included. Furthermore, as predicted by Garrett and Mitchell (1999), the coefficients for the FCA variables were vastly different when the regressions were performed with and without the province fixed effects, which further led me to heed their advice of maintaining their inclusion.

This same reasoning for the inclusion of province fixed effects may be applied to the inclusion of time fixed effects. However, due to the structure of TSCS data in which there is a large number of time periods, the inclusion of year dummies can greatly reduce the number of degrees of freedom and thus the efficiency of the estimation. It is for this reason that Cameron and Trivedi (2009) suggest that researchers use a time trend (or quadratic time trend) rather than year dummies to account for the temporal change in any unobservable characteristics. Like the province fixed effects, I will perform $F$-tests to see whether or not year dummies should be included in the regressions, but I will also perform regressions in which a common time trend, a quadratic time trend, or both are substituted into the analysis, to compare the outcomes under these differences. The inclusion of both province fixed effects and either time fixed effects or time trends and the use of PCSEs will hopefully yield a true estimate of the effects of FCA on decertifications that are not, as Beck and Katz describe others' results, "merely statistical artifacts" (p. 636).

\section{Summary}

The structure of the data set in which there are repeated observations of similar units over time lends itself to time-series cross-sectional (TSCS) analysis. While OLS parameter estimates 
are consistent with such data if no autocorrelation exists, the standard errors of such estimates are often incorrect as the Guass-Markov theorem is often violated due to the presence of groupwise heteroskedasticity, contemporaneous correlation or autocorrelation in the TSCS setting. The presence of any or all of these three problems necessitates a transformation of the error variancecovariance matrix to produce accurate standard errors. Two methods have historically been used in the past to analyze TSCS data: the Parks (1967) method which uses FGLS estimation and the Beck and Katz (1995) method which uses panel-corrected standard errors (PCSEs). This study prefers the latter method since Beck and Katz (1995) show that the use of PCSEs results in a more accurate estimation of the true variability of the parameter estimates and is the more conservative approach. The next section provides a description of the data used to undertake this methodology, which is followed by an explanation of the results of the study's regression analysis. 


\section{Data}

The principle data concerning the industrial relations statistics in the dataset were collected from the respective provincial labor board Annual Reports, which prior to being released as stand-alone documents were often included as sections of the annual reports of the respective provincial ministries/departments of labor. When unable to acquire the necessary annual reports, the relevant labor board (or government agency in the case of Quebec) was contacted, many of which responded and provided the missing data that was requested. However, when the labor board failed to respond or was unable to produce the data in question, Martinello (2002), a dataset with certification, decertification and first contract arbitration statistics from the same labor board Annual Reports covering the years 1949-1993, was used to obtain missing data as a last resort. The description of the data for each of the provinces below identifies the source of all of the data, as well as highlights where missing data remains and any other issues

The federal jurisdiction is omitted from the dataset due to the difficulty with obtaining the appropriate environmental variable statistics to accompany the industrial relations statistics for that jurisdiction. Since the workers that fall under the federal jurisdiction (less than 10 percent of the overall Canadian workforce) is determined by industry, rather than geographical area, a number of the variables included in the models, such as the employment, unemployment, and CPI rates, are not calculated with regard to this jurisdiction. Furthermore, the industries that are covered by the Canada Labour Code, such as banking, telecommunications, airlines and railways, are systematically different than the industries that are covered by provincial labor legislation, which further warrants the federal jurisdiction's exclusion due to the noncomparability between the two sets of industries. Additionally, the smallest Canadian 
province, Prince Edward Island, and the three territories in Canada are omitted from the dataset due to difficulties with obtaining data, but these four jurisdictions are sparsely populated and account for less than one percent of the overall Canadian population. Thus, irrespective of some missing data (as noted below), the overall dataset includes nine provinces, representing over 90 percent of the Canadian population for the period 1970 to 2010.

\section{Labor Board Data}

This section includes the statistics concerning certifications, decertifications, first contract arbitration and unfair labor practices for each of the provinces. While some of the provinces report on a calendar year basis, many of them report by fiscal year, which is problematic in that many of the general statistics used as control variables are reported by calendar year. Thus in order to align the board statistics between those that report by fiscal year and those by calendar year as well as with the general statistics, when a board reports by fiscal year, the observation year in the dataset pertains to the fiscal year that comprises the majority of the calendar year. For example, the information for the fiscal year April 1, 1995 to March 31, 1996 is entered into the dataset as 1995 . The following data descriptions for each province indicate whether the board reports on a fiscal or calendar year basis, and for what years, as well as any other issues that arise within the reports.

\section{a. Alberta}

The data for Alberta is reported by the calendar year for the period 1970 to 1973, after which the data is reported by the fiscal year of April 1 to March 31. However, the number of certifications and decertifications granted in the fiscal years 1986/87-87/88 are unavailable due to a change brought about by a partial conversion to computerization at the Alberta Labour 
Board (ALB). Furthermore, only four months of statistics is reported for the fiscal year 1988/89 during which this computerization took place. All of these statistics were obtained from the annual reports, except for those for the years 1970-1972 which were obtained directly from the

ALB. Lastly, the Board only reported the number of unfair labor practices disposed for much of the 1970s and these values are used in place of the number of unfair labor practices received, which likely biases the statistics downward for these years. The number of unfair labor practices in the year 1970 was unreported and thus, represents another missing data value.

\section{b. British Columbia}

All of the data for British Columbia is reported by calendar year from the board's annual reports and there is no missing data for any of the years under analysis. The only other issue to note was that the Board retroactively revised previous totals of the number of unfair labor practice charges received for the period 1989 to 1995 and these values are used in the dataset rather than those listed in the annual reports corresponding to those years. Furthermore, the annual reports for 1970 to 1972 only list the unfair labor practices that were filed under Section 7 of the labor code, whereas later years include totals for sections 5, 6, 7 and 9. These respective sections of the British Columbia Labour Code deal with the discrimination, intimidation, coercion, and unfair dismissal of employees for trade union activity; employer participation/interference with trade union activity (including all of those actions listed in section 5); the limitations on trade union activities and rules regulating access to the workplace; and coercion or intimidation used to compel a person to become, continue or refrain from being a member of a trade union. Thus, the data for the former years that include only those complaints filed under Section 7 likely undercounts the total number of ULPs received for those years. 


\section{c. Manitoba}

All of the data for Manitoba is from Manitoba Labour Board (MLB) annual reports and prior to 1984 , this was reported for the period November to October when it was included in the Department of Labour annual report. The MLB also began producing its own annual report in 1984, based upon the fiscal year from March to April, and thus, two reports were produced for that year based upon the respective periods. Due to the aggregation of the data and the substantial overlap between the two reports, I had to choose one to include and one to omit, but regardless of which was preferred, the omission resulted in a loss of five months of data. I chose to include the statistics from the MLB annual report since this was more cohesive with the majority of statistics from this province, but this means that November 1983 to March 1984 is unaccounted for in the dataset. The MLB reports count both the number of decertification applications and their disposition and the number of termination of bargaining rights applications (and their dispositions), but in striving for comparability across the provinces, the termination of bargaining rights applications that were granted were not included in the decertification statistics. Furthermore, the total number of ULPs received was not provided as a single category in the annual reports prior to 1984 and thus, the total for those years are the result of my calculations of all of the violations that were filed under the relevant sections of the labor code.

\section{d. New Brunswick}

Prior to 1970, the New Brunswick Labour Board reported based on the fiscal year, but in 1970 it underwent a change to become the Industrial and Labour Relations Board and began reporting on a calendar year basis. This resulted in a release of a report for the first 21 months (April 1970 through December 1971) of the Board's existence to deal with the transition from the former reporting period to the latter. To deal with this, I used Martinello (2002), which had 
the statistics broken down into the 9 months in 1970 and the 12 months in 1971 and I checked the addition of these totals against the values listed in the annual report. The Industrial and Labor Relations Board continued reporting on a calendar year basis until 1976, but eventually switched back to the fiscal year in 1977/78, which resulted in the release of report that covered 15 months to avoid a gap in the reporting. The Labour Board reported on a fiscal year basis for the remainder of the period under analysis, with the exception of its 1994/95 report, which was the first year that the Board released its own report detached from the department of labor. This initial isolated report only covers about four and a half months (11/14/1994 to 3/31/95) and thus there is a gap of seven and a half months (4/1/1994 to 11/13/1994) that is unaccounted for in the dataset. Furthermore, the Department of Labour annual reports for the fiscal years 1992/93 and 1993/94 did not include statistics from the Labour Board and I received no response from the Labour Board regarding requests for this missing data. Therefore, the statistics for these fiscal years were also taken from Martinello (2002), but unfortunately, his dataset does not include any statistics concerning ULPs. Thus the number of unfair labor practices received for these two fiscal years are missing from the dataset. Lastly, the annual report for 1975 did not contain decertification or unfair labor practice statistics and the number of unfair labor practices received is also missing from the 1970 and 1971 annual reports, all of which represents missing data.

\section{e. Newfoundland and Labrador}

The data for Newfoundland and Labrador are reported by the calendar year up until 2005 at which point the annual reports became digitized and posted online for the fiscal year. This change in the reporting period resulted in a three month gap (January 2005 to March 2005) being unaccounted for in the dataset. I was unable to obtain the annual reports for the years 1979 to 1981 and I contacted the Newfoundland and Labrador Labor Relations Board (NLLRB) to obtain 
the statistics for those years. The Board did not have the annual reports for those in their possession so the data for the 1979 report was obtained through the Centre for Newfoundland Studies at Memorial University and the data for the other two were obtained from the Newfoundland Legislative Library. Unfortunately, unfair labor practices are not included in all of the annual reports such that the ULP totals are missing for 1970 to 1975 and thus, these observations are omitted. Lastly, there is missing data for the number of decertifications granted in the $2007 / 08$ to $2010 / 11$ annual reports as they only report the number of decertification applications filed during those years. Thus, I contacted the NLLRB and was able to obtain the number of decertification granted for those fiscal years directly from the Board.

\section{f. Nova Scotia}

All of the data for Nova Scotia is for the fiscal year period April to March and the data from 1970/71 until 1998/99 are from annual reports, while the remaining years include data that was requested from the Nova Scotia Labour Board (NSLB) or was posted online by the Board. The NSLB only posted data for the fiscal years 2003/04 to 2007/08, which necessitated my request for additional data from the NSLB. There is some discrepancy between the data posted online and those that I received from the NSLB, the latter of which was included in the dataset when the values differed. Unfortunately, the NSLB only provided the number of ULPs disposed in their response to my request and thus, these values are used in place of the number of ULPs received which likely results in a downward bias for the relevant years.

\section{g. Ontario}

All of the data for Ontario are reported by fiscal year in the annual reports and there is no missing data for the years under analysis. 


\section{h. Quebec}

The data for Quebec is reported by the calendar year in the annual reports for the period 1970 to 1972 and then switches to reporting by fiscal year for the annual reports from 1973/74 until 2000/01. This switch would normally result in a three month gap that would be unaccounted for, but the preponderance of missing data prior to the $1977 / 78$ fiscal year makes this discrepancy irrelevant. The number of certifications granted is not reported in the 1970 annual report, while the number of decertifications granted is not reported until 1977/78. I attempted to fill in the gaps where possible with Martinello (2002), but the fact that he is missing much of the same data leads me to believe that much of this information is unavailable. Furthermore, the Commission des Relations du Travail, which is the governmental body in charge of overseeing the certification and decertification process, stopped releasing annual reports with the relevant data contained in previous reports after 2000/01 and only released reports concerning the financial performance of the agency in the years thereafter. Thus, the data for the years 2001 to 2011 was obtained directly from the Commission and is based upon the calendar year, which means there is an overlap of three months from January to March 2001 in the dataset. Thus, 1978 is the first year with comprehensive enough data to be included in the analysis and therefore, unlike the other provinces, the period of analysis for Quebec is 1977 to 2010. Lastly, unfair labor practices are not kept as its own statistic (or at least as easily identifiable as it is in the other provinces) and thus, where available, the number of unfair dismissals is used as the values for unfair labor practice complaints received, which likely underestimates the actual amounts. However, a more general count of unfair labor practices, including complaints of discrimination and bad faith bargaining, in addition to unfair dismissals, was obtained in the data I received from the Commission. 


\section{i. Saskatchewan}

All of the statistics for Saskatchewan are reported by fiscal year and there is no missing data for the years under analysis. However, I was unable to obtain the annual report for the fiscal year 1990/91 and as such, I obtained the necessary statistics through correspondence with the Saskatchewan Labour Relations Board (SLRB).

\section{General Economic/Legal Data}

All of the general statistics that are used as control variables in the above models are taken from Canadian government sources or other scholarly articles. The following sections provide a description of all of the general statistics, including their source and how they are calculated (if applicable).

\section{a. Provincial Unemployment Rate}

The provincial unemployment rate is the number of unemployed persons expressed as percentage of the total labor force in that province and the figures are rounded to the nearest tenth of the percentage. This data is taken from Statistics Canada's CANSIM database (CANSIM table 282-0002) for the period 1976 to 2010 and from the Labour Force Survey (LFS) statistics, based upon a monthly survey of Canadian households, for the period 1970 to 1975.

\section{b. Provincial Employment Rate}

The provincial employment rate is the number of persons employed in the province expressed as a percentage of the provincial population aged 14 or 15 years old and over and the figures are rounded to the nearest tenth of a percentage. This data is taken from the same sources as the unemployment rate data for the same respective periods, but since the Labour Force Survey contains only a participation rate and not an employment rate, I calculated the 
employment rates for the years 1970 to 1975 to maintain consistency with the later data. Although the LFS provides annual totals for the number of persons employed in each province for all of the years requiring calculation, the LFS does not contain annual totals for the provincial population aged 14 and over. It does, however, provide monthly totals for the population aged 14 and over and thus, I aggregated this monthly data to find an annual average for each of the provinces. Unfortunately, the LFS only provides the provincial totals after the September 1971 issue, prior to which it provides the population aged 14 and over on a regional basis. This issue did not affect the calculations for the provinces of Quebec, Ontario or British Columbia since they are treated as their own region, but the other provinces are aggregated into either the Atlantic region (New Brunswick, Newfoundland, Nova Scotia and Prince Edward Island) or the Prairie Region (Alberta, Manitoba and Saskatchewan). Therefore, in order to calculate the annual average of the population aged 14 and over for these latter provinces, I had to take the average of all of the monthly totals for each individual province from September 1971 to December 1975 and then use that as a proportion for the respective regions of those provinces. These proportions were used for both of the 1970 to 1971 annual totals, but the months in which the LFS calculated the totals by province were included in the calculation for the 1971 annual average. Unfortunately, I was unable to obtain the January 1970 issue of the LFS and thus the calculation of the 1970 annual total is without this data and the calculation was performed with the other 11 months of that year. Lastly, the reason that the rate is expressed as percentage of the population aged either 14 or 15 and over is because the CANSIM database uses the provincial population 15 years of age and over as the denominator of the rate, whereas the LFS historical statistics uses the total provincial population 14 years of age and over, but this discrepancy is likely to have little influence on the analysis. 


\section{c. Consumer Price Index}

The consumer price index (CPI) shows the changes in prices over time by comparing the prices of a fixed basket of goods and services. This data is taken from Statistics Canada's CANSIM database (CANSIM table 326-0021) and this data uses the year 2009 as the reference period and 2002 as the base year (thus, 2002=100). According to Statistics Canada, the principle parts comprising the basket of goods and services used to calculate this rate include (1) food, (2) shelter, (3) household operations, furnishings and equipment, (4) clothing and footwear, (5) transportation, (6) health and personal care, (7) recreation, education and reading, and (8) alcoholic beverages and tobacco products (Statistics Canada). Unfortunately, the provincial CPI rate was not collected prior to 1978 and thus, as is found in previous studies (see Martinello 1996), the national CPI rate is used for all of the provinces in the years prior to that date.

\section{d. Provincial Union Density Rate}

The provincial union density rate is derived from two sources: the Corporations and Labour Unions Returns Act (CALURA) survey for the years prior to 1996 and the Labour Force Survey (LFS) from 1997 until 2010, both of which can be obtained from Statistics Canada (CANSIM Table 279-0025 and CANSIM Table 282-0078 respectively). The union density rate from the former source is the number of unionized workers in the province expressed as percentage of the total number of employees in the province, in which the numerator is the CALURA survey estimates of unionized workers as of December 31 for that year and the denominator is the December estimates of employees from the monthly Labour Force Survey. The provincial union density rate from the latter source, however, is calculated as the number of union members and nonunion members covered by a collective bargaining agreement divided by the number of employees in the province. Unfortunately, the CANSIM database only contains 
CALURA union density estimates back to 1976, and thus I was forced to calculate the union density rates for the years 1970-1975. The aforementioned calculation of the CALURA estimates was replicated in producing the density rates for these earlier years, but the LFS did not calculate the total number of employees for each individual province until the August 1971 monthly issue. Prior to that date, the LFS calculated the totals according to region, which were the same as those described above. Thus, in calculating the union densities for the provinces included in the amalgamated regions in 1970, I used a similar method as when I was calculating the employment rate above. I found the average employee totals for the five years following 1970 for each individual province which I then used to find the proportion that each province represented from the average total number of employees for the region from those years. I then used that proportion, multiplied by the employee total given for the entire region in the December 1970 issue of the LFS, to find an approximated estimate of the employee total for each province for December 1970 that could be used as the denominator in the calculation of union density rate for that year.

Due to the discrepancy in measurement, the use of both CALURA and LFS estimates presents a number of problems: (1) the comparability between the two surveys and (2) there is no union density rate for the year 1996 as this was between the termination of CALURA and the start of using the LFS to measure union density. Regarding the former problem, the CALURA data has been revised to make them more comparable to the LFS data, but the CALURA estimates tend to be slightly higher due to survey design and the definition of who constitutes a union employee (Akyeampong 2004). Regarding the latter problem, rather than omit 1996, I averaged the union density rates from the year before and after 1996 and inserted those as the 1996 values for each of the provinces. 


\section{e. Provincial Unionized Workforce}

The provincial unionized workforce totals are taken from the same two sources as the union density rates: the Corporations and Labour Unions Returns Act (CALURA) survey prior to 1996 and the Labour Force Survey (LFS) from 1997 until 2010. The same problems of comparability and missing data applies to this variable as those stated in the union density section. Regarding the latter problem, the issue was handled in the same manner with the average of the years before and after 1996 being calculated and used as the 1996 values in the dataset.

\section{f. Provincial Political Party in Power}

The dummy variable for whether the conservative party is the provincial political party in power and the dummy variable for the anti-union government are both taken from the Parliament of Canada website, which lists the dates of entering and exiting premiers for all of the provinces. Similar to the dummy variables for FCA and mandatory vote legislation, when a political party gains power, it does not neatly correspond with the calendar year and thus, this variable takes the value of 1 if the Conservative party, or an anti-union government, is the party in power for the majority of that year. ${ }^{6}$

\section{g. Mandatory Representation Vote Legislation}

The data for the dummy variable for mandatory representation vote legislation is taken from Johnson (2004), which recounts the changes in this type of legislation through 2001. Thus, I had to inquire if there were any changes in mandatory vote legislation in more recent years and I found that there was one such change in the period of analysis in that Saskatchewan enacted

\footnotetext{
${ }^{6}$ This discrepancy for this variable, as well as the mandatory vote and first contract arbitration dummy variables, likely introduces some measurement error into the analysis. When legislation is passed, it may not take effect until the start of the following calendar year, which may be at odds with the statistics provided by annual reports that report on a fiscal year basis. However, not all of the observations are based on the fiscal year.
} 
mandatory vote legislation in 2008, which has been accounted for in the data set. As with other variables, the date that the legislation was enacted is noted and if this comprised the majority of the year in which it was enacted then it was coded as a 1 for that year, otherwise it takes the value 1 in the following year.

\section{h. First Contract Arbitration Legislation}

The data for the dummy variables for the first contract arbitration legislation is taken from Johnson (2010) and Slinn and Hurd (2011) and was cross-checked with the Labor Board annual reports where possible. Furthermore, I checked to see if there have been any changes in first contract arbitration legislation since those articles were published. There was one change with the passage of FCA in Nova Scotia in 2011, but this falls outside of the period of analysis in this study. As with other variables, the date that the legislation was enacted is noted and if this comprised the majority of the year in which it was enacted then it was coded as a 1 for that year, otherwise it takes the value 1 in the following year. See Figure 2 below for a timeline showing the type of FCA legislation prevailed in the province in addition to when mandatory vote legislation also prevailed. 


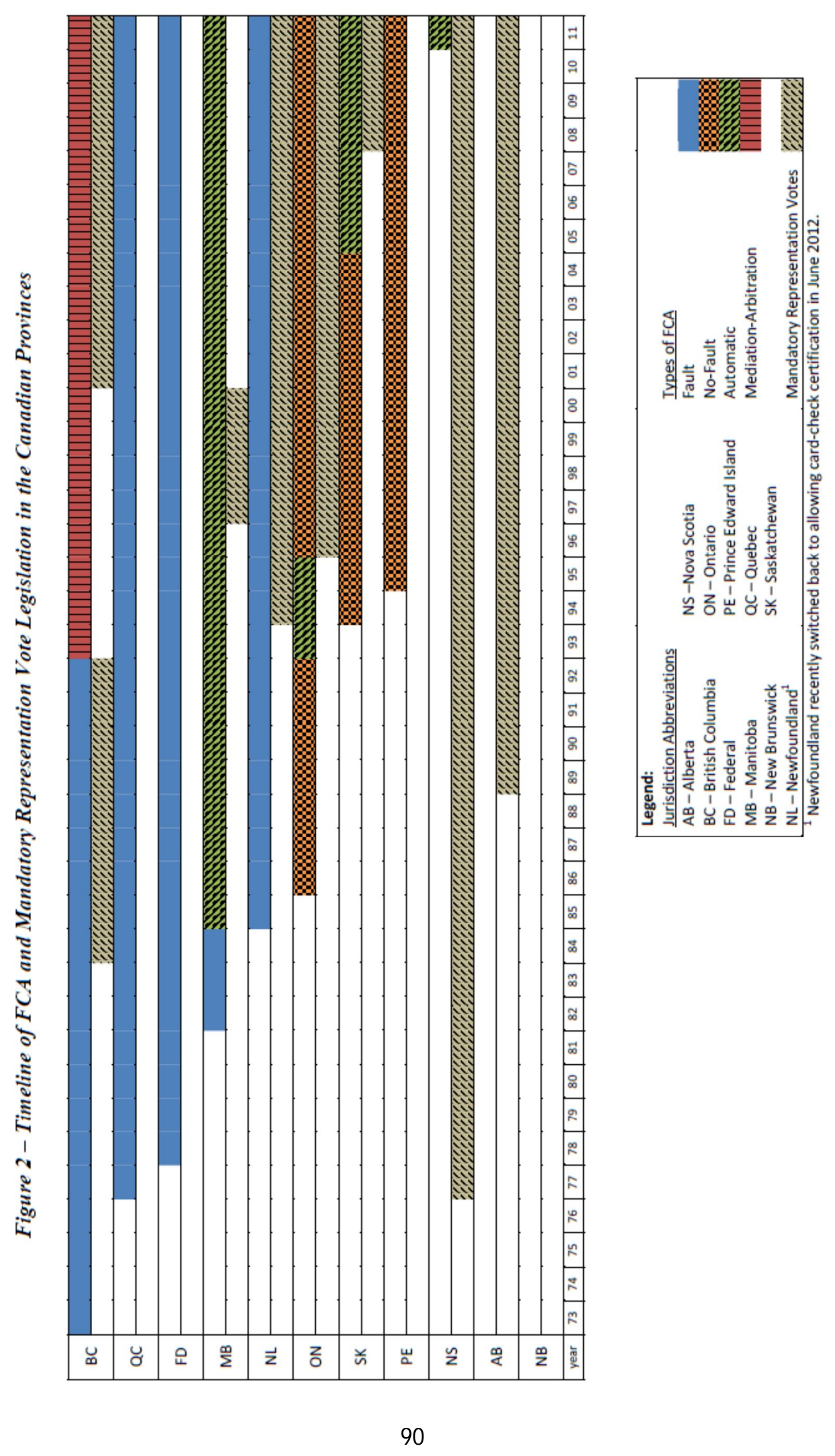




\section{Summary}

This study draws upon data from the annual reports of the respective labor boards, or equivalent governmental agency, from nine Canadian provinces concerning the number of certifications, decertifications, and unfair labor practices. When the annual reports were not obtainable or did not contain the above information, much of the missing data was obtained directly from the labor board or from other secondary sources. The study also draws upon environmental and legal data from a variety of sources, including governmental agencies and other scholarly articles, to amass a data set that allows for the investigation of first contract arbitration legislation over a four decade period. With the omission of the federal jurisdiction, Prince Edward Island, and the sparsely populated Territories, this data set covers more than 90 percent of the Canadian population and produces a best-case scenario of 369 total state-year pair observations for the period 1970 to 2010 . With the presence of some missing data, as noted above, regression analysis using the total 369 state-year observations is not possible, but missing data is scarce enough that all regressions draw upon well over 300 observations. For a table providing summary statistics and a table of correlations for all of the variables included in the specifications, see appendix 3. The next section provides an analysis of the results of the regressions described in the methodology section. 


\section{Results}

Table 2 below presents all of the results for Model (1) in which the main explanatory variable is a dummy variable for whether or not the province contains a first contract arbitration provision. Regressions (1) - (4) use the natural log of the number of decertifications granted divided by the unionized workforce as the dependent variable, while regressions (5) - (8) use the $\log$ of the number of decertifications granted divided by the number of certifications granted as the dependent variable. Other than the variation in the dependent variable, all of the regressions are the same except for the variation in how time is incorporated into the specification. A normal time trend is included in regressions (1) and (5), a quadratic time trend is used in regressions (2) and (6), both a normal and quadratic time trend are included in regressions (3) and (7), and lastly, regressions (4) and (8) are estimated with year fixed effect dummy variables. Separate regressions for each of the dependent variables were initially run using ordinary least squares estimation and post-estimation diagnostic tests were used to assess the presence of groupwise heteroskedasticity, contemporaneous correlation and/or serial correlation. The results of these tests for Model 1 showed that the OLS errors exhibited groupwise heteroskedasticity and contemporaneous correlation for the dependent variable decertifications granted divided by the union workforce, but only groupwise heteroskedasiticy for the dependent variable decertifications granted scaled by certifications granted. The error structure for neither of the dependent variables exhibited serial correlation. $F$-tests were also performed on the joint significance of the province fixed effects and the year fixed effects respectively. The former test rejected the null hypothesis that the effects were jointly equal to zero for both dependent variables, while the latter test failed to reject the null hypothesis that the joint year dummies were significantly different from zero (the accompanying p-values are .1386 and .0646 respectively, 
the latter of which is very close to a rejection of the null). Even though the latter $F$-tests failed to reject the null, when time trends are included in the other specification, they are statistically significant. This finding, combined with the close proximity of the test result to the rejection region, leads me to believe that I need to account for unobserved factors that change over time and thus, to continue to include either a time trend(s) or year dummies in all of the specifications. $^{7}$ Furthermore, I ran OLS regressions on each individual province and used Durbin-Watson and Breusch-Pagan post-estimation tests to see if there was any autocorrelation or heteroskedasiticy exhibited within each panel, none of which was found. Thus, I calculated the panel corrected standard errors (PCSEs) described in the methodology section in order to correct the error structure to produce accurate standard errors. The parameters of the OLS estimation are presented in Table 2 (below) and the PCSEs are displayed in the parentheses found below each coefficient.

The main explanatory variable under investigation, the FCA dummy variable, is in the correct direction and statistically significant at the conventional 5\% level in six out of the eight regressions for this model. The regressions in which the dependent variable is the log number of decertifications granted divided by the unionized workforce (columns (1) - (4)) produce statistically significant coefficients at the 5\% level when either both time trends or year fixed effects are included, but not when a single time trend is used. These significant coefficients indicate that the presence of an FCA statute in a province correlates with approximately 23 to 25 percent less decertifications granted, divided by the unionized workforce, than in its absence.

\footnotetext{
${ }^{7}$ Furthermore, when the models are run with the PCSEs, a joint F-test on the year fixed effects shows that they are statistically significantly different than zero, which further warrants their conclusion.
} 
Table 2 -Regression Results for Model 1

\begin{tabular}{|c|c|c|c|c|c|c|c|c|}
\hline \multirow{2}{*}{$\begin{array}{l}\text { Dependent Variable: } \\
\text { FCA }\end{array}$} & \multicolumn{2}{|c|}{$\begin{array}{l}\text { (1) }(2) \\
\text { Log Decertifications }\end{array}$} & \multicolumn{2}{|c|}{$\begin{array}{c}\text { (3) } \\
\text { Granted/Union Workforce }\end{array}$} & \multicolumn{4}{|c|}{$\begin{array}{l}\text { (5) }(7) \\
\text { Log Decertifications Granted/Certifications Granted }\end{array}$} \\
\hline & -0.1903 & -0.1906 & $-0.2833^{*}$ & $-0.2645^{*}$ & $-0.3354^{*}$ & $-0.3353^{*}$ & $-0.3912^{* *}$ & $-0.3584^{*}$ \\
\hline & $(0.1287)$ & $(0.1287)$ & (0.1298) & $(0.1335)$ & $(0.1434)$ & $(0.1434)$ & $(0.1461)$ & $(0.1473)$ \\
\hline \multirow[t]{2}{*}{ Mandatory Rep. Vote } & $0.3969 * * *$ & $0.3976^{* * *}$ & $0.3444 * *$ & $0.3960 * *$ & $0.6130 * * *$ & $0.6136^{* * *}$ & $0.5815^{* * *}$ & $0.6065^{* * *}$ \\
\hline & $(0.1186)$ & $(0.1185)$ & (0.1191) & $(0.1283)$ & $(0.1266)$ & $(0.1266)$ & $(0.1274)$ & $(0.1367)$ \\
\hline \multirow[t]{2}{*}{ Conservative Govt. } & 0.1219 & 0.1217 & 0.1062 & 0.1116 & $0.1718^{+}$ & $0.1717^{+}$ & $0.1624^{+}$ & $0.1690^{+}$ \\
\hline & $(0.0852)$ & $(0.0852)$ & $(0.0842)$ & $(0.0849)$ & $(0.0942)$ & $(0.0942)$ & $(0.0943)$ & (0.0949) \\
\hline \multirow[t]{2}{*}{ Anti-Union Govt. } & $0.2275^{+}$ & $0.2272^{+}$ & $0.3112^{* *}$ & $0.3337^{* *}$ & 0.1829 & 0.1825 & $0.2330^{+}$ & $0.3324^{*}$ \\
\hline & (0.1198) & $(0.1198)$ & $(0.1195)$ & $(0.1244)$ & $(0.1406)$ & $(0.1405)$ & $(0.1374)$ & $(0.1400)$ \\
\hline \multirow[t]{2}{*}{ ULPs/Union Workforce } & $0.2862^{* *}$ & $0.2844 * *$ & $0.1991^{*}$ & $0.2450^{*}$ & 0.0588 & 0.0579 & 0.0066 & 0.1035 \\
\hline & $(0.0912)$ & $(0.0912)$ & $(0.0914)$ & $(0.0998)$ & $(0.0983)$ & $(0.0983)$ & (0.0981) & (0.0993) \\
\hline \multirow[t]{2}{*}{ Unemployment Rate } & -0.0329 & -0.0339 & $-0.0800^{* *}$ & $-0.1219 * *$ & -0.0043 & -0.0047 & -0.0325 & $-0.1599 * * *$ \\
\hline & $(0.0273)$ & $(0.0273)$ & $(0.0266)$ & $(0.0445)$ & $(0.0285)$ & $(0.0285)$ & $(0.0312)$ & $(0.0480)$ \\
\hline \multirow[t]{2}{*}{ Employment Rate } & -0.0011 & -0.0013 & -0.0342 & -0.0346 & 0.0098 & 0.0098 & -0.0100 & $-0.0707^{*}$ \\
\hline & $(0.0213)$ & $(0.0213)$ & $(0.0211)$ & $(0.0321)$ & $(0.0226)$ & $(0.0226)$ & $(0.0247)$ & $(0.0345)$ \\
\hline \multirow[t]{2}{*}{ CPI Rate } & 0.0082 & 0.0087 & -0.0136 & -0.0335 & 0.0099 & 0.0103 & -0.0031 & $-0.0540^{*}$ \\
\hline & $(0.0124)$ & $(0.0123)$ & $(0.0127)$ & $(0.0265)$ & $(0.0132)$ & $(0.0131)$ & $(0.0150)$ & $(0.0252)$ \\
\hline \multirow[t]{2}{*}{ Union Density Rate } & $0.0306^{*}$ & $0.0303^{*}$ & $0.0251^{+}$ & $0.0303^{*}$ & $0.0406^{* *}$ & $0.0405^{* *}$ & $0.0373^{*}$ & $0.0425^{* *}$ \\
\hline & $(0.0138)$ & $(0.0138)$ & $(0.0136)$ & $(0.0141)$ & $(0.0150)$ & $(0.0150)$ & $(0.0150)$ & $(0.0153)$ \\
\hline \multirow[t]{2}{*}{ Constant } & 77.6716 & 38.0675 & $-7946.1695^{* * *}$ & -0.3787 & -2.3245 & -2.7009 & $-4808.2210^{*}$ & 1.2263 \\
\hline & (59.9171) & $(29.3794)$ & $(1910.1393)$ & $(1.7952)$ & (63.8949) & $(31.4096)$ & $(2360.6645)$ & $(1.9348)$ \\
\hline Province Fixed Effects & Yes & Yes & Yes & Yes & Yes & Yes & Yes & Yes \\
\hline Time Trend & Yes & No & Yes & No & Yes & No & Yes & No \\
\hline Quadratic Time Trend & No & Yes & Yes & No & No & Yes & Yes & No \\
\hline Year Fixed Effects & No & No & No & Yes & No & No & No & Yes \\
\hline Observations & 344 & 344 & 344 & 344 & 344 & 344 & 344 & 344 \\
\hline R-squared & 0.490 & 0.490 & 0.514 & 0.564 & 0.496 & 0.496 & 0.503 & 0.579 \\
\hline
\end{tabular}

Standard errors in parentheses

${ }^{+} \mathrm{p}<0.10,{ }^{*} \mathrm{p}<0.05,{ }^{* *} \mathrm{p}<0.01,{ }^{* * *} \mathrm{p}<0.001$

The coefficients on the control variables are in the hypothesized direction for those

predicted by theory. The legal control dummy variable for whether or not unions may obtain certification through card check or through a mandatory representation vote is positive and highly statistically significant at the $1 \%$ level or greater for all specifications. Furthermore, according to these specifications, the presence of mandatory vote legislation has the greatest effect on the dependent variable in that it correlates with a 41 to 49 percent higher rate of decertifications divided by the unionized workforce. Thus, it appears that either the hypotheses that increased managerial resistance under a mandatory vote regime affects subsequent outcomes beyond certification or that this legislation indicates a period of union weakness prevails over the hypothesis that it will lower decertification by making it more difficult for weaker bargaining units to certify. This finding is similar to that of Benthem (2002) who found a 41 percent 
increase in the decertification rate in provinces that maintained mandatory representation vote legislation. Furthermore, as stated in the theory section, this may also be due to the easing of decertification restrictions that may accompany such mandatory representation vote laws. Unfortunately, the two effects, having a certification vote and the lessening of requirements to revoke a certification, cannot be disentangled in this analysis and thus, this coefficient should be interpreted as the possible summation of the two effects.

The dummy variable for when an anti-union government is the party in power in the province is in the expected direction and statistically significant at the $1 \%$ level when both time trends or year fixed effects are used, but it loses its significance (although it is still marginally significant at the $10 \%$ level) when either single time trend is used. The presence of such a government correlates with an approximately 26 to 40 percent higher rate of decertifications divided by the unionized workforce, although the coefficients that are significant at the $1 \%$ level correlate with a 36 to 40 percent increase. While the aforementioned variable measures government resistance to unionization, the number of ULP complaints received scaled by the size of the unionized workforce, is used to measure employer resistance to unionization. This variable produces coefficients that are in the expected direction and also statistically significant. The specifications in columns (1) and (2) that use only a single time trend are highly significant at the $1 \%$ level, but this drops to the $5 \%$ level in columns (3) and (4). The former coefficients indicate that an increase of one percentage point in the filing of ULP complaints, scaled by the unionized workforce, results in an approximately 29 percent increase in the rate of decertifications (as divided by the unionized workforce) when only a single time trend is used and either a 19 or 25 percent increase when both time trends or time fixed effects are used respectively. This might seem like a drastic finding since the number of ULPs filed in any given 
year can fluctuate rather extensively and this is a relatively large effect on the number of decertifications. However, since the number of ULP complaints is scaled by the unionized workforce, it is important to highlight that it may require a large increase in the number of ULP complaints received to have such a large effect on this dependent variable.

The unemployment rate and the provincial union density rate are the only control variables for the economic environment that display statistical significance. The unemployment rate is statistically significant at the $1 \%$ level, but only when both time trends or year fixed effects are included. These coefficients indicate that a one point increase in the unemployment rate correlates with an 8 to 12 percent decrease in the number of decertifications divided by the unionized workforce. Thus, this finding provides evidence for the hypothesis that as the unemployment rate increases, workers will be less likely to shed the protection that is provided by the union and a collective agreement. The other economic environment variable, the provincial union density rate, is statistically significant at the $5 \%$ level for all specifications, except for when both time trends are included in which it still maintains marginal significance. This variable indicates that a one unit increase in the union density rate results in an approximate 3 percent increase in the rate of decertifications granted divided by the unionized workforce. Thus, this data appears to lend support to the hypothesis that as the union density increases, the number of decertifications may increase due to "union saturation". However, one should be wary of accepting this finding since I do not have union density rates by industry, the level of analysis at which this is likely to occur. Furthermore, as stressed above, this can only be applied to this data set as others, such as Anderson et al. (1980), have found evidence towards the contrary for different countries and time periods. Finally, the variables for a conservative 
provincial government in power, the employment rate, and the provincial CPI rate are all statistically insignificant for all specifications of columns (1) - (4).

When the same independent variables are regressed onto the other dependent variable, the number of decertifications granted divided by the number of certifications granted, the presence of an FCA statute is shown to be even larger by this measure correlating with a decrease of approximately 28 to 32 percent. Every specification using this dependent variable (columns (5) - (8)) is statistically significant with those using a single time trend or year fixed effects significant at the $5 \%$ level, while the specification using both time trends is significant at the $1 \%$ level. Similarly to above, the coefficients on the dummy variable for mandatory vote legislation are in the expected direction, highly significant at the $0.1 \%$ level and have the greatest effect on the dependent variable in these four specifications. Here the presence of mandatory vote legislation correlates with a 79 to 85 percent higher rate of decertifications granted divided by certifications granted, which is about double the magnitude as was found for the other dependent variable.

For this dependent variable, the coefficient for an anti-union government is only significant at the conventional $5 \%$ level when year fixed effects are included. It is marginally significant with the inclusion of both time trends, but insignificant in the specifications with only one time trend. The magnitude of these significant coefficients is similar to those on the other dependent variable with the coefficients correlating with a 39 and 25 percent increase in decertifications respectively. However, unlike above, the coefficient on the dummy variable for when a conservative government is in power in the province is marginally significant at the $10 \%$ level for all of these specifications and this correlates with an approximately 18 to 19 percent increase in this dependent variable. 
All of the coefficients on the control variables for the economic environment are statistically significant for the specification incorporating years fixed effects, but the provincial union density rate is the only one that is statistically significant in any of the other specifications. The unemployment rate is statistically significant at the greater than $1 \%$ level and correlates with a 16 percent decrease in decertifications divided by certifications when the unemployment rate increases by one point. The employment rate and CPI rates are both significant at the 5 percent level and they show a 7 percent and 5 percent decrease in decertifications divided by certifications for a one point increase in those respective rates. These findings indicate that union members are more likely to leave their current employment, rather than decertify, when more job opportunities exist and that they will be less likely to decertify when inflation increases due to the protection that a collective agreement provides. The density rate mimics the results of the regressions described above for the other dependent variable, except at greater significance levels. The coefficients are statistically significant at the $1 \%$ level when either an individual time trend or year fixed effects are included and the significance declines to the 5\% level when both time trends are included. These coefficients indicate that a one percentage point increase in the union density rate correlates with a 4 percent increase in the number of decertifications granted divided by certifications granted. However, unlike the regressions using the other dependent variable described above, the number of ULP complaints received scaled by the unionized workforce is not significant in any of these specifications.

Similar to Johnson (2010), the above findings hinge on the assumption that the passage of FCA provisions is exogenous and that these variables are not simply explaining a larger trend of decreasing decertifications. Thus, to test this assumption, I employed the same informal test of exogeneity that Johnson (2010) employs in her paper in which a dummy variable for the two 
years prior to the passage of an FCA provision is included in the specifications used for Model 1. The results of this test are presented in Table 3 below, which shows that the coefficient on the two year dummy variable is statistically insignificant in all specifications and it is positive in seven out of the eight regressions. Furthermore, all of the coefficients for the first contract arbitration dummy variable remain negative, although only those using the latter dependent variable remain statistically significant. Thus, this provides some evidence, both through the qualitative results of the test (the directions of the coefficients) and the quantitative results (the statistical significance of the latter coefficients), that FCA is exogenous. Therefore, it would appear that the introduction of an FCA provision is related to the decrease in decertifications in those provinces that have such provisions and that this relationship is not spurious due to larger overall trends.

Table 3 - Informal Test of the Exogeneity of First Contract Arbitration Provisions

\begin{tabular}{|c|c|c|c|c|c|c|c|c|}
\hline \multirow{2}{*}{$\begin{array}{l}\text { Dependent Variable: } \\
\text { FCA }\end{array}$} & \multirow{2}{*}{$\begin{array}{c}\text { (1) } \\
\text { Log Dec } \\
-0.1327\end{array}$} & \multicolumn{2}{|c|}{$\begin{array}{c}\text { (2) } \\
\text { tifications Granted/Union }\end{array}$} & $\begin{array}{c}\text { (4) } \\
\text { Norkforce }\end{array}$ & \multirow{2}{*}{$\begin{array}{c}\text { (5) } \\
\text { Log Decer } \\
-0.3159^{+}\end{array}$} & \multirow{2}{*}{$\begin{array}{c}\text { (6) } \\
\text { cations Gr } \\
-0.3158^{+}\end{array}$} & \multirow{2}{*}{$\begin{array}{c}\text { (7) } \\
\text { d/Certifica } \\
-0.3757^{*}\end{array}$} & \multirow{2}{*}{$\begin{array}{c}\text { (8) } \\
\text { s Granted } \\
-0.3639^{*}\end{array}$} \\
\hline & & -0.1330 & -0.2322 & -0.2373 & & & & \\
\hline & (0.1461) & (0.1462) & (0.1477) & (0.1500) & (0.1624) & (0.1624) & (0.1658) & (0.1663) \\
\hline \multirow[t]{2}{*}{ Two Year Dummy } & 0.2080 & 0.2083 & 0.1828 & 0.1034 & 0.0705 & 0.0707 & 0.0553 & -0.0209 \\
\hline & $(0.1976)$ & $(0.1975)$ & $(0.1950)$ & $(0.2065)$ & $(0.2283)$ & $(0.2282)$ & $(0.2266)$ & $(0.2317)$ \\
\hline Province Fixed Effects & Yes & Yes & Yes & Yes & Yes & Yes & Yes & Yes \\
\hline Time Trend & Yes & No & Yes & No & Yes & No & Yes & No \\
\hline Quadratic Time Trend & No & Yes & Yes & No & No & Yes & Yes & No \\
\hline Time Fixed Effects & Yes & Yes & Yes & Yes & Yes & Yes & Yes & Yes \\
\hline Observations & 344 & 344 & 344 & 344 & 344 & 344 & 344 & 344 \\
\hline R-squared & 0.491 & 0.491 & 0.515 & 0.564 & 0.496 & 0.496 & 0.503 & 0.579 \\
\hline
\end{tabular}

When the FCA variable is subdivided into four dummy variables representing each type of FCA found in Canada, as is done in Model 2 and presented in Table 4 below, we receive a much different perspective on the effects of FCA statutes. Table 4 follows the same format as Table 2 with the first four regressions (columns (1) - (4)) using the log number of decertifications granted over the unionized workforce as the dependent variable, while the latter 
four regressions (columns (5) - (8)) use the log number of decertifications granted over certifications granted as the dependent variable. Within these two groupings, the only variation is how each specification accounts for temporal change. As with the regressions for Model 1, I performed each of these regressions using OLS estimation and then ran the same post-estimation diagnostic tests to detect problems with the error structure. These tests produced exactly the same results as in Model 1 with the presence of both groupwise heteroskedasticity and contemporaneous correlation detected for the number of decertifications granted scaled by the unionized workforce and just groupwise heteroskedasticity for the number decertifications granted scaled by certfications granted. There was no indication of serial correlation in the error structure for either estimation. The $F$-tests used to judge whether to include provincial fixed effects and/or time fixed effects were again undertaken and also produced the same results as in Model 1 above. The $F$-tests for both dependent variables pointed to the inclusion of province fixed effects and the exclusion of year fixed effects, although again the latter test produced results that were somewhat close to the rejection region (.1605 and .1502 respectively). Similar to above, when a time trend is included in this specification, the coefficient on it is highly statistically significant, which signals to me that temporal change still needs to be accounted for in the regressions. Thus, even though the $F$-test may indicate that year effects may not be necessary, as with above, I decided to continue to run one regression with year effects, in addition to the specifications in which I used time trend(s), to be consistent with the other specifications. ${ }^{8}$

\footnotetext{
${ }^{8}$ Joint F-tests run after the inclusion of the PCSEs also indicated that the year fixed effects were statistically significantly different than zero for this model too, which provided additional justification for their ultimate inclusion.
} 
Table 4-Regression Results for Model 2

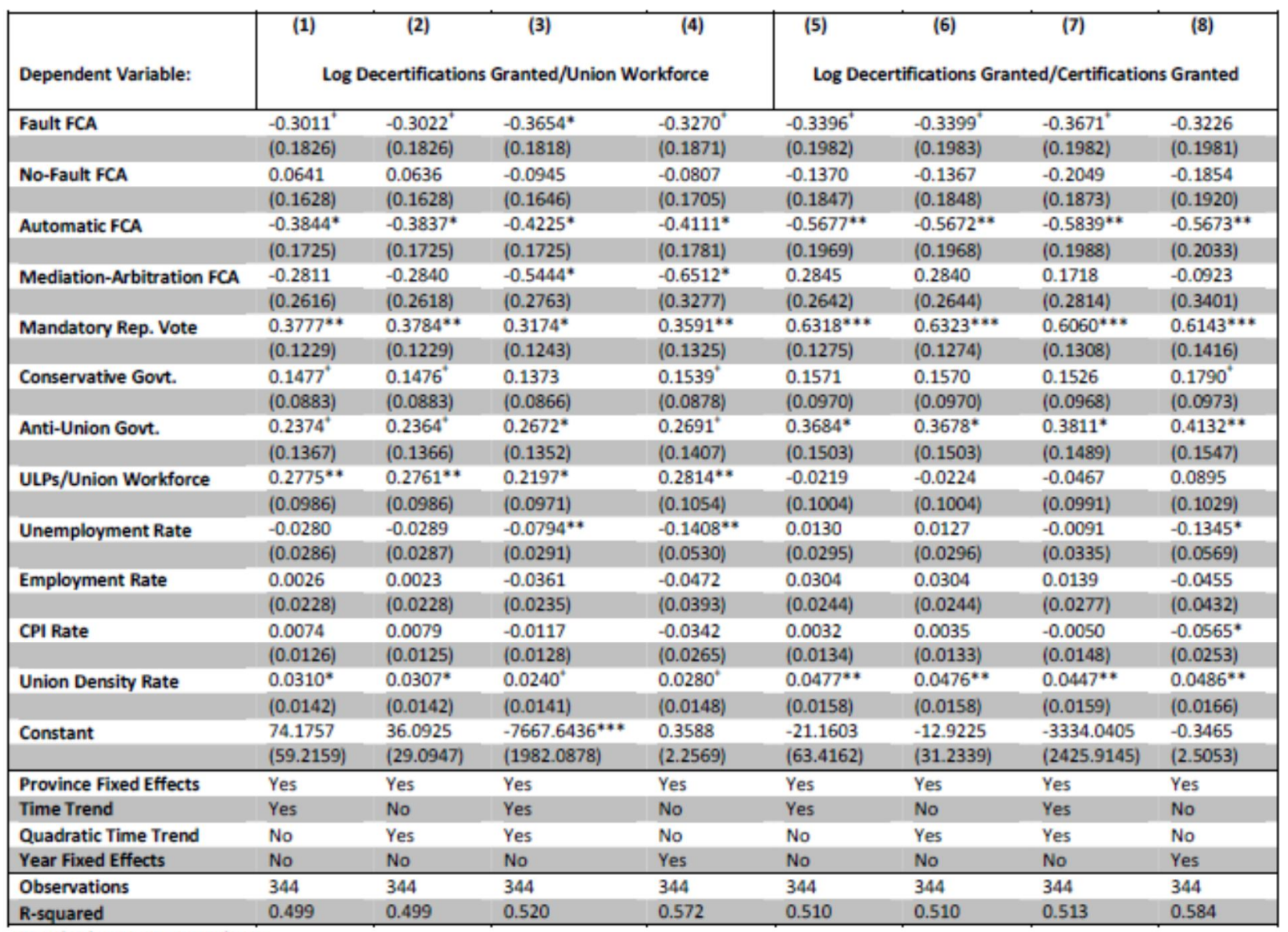

Standard errors in parentheses.

" $p<0.10, *$ * $<0.05, * *$ p $<0.01,{ }^{* * *} p<0.001$

Using the log number of decertifications granted divided by the provincial unionized

workforce as the dependent variable (columns (1) - (4)), the coefficients on the various types of FCA paint an interesting picture. The coefficient on the automatic form of FCA is statistically

significant at the $5 \%$ level for all four of these specifications and correlates with 32 to 34 percent less decertifications, divided by the unionized workforce, than in provinces where no such FCA statute exists. The coefficients on the fault form of FCA is also statistically significant across all four of these specifications, but it is only statistically significant at the $5 \%$ level when both time trends are included and it is marginally significant at the $10 \%$ percent level for the other three specifications. These coefficients indicate that the fault form of FCA correlates with 
approximately 26 to 31 percent less decertifications granted (divided by the unionized workforce) than in those provinces without FCA. The coefficient on the mediation-arbitration form of FCA is significant at the 5\% level, but only when both time trends or year fixed effects are included in the regression. However, the significant coefficients on this form of FCA correlate with approximately 42 to 48 percent less decertifications granted when compared to a province that has no such FCA provision, which is the largest magnitude of any of the forms of FCA. Lastly, the coefficient on the no-fault form of FCA is positive in the specifications that include only a single time trend, which is contrary to the hypothesized direction and may be a troubling finding since this means that the no-fault form of FCA could actually correlate with an increase in decertifications. However, despite the positive coefficient on the first two specifications, all of the coefficients on this form of FCA are statistically insignificant.

As one might expect, the coefficients for the control variables are somewhat similar across the two models for this dependent variable. The coefficient on the dummy variable for mandatory representative votes is positive and highly statistically significant at the $1 \%$ level, except when both time trends are included which drops the significance level to 5\%. The magnitude has decreased slightly in Model 2 (hence the lower levels of significance) such that it now correlates with a 37 to 46 percent higher rate of decertifications depending on the specification. The coefficient on the dummy variable of whether a conservative government is in power in the province is positive and marginally statistically significant at the $10 \%$ level for the specifications in which either time trend or year fixed effects are used and it shows that a conservative government correlates with an approximately 16 to 17 percent increase in the decertification rate under these specifications. The coefficient on the dummy variable is for an anti-union government is also marginally significant at the $10 \%$ level for the same specifications 
as the conservative government dummy variable, but it is also statistically significant at the 5\% level when both time trends are included. Thus, this coefficient correlates with a 27 to 31 percent higher rate of decertifications granted than when a neutral or pro-labor government is in power in the province. The coefficient on the number of ULP complaints received divided by the unionized workforce is positive and statistically significant at the $1 \%$ level when either a normal time trend, quadratic time trend or year fixed effects are included and at the 5\% level when both trends are used. These coefficients indicate that a one percentage point increase in the number of ULP complaints filed divided by the unionized workforce, the rate of decertifications granted divided by the unionized workforce increases by 22 to 28 percent. Like above, the coefficients for the unemployment rate are significant at the $1 \%$ level when both time trends or year effects are included, although the range has increased such that an increase of one point in the unemployment rate now correlates with a decrease of 8 to 14 percent in the number of decertifications granted over the union workforce. The provincial union density rate coefficients are also positive and statistically significant at the $5 \%$ level, but only when the normal or quadratic time trend is used in the regression. The coefficient drops to the $10 \%$ level of significance when both time trends or years fixed effects are included in the specification. These coefficients show that a one percentage point increase in the provincial union density rate correlates with a 2 to 3 percent increase in the number of decertifications granted over the unionized workforce.

When the types of FCA are regressed on the other dependent variable, the log number of decertifications granted over certifications granted, the results change for all four types of FCA (columns (5) - (8)), but more drastically so for the automatic and mediation-arbitration forms of FCA. The coefficients on the no-fault form of FCA change such that all of them are now in the 
hypothesized direction and they experience an increase in magnitude, but they remain statistically insignificant. The coefficient on the fault form of FCA is of similar magnitude to those for the other dependent variable, but the statistical significance of the specification with both time trends falls to the $10 \%$ level and the specification with year fixed effects becomes insignificant. These marginally significant coefficients on the fault form of FCA correlate with a 29 to 31 percent decrease in the number of decertifications granted divided by certifications granted when compared to a province without FCA. The coefficients on the automatic form of FCA change in these specifications such that they are all now highly statistically significant at the $1 \%$ level and they also experience an increase in magnitude, such that this form of FCA correlates with an approximately 43 to 44 percent lower rate of decertification to certifications. Conversely, the coefficients on the mediation-arbitration form of FCA not only lose their statistical significance in these specifications, but change direction such that they become positive for three out of the four specifications. This is contrary to the hypothesized direction for this coefficient and is a troubling finding since, on the surface at least, it means that this form of FCA could perhaps hinder the formation of bargaining relationships. Although as with the coefficient on the no-fault variable for the other dependent variable, perhaps it is not too troubling since one specification is still negative and all of them are statistically insignificant. The drastic change in both magnitude and direction for three of the specifications leads me to believe that the difference is due to the denominator of the dependent variables since that is the only difference between the respective groupings of columns. Since this form of FCA is only found in British Columbia from 1993 until the present, one can look towards that province for an explanation of why this coefficient is positive. Indeed, it appears that this result can partially be explained by the certification activity experienced by British Columbia during the period of 
analysis. In the 1980s, B.C. experience a large decline in certification activity and although there was slight recovery in this activity after the passage of the labor law reform package of 1993, which included the mediation-arbitration form of FCA, the certification rate never recovered to the level prior to its decline. Furthermore, this decline has continued more recently such that the certification activity reached record lows in the most recent years for the period under analysis. This combined with a more level decline in decertification activity has meant that the denominator of this dependent variable has become much smaller during the time period in which the mediation-arbitration form of FCA prevails and thus, every decertification that has taken place during this post 1993 time period has had a more significant effect on this rate than those prior to 1993. In light of this, the steady decline in the number of decertifications granted in British Columbia since 1993 (and the results with the other dependent variable) may suggest that although fewer certifications are creating bargaining relationships, those that are being created have an improved chance of taking hold.

Concerning the control variables, there are a number of differences between the coefficients on the legal and governmental control variables between Models 1 and 2, but only marginal differences between the economic environment variables. The coefficient for the mandatory representation vote legislation is still highly statistically significant at the $0.1 \%$ level, but has a slightly higher magnitude than in Model 1 such that the presence of this type of statute correlates with an approximately 83 to 88 percent higher decertification rate than in those provinces that allow card-check certification. The variable for whether or not the Conservative Party is the party in control of the provincial government loses its statistical significance in Model 2, except for the specification using year fixed effects in which it maintains marginal significance at the $10 \%$ level. This lone significant coefficient correlates with an approximate 20 
percent higher decertification rate when a conservative government is in power than when another party is in power in the province. Furthermore, the dummy variable that indicates when an anti-union government is the party in power improves in statistical significance to the 5\% level for all of the specifications using a time trend and to the $1 \%$ level for the specification that includes year fixed effects. These coefficients indicate that the presence of an anti-union provincial government correlates with a 44 to 51 percent higher decertification to certification rate than when another government that is more amenable to labor is in power. Similar to Model 1, the coefficients for the unemployment rate and the CPI rate are statistically significant, but only for the specification that includes year fixed effects. The former variable correlates with a 13 percent decrease in decertification over certifications for every one point increase in the unemployment rate, while the latter correlates with an approximate 6 percent decrease in the decertifications over certifications rate. Finally, the coefficient for the provincial union density rate is highly statistically significant at the $1 \%$ level for all of the specifications in this model. These coefficients indicate that a one percentage point increase in the provincial union density rate correlates with an approximately 4 to 5 percent increase in the decertification rate. The number of ULP complaints received, as scaled by the union workforce, is no longer statistically significant when regressed on this dependent variable, which is also similar to the results in Model 1 above.

\section{Summary}

The results of these regressions show that first contract arbitration provisions correlate with less decertifications, on aggregate, in provinces that have them than those that do not and this implies that there are more bargaining relationships in their presence than their absence. 
When first contract arbitration is modeled as a dummy variable that represents whether or not a province has an FCA provision, the results show that six out of the eight regressions produce a statistically significant coefficient that indicates that the presence of such a provision correlates with a 23 to 25 percent lower rate in the number of decertifications divided by the unionized workforce and a 28 to 32 percent lower rate in the number of decertifications divided by the number of certifications granted. When the FCA dummy variable is further divided into dummy variables representing each of the individual types of FCA, the results show that the automatic form of FCA produces the best results in terms of lowering the decertification rate, while the fault form of FCA may produce similar results but at a lesser magnitude. The automatic form of FCA correlates with a 32 to 34 percent decrease in decertifications when scaled by the unionized workforce and with a 43 to 44 percent decrease when it is scaled by the number of certifications, whereas the fault form correlates with a 26 to 31 percent decrease for the former and a 29 to 31 percent decrease for the latter measure. On the one hand, these results show that the mediationarbitration form of FCA may correlate with the largest decrease in the decertification rate (42 to 48 percent), but this is only found when decertifications is scaled by the size of the unionized workforce and both time trends or year fixed effects account for temporal change. On the other hand, however, they also show that the no-fault or mediation-arbitration forms of FCA may correlate with no effect or even an increase in the decertification rate when the dependent variable is scaled by the unionized workforce for the former type of FCA and the number of certifications granted for the latter. However, some of the specifications using these dependent variables do produce negative coefficients and all of them are statistically insignificant. As explained above, the findings concerning the mediation-arbitration form of FCA are probably due to extraneous factors outside of the effect of FCA in British Columbia. Such a hypothesis 
may be bolstered by the data which shows that the number of decertifications actually decreased (and continues to do so) in British Columbia during the period in which B.C. has used this form of FCA.

The use of panel corrected standard errors instills confidence that the above statistically significant findings are not statistical artifacts that are the result of artificially suppressed standard errors. Their use hopefully provides us with a more accurate reflection of the effect that FCA provisions can have on the decertification rate and, thus, bargaining relationships.

Furthermore, the statistically significant findings seem more robust in light of the hesitancy with which Beck (2001) suggests including fixed effects into models that undertake TSCS analysis. As mentioned above, due to the likelihood of high collinearity between fixed effects dummy variables and slow changing independent variables, which those representing the FCA provisions certainly qualify, may result in the fixed effects soaking up much of the explanatory power of those independent variables. Therefore, the finding of significance on a number of the FCA dummy variables perhaps makes these findings more robust that FCA provisions actually do result in more bargaining relationships on aggregate by decreasing the decertification rate and that these findings may actually understate their true effect.

Thus it would appear that Nova Scotia, who passed a first contract arbitration provision instituting an automatic system in the previous year, made a wise decision in choosing that type of FCA if its goal was to help foster bargaining relationships. Furthermore, in light of these results, it appears those who crafted the Employee Free Choice Act chose a framework that would have produced the best outcomes given the evidence from the Canadian provinces to help create and develop bargaining relationships by allowing newly certified union bargaining units an improved chance of obtaining a first collective agreement. 


\section{Future Research}

While this study may provide evidence that first contract arbitration provisions do result in the existence of more bargaining relationships per a given size of the unionized workforce/number of certifications granted in the provinces in which they are found than those in which they are absent due to its effect on decertifications, this finding alone does not satisfy the initial goal that was enumerated when first contract arbitration was first conceived: to foster enduring bargaining relationships. As mentioned above, the annual aggregated, provincial-level data that is reported in the annual reports of the provincial labor boards does not allow me to investigate the duration of bargaining relationships, only their continuation through a reduction in decertifications. To undertake such an investigation of the length of bargaining relationships, one would need micro-data at the bargaining unit level to determine the outcomes beyond the settlement/imposition of the first agreement. One path forward could be to perform an analysis that is similar to that of this study, but use a large survey to obtain the bargaining unit level data across all of the jurisdictions. Such a method may be difficult to undertake however, since it would require obtaining information on individual cases around the time of enactment of FCA provisions in all or nearly all of the provinces, which may not be a feasible option for such a multi-jurisdictional approach.

Another possibility is the use of the difference-in-differences (DID) estimator with matched provinces to see whether there is a significant difference between the lengths of bargaining relationships in the presence of an FCA provision versus its absence. DID is often used to measure the impact of a change in policy by treating one group as the control group in which no change occurs and comparing this to a treatment group that undergoes a change (the enactment of the policy) during this same time period. Thus, this is similar to the TSCS analysis 
undertaken in this thesis in that I pooled the provinces that had enacted FCA (Model 1) or the type of FCA (Model 2) and used them as a treatment group and pooled the provinces that had not enacted FCA to be used a control group and examined their differences in this analysis. In the DID context, however, one could use a province that undergoes the enactment of an FCA provision against a comparable province in which no such change occurs to look at the effects that FCA has on bargaining relationship length and by only using two provinces, the acquisition of micro-data that includes specific information on the subsequent outcomes and the length of such relationships may be more feasible. Similarly, one could compare the different types of FCA, rather than the absence of FCA, across the two provinces if they have the same type of FCA in the pre-treatment period and then one switches to another type during the period of analysis. One could also use a singular province, such as Riddell (forthcoming), if a province switches from one form of FCA to another form and then back again.

Furthermore, the use of micro-data could permit a richer investigation of the deterrent effect of FCA. Not only is the deterrent effect underrepresented as an area of analysis of FCA provisions, but such an investigation might produce interesting findings since previous research shows that FCA is rarely accessed, which may lead to the hypothesis that its greatest effect is actually through the deterrence of misconduct. By using case-level data, one would be able to determine which cases used the FCA process and the ability to divide the cases into these two groups would hopefully enable the researcher to determine (1) if there is a deterrent effect through an FCA provision and (2) if so, possibly measure it's magnitude. While one could still assess the overall effects, both direct and deterrent, by comparing the population of cases from the treatment province to the control province, the researcher could also measure the direct effects of FCA provisions by looking at the effect that it has on the duration of bargaining 
relationships for those cases that access the system in the province where it is available versus the cases in the province where it is unavailable. Furthermore, the researcher could use this same control group (or one slightly modified as explained below) and compare it to the cases in the province that has FCA but who don't access the system. If it is shown that the length of bargaining relationships increases for those cases not accessing FCA then this may hypothetically be due to the deterrence effect (this is of course assuming that there is a good matched comparison between the two provinces such that other possible explanations may be ruled out, which should be performed in the DID context anyways). In trying to isolate the deterrence effect though, one would likely have to control for the differences between those cases that do not access the system of FCA in the treatment province and the cases in the control province by restricting the latter to make them comparable to the former.

Lastly, in obtaining micro-data, one could also investigate the effect that first contract arbitration has on employer opposition. As pointed out earlier, in crafting the first FCA provision, Paul Weiler believed that there were two types of employers that resisted unionization: those who were inexperienced in dealing with a union and those who were ideologically opposed. FCA was created initially to counteract the opposition that arose through inexperience and thus, regardless of how effective the FCA provisions was going to be, it was recognized that employer opposition and misconduct would still take place. Therefore, it would be interesting to see, as Bentham (2002) highlights, whether the passage of an FCA provision results in a shift of employer opposition to another point in the certification/bargaining process. For example, one might hypothesize that if an FCA provision is successful at ensuring that a union who is granted access to the process will obtain a first agreement, then employers might shift their opposition to the certification stage of the process in the presence of such a statute. 
This could be taken a step further to investigate employer opposition in the presence of either a card-check regime or mandatory vote regime as the former would present employers with less of an opportunity to shift their opposition to the certification stage than the latter. Thus, all of this could help academics, policymakers and the stakeholders in the industrial relations system attain a better understanding of first contract arbitration and the effects that it may have on many facets of the industrial relations system. 


\section{Conclusion}

This study joins Johnson (2010) and Riddell (forthcoming) as the only studies to undertake an analysis that incorporate the whole of the industrial relations system, meaning cases that do and do not access the FCA machinery, to examine the effects of first contract arbitration and thus, represents the only studies to account for the possibility of a deterrent effect in the statistical analysis of FCA. However, whereas the other two studies investigate the goals of ending work stoppages and securing a first agreement respectively, this study is the only one to undertake the preliminary investigation of the goal of creating lasting bargaining relationships within this framework. While this study is unable to provide the evidence that the bargaining relationships created within the umbrella of an FCA provision are lasting, it provides evidence that more bargaining relationships exist on aggregate due to its effect on decertifications and this is a start to such an investigation concerning the length of the bargaining relationships created.

The findings in this study show that FCA provisions correlate with a lower decertification rate in the provinces that have such laws versus the provinces that do not. When the different types of FCA are modeled, the results show that the automatic form of FCA has the most robust effect on the number of decertifications and this holds for both dependent variables across all specifications. Furthermore, the fault and mediation-arbitration forms of FCA are shown to result in lesser decertifications, and therefore more bargaining relationships, in a number of the specifications. At the very least, the results show that FCA provisions likely do not result in an increase in decertifications, and thus less bargaining relationships.

Although the FCA provisions in many of the Canadian provinces in which they exist are now accepted parts of the industrial relations framework, the passage of an FCA provision in the Canadian province of Nova Scotia only nine months ago and the attempted passage of the 
Employee Free Choice Act in the United States only a few years ago, shows that this study is germane to labor law debates in both countries. Furthermore, even though no Canadian provinces have ever completely overturned an FCA provision, there are a number of provinces that have changed the type of FCA operating within them. Thus, if research shows that one type of FCA, such as the automatic type in this study, can produce improved outcomes over the other types then it is still informative to those provinces who already enacted this piece of labor law. As Paul Weiler (1980) once wrote decades ago, the law may take one of three distinct attitudes: negative, affirmative or neutral. I believe that the evidence presented in this study shows that if the government is to adopt an affirmative approach to collective bargaining and enact laws that facilitate workers' right to contribute to the determination of the terms and conditions of their work through the exercise of collective bargaining, then it would be prudent to enact first contract arbitration legislation to assist in the formation and maintenance of bargaining relationships. 


\section{Appendices}

Appendix 1: Review of Articles on First Contract Achievement Rates in the U.S. and Canada

\begin{tabular}{|c|c|c|c|c|}
\hline Author & $\begin{array}{l}\text { Country } \\
\text { (Jurisdiction) }\end{array}$ & Years & $\begin{array}{l}\text { Percentage of Units Unable to } \\
\text { Secure a First Contract }\end{array}$ & Effect of Unfair Labour Practices \\
\hline Weiler (1984) & United States & $\begin{array}{l}1955- \\
1980\end{array}$ & $\begin{array}{l}1955-14 \text { percent } \\
1970-22 \text { percent } \\
1980-37 \text { percent }\end{array}$ & \\
\hline Solomon (1984) & $\begin{array}{l}\text { Canada } \\
\text { (Ontario) }\end{array}$ & $\begin{array}{l}1980- \\
1981\end{array}$ & $\begin{array}{l}13.4 \text { percent (random sample of } 150 \\
\text { units) }\end{array}$ & \\
\hline Solomon (1985) & $\begin{array}{l}\text { Canada } \\
\text { (Federal) }\end{array}$ & $\begin{array}{l}1979- \\
1980\end{array}$ & 16.9 percent & $\begin{array}{l}\text { negative (magnitude } \\
\text { unspecified) }\end{array}$ \\
\hline Cooke (1985) & United States & $\begin{array}{l}1979- \\
1980\end{array}$ & $\begin{array}{l}22-23 \text { percent; within two years of } \\
\text { certification }\end{array}$ & 32-35 percent decrease \\
\hline Forrest (1986) & $\begin{array}{l}\text { Canada } \\
\text { (Ontario) }\end{array}$ & 1970s & $\begin{array}{l}14.3-20.0 \text { percent depending on } \\
\text { the industry }\end{array}$ & $\begin{array}{l}\text { negative (magnitude } \\
\text { unspecified) }\end{array}$ \\
\hline Pavy (1994) & United States & $\begin{array}{l}1970- \\
1987\end{array}$ & $\begin{array}{l}1970-22 \text { percent } \\
1982-39 \text { percent } \\
1987-35 \text { percent }\end{array}$ & \\
\hline $\begin{array}{l}\text { Bronfenbrenner } \\
(1994,1996)\end{array}$ & United States & & 20 percent (sample of 100 units) & 25-50 percent decrease \\
\hline Bentham (2002) & Canada & & & 14-22 percent decrease \\
\hline Ferguson (2008) & United States & $\begin{array}{l}1999- \\
2004\end{array}$ & $\begin{array}{l}86 \text { percent within } 1 \text { year } \\
44 \text { percent within } 2 \text { years }\end{array}$ & 30 percent decrease \\
\hline $\begin{array}{l}\text { Bronfenbrenner } \\
\text { (2009) }\end{array}$ & United States & $\begin{array}{l}1999- \\
2003\end{array}$ & $\begin{array}{l}52 \text { percent within } 1 \text { year } \\
37 \text { percent within } 2 \text { years } \\
30 \text { percent within three years } \\
25 \text { percent never achieved a } \\
\text { contract }\end{array}$ & \\
\hline Johnson (2010) & United States & $\begin{array}{l}1996- \\
2004\end{array}$ & $30-45$ percent within 2 years & \\
\hline $\begin{array}{l}\text { Riddell } \\
\text { (forthcoming) }\end{array}$ & $\begin{array}{l}\text { Canada } \\
\text { (Ontario) }\end{array}$ & $\begin{array}{l}1995- \\
1998\end{array}$ & 40 percent within 2 years & 17 percent decrease \\
\hline
\end{tabular}




\begin{tabular}{|c|c|c|c|c|c|}
\hline & \\
\hline Author & $\begin{array}{l}\text { Province(s) } \\
\text { And years }\end{array}$ & End Work Stoppages & Secure a First Agreement & Foster Lasting Bargaining Relationships & Act as a Deterrent \\
\hline $\begin{array}{l}\text { Cleveland } \\
\text { (1982) }\end{array}$ & $\begin{array}{l}\text { British } \\
\text { Columbia } \\
\text { 1974-1979 }\end{array}$ & $\begin{array}{l}\text { Cleveland found the } \\
\text { percentage of whether or not } \\
\text { newly certified unions were } \\
\text { unable to obtain an agreement } \\
\text { in } 18 \text { months to be highly } \\
\text { variable over the time period } \\
\text { and concluded that there were } \\
\text { too many factors influencing } \\
\text { such a measure to identify a } \\
\text { deterrent effect. She did find } \\
\text { that the FCA provision } \\
\text { provided a deterrent effect in } \\
\text { that the process gave the } \\
\text { Labour Board an opportunity } \\
\text { to mediate settlements that it } \\
\text { did not have prior to the } \\
\text { enactment of FCA. Lastly, she } \\
\text { concluded that FCA reduces } \\
\text { the occurrence of highly } \\
\text { contentious first agreement } \\
\text { work stoppages since she } \\
\text { found that there was a } \\
\text { decrease in these over the } \\
\text { period of study. }\end{array}$ & $\begin{array}{l}28 \text { Total Cases } \\
\text { - } 24 \text { Concluded with a first agreement ( } 85.71 \%) \\
\text { - } 11 \text { Agreements arbitrated by BC Labour board } \\
\text { ( } 39.28 \%) \\
\text { - } 13 \text { Agreements settled by the parties ( } 46.43 \%) \\
\text { - } 4 \text { ended without an agreement ( } 14.29 \%) \\
\text { Percentage of Cases ending with a CA: } 85.71 \%\end{array}$ & $\begin{array}{l}\text { 24 Total Cases Ending with an Agreement } \\
9 \text { concluded only one agreement } \\
\text { - } 6 \text { were imposed } \\
\text { - } 3 \text { were voluntarily settled } \\
15 \text { concluded second agreement } \\
\text { - } 5 \text { were from initially imposed agreements } \\
\text { o } 1 \text { resulted in further agreements } \\
\text { - } 8 \text { were from initially settled agreements } \\
\text { o } 4 \text { resulted in further agreements } \\
\text { - } 6 \text { of these concluded further agreements } \\
\text { 28 Total Cases } \\
\text { - } 9 \text { Decertifications ( } 32 \%) \\
\text { - } 5 \text { Dormant certifications (18\%) } \\
\text { - } 11 \text { Active certifications ( } 39 \%) \\
\text { - } 3 \text { Other (11\%) }\end{array}$ & $\begin{array}{l}\text { Found no evidence of a deterrent } \\
\text { effect when analyzing the percentage } \\
\text { of newly certified unions unable to } \\
\text { obtain a first agreement within } 18 \\
\text { months of obtaining certification, but } \\
\text { concedes that there are too many } \\
\text { factors influencing this measure. } \\
\text { Found that there was a deterrent } \\
\text { effect for those cases that were } \\
\text { granted access to the FCA process as it } \\
\text { provided the Labour Board with an } \\
\text { opportunity to mediate a settlement. } \\
\text { The author believed that there was a } \\
\text { deterrent effect on highly publicized } \\
\text { work stoppages as they receded after } \\
\text { enactment. Lastly, the author found } \\
\text { that there may be a deterrent effect } \\
\text { for unions in that application to the } \\
\text { FCA process may indicate weakness to } \\
\text { the employer. }\end{array}$ \\
\hline
\end{tabular}




\begin{tabular}{|c|c|c|c|c|c|}
\hline \multicolumn{2}{|c|}{ Appendix 2: FCA Review } & \multicolumn{4}{|c|}{ GOALS } \\
\hline Author & $\begin{array}{l}\text { Province(s) } \\
\text { And years }\end{array}$ & End Work Stoppages & Secure a First Agreement & Foster Lasting Bargaining Relationships & Act as a Deterrent \\
\hline $\begin{array}{l}\text { Girard } \\
\text { and St- } \\
\text { Onge } \\
\text { (1982) }\end{array}$ & $\begin{array}{l}\text { Quebec } \\
\text { 1978-1981 }\end{array}$ & & $\begin{array}{l}\text { 135 Total Applications } \\
71 \text { Granted (52.6\%) } \\
\text { - } 33 \text { Agreement imposed (46.5\%) } \\
\text { - } 15 \text { Still ongoing (21.1\%) } \\
\text { - } 9 \text { Agreements before arbitration (12.7\%) } \\
\text { - } 5 \text { Decisions not to intervene (7.0\%) } \\
\text { - } 3 \text { Agreements during arbitration (4.2\%) } \\
\text { - } 3 \text { Union decertifications (4.2\%) } \\
\text { - } 3 \text { Business closures (4.2\%) } \\
\text { - } 1 \text { Union withdrawal (1.4\%) } \\
\text { 34 Refused ( } 25.0 \%) \\
\text { - } 13 \text { Decertifications (38.2\%) } \\
\text { - } 6 \text { Business closures (17.6\%) } \\
\text { - } 6 \text { Withdrawal of union rep. rights (17.6\%) } \\
\text { - } 3 \text { Ended due to union inactivity (8.8\%) } \\
\text { - } 1 \text { Voluntary arbitration (2.9\%) } \\
\text { - } 1 \text { Agreement (2.9\%) } \\
\text { - } 2 \text { Denied for other reasons (5.9\%) } \\
26 \text { Voluntarily settled agreements (19.3\%) } \\
4 \text { Under ministerial review (3.0\%) } \\
\text { Percentage of Cases ending with a CA: } 54.07 \%\end{array}$ & & \\
\hline $\begin{array}{l}\text { Korpesho } \\
\text { (1986) }\end{array}$ & $\begin{array}{l}\text { Manitoba } \\
1982-1985\end{array}$ & & $\begin{array}{l}21 \text { Total Applications } \\
11 \text { Imposed agreements (52.4\%) } \\
6 \text { Voluntarily settled agreements (28.6\%) } \\
2 \text { Withdrawn applications (9.5\%) } \\
1 \text { Rejected application (4.7\%) } \\
1 \text { Case still before the courts (4.7\%) } \\
\text { Percentage of Cases ending with a CA: } 80.95 \%\end{array}$ & $\begin{array}{l}7 \text { Imposed agreements that had expired } \\
4 \text { Renewals }(57.1 \%) \\
\text { - } 1 \text { Decertification after } 2 \text { nd agreement } \\
\text { ended } \\
2 \text { Decertifications }(28.6 \%) \\
1 \text { Dormant certification }(14.3 \%)\end{array}$ & \\
\hline $\begin{array}{l}\text { Sexton } \\
\text { (1987a) }\end{array}$ & $\begin{array}{l}\text { Manitoba } \\
\text { 1982-1986 } \\
\text { (though } \\
\text { does not } \\
\text { cover all of } \\
\text { 1986) }\end{array}$ & & $\begin{array}{l}25 \text { Total Applications } \\
11 \text { Agreements imposed (44.0\%) } \\
8 \text { Agreements voluntarily settled (32.0\%) } \\
2 \text { Applications withdrawn (8.0\%) } \\
1 \text { Application rejected (4.0\%) } \\
1 \text { Yet to be determined (4.0\%) } \\
1 \text { Pending a court decision (4.0) } \\
\text { Percentage of Cases ending with a CA: } 76.00 \%\end{array}$ & $\begin{array}{l}17 \text { Cases with expired agreements } \\
10 \text { Renewed agreements/ cases still under } \\
\text { negotiation (58.8\%) }\end{array}$ & \\
\hline
\end{tabular}




\begin{tabular}{|c|c|c|c|c|c|}
\hline \multicolumn{2}{|c|}{ Appendix 2: FCA Review } & \multicolumn{4}{|c|}{ GOALS } \\
\hline Author & $\begin{array}{l}\text { Province(s) } \\
\text { And years }\end{array}$ & End Work Stoppages & Secure a First Agreement & Foster Lasting Bargaining Relationships & Act as a Deterrent \\
\hline $\begin{array}{l}\text { Sexton } \\
\text { (1987b) }\end{array}$ & $\begin{array}{l}\text { Quebec } \\
\text { 1978-1984 }\end{array}$ & & $\begin{array}{l}\text { 376 Total Applications } \\
205 \text { Accepted ( } 54.5 \%) \\
\text { - } 88 \text { Imposed agreements ( } 42.9 \%) \\
\text { - } 63 \text { Voluntarily settled agreements ( } 30.7 \%) \\
\text { - } 13 \text { Withdrawn by the union }(6.3 \%) \\
\text { - } 12 \text { Decisions not to intervene }(5.9 \%) \\
\text { - } 8 \text { Decertifications of the union (3.9\%) } \\
\text { - } 8 \text { Business closures (3.9\%) } \\
165 \text { Refused (43.8\%) } \\
6 \text { Still under consideration ( } 1.5 \%) \\
\text { Percentage of accepted cases ending with a CA: } \\
73.66 \%\end{array}$ & $\begin{array}{l}72 \text { Case Sample of imposed agreements } \\
\text { (Out of a population of } 88 \text { ) } \\
49 \text { Yet to come up for renewal ( } 68.1 \%) \\
\text { - } 16 \text { Still active ( } 22.2 \%) \\
\text { - } 16 \text { Decertifications/ Decertifying ( } 22.2 \%) \\
\text { - } 10 \text { Business closures ( } 13.8 \%) \\
\text { - } 4 \text { Under negotiation ( } 5.6 \%) \\
22 \text { Unclear what the outcome was } \\
23 \text { Cases in which the agreement was } \\
\text { renewed } \\
\text { - } 17 \text { of these did not need assistance } \\
\text { - } 5 \text { cases renewed twice } \\
\text { - } 4 \text { cases renewed three times } \\
\text { * Note that the numbers do not add up to } 72 \\
\text { and it is unclear what happened in the four } \\
\text { cases for which the author does not account. }\end{array}$ & \\
\hline $\begin{array}{l}\text { Walker } \\
\text { (1987) }\end{array}$ & $\begin{array}{l}\text { British } \\
\text { Columbia } \\
\text { 1974-mid } \\
1983\end{array}$ & & & & $\begin{array}{l}\text { Looked at the percentage of newly } \\
\text { certified bargaining units unable to } \\
\text { obtain an agreement within } 18 \\
\text { months following certification and } \\
\text { found no discernible trend which led } \\
\text { the author to conclude that there was } \\
\text { no deterrent effect. The author notes } \\
\text { that any deterrence effect may be } \\
\text { negated though by political capture of } \\
\text { the process through the ministerial } \\
\text { screen when an anti-union } \\
\text { government is in power. }\end{array}$ \\
\hline
\end{tabular}




\begin{tabular}{|c|c|c|c|c|}
\hline Appendix & FCA Review & \multicolumn{3}{|c|}{ GOALS } \\
\hline Author & $\begin{array}{l}\text { Province(s) } \\
\text { And years }\end{array}$ & End Work Stoppages & Secure a First Agreement & Foster Lasting Bargaining Relationships \\
\hline $\begin{array}{l}\text { Mitchell } \\
\text { (1992) }\end{array}$ & $\begin{array}{l}\text { Manitoba } \\
\text { 1982-1991 }\end{array}$ & & $\begin{array}{l}93 \text { Total Applications } \\
48 \text { Agreements settled voluntarily (51.6\%) } \\
37 \text { Agreements imposed (39.8\%) } \\
3 \text { Applications withdrawn by parties (3.2\%) } \\
2 \text { Application yet to be determined (2.2\%) } \\
\text { Percentage of Cases ending with a CA: } 91.40 \%\end{array}$ & $\begin{array}{l}80 \text { Total Applications (From 1983-1991) } \\
25 \text { Agreements still in effect } \\
14 \text { Decertifications } \\
10 \text { Settled second agreements } \\
\text { - } 23 \text { Agreements negotiated/settled beyond } \\
\text { 2nd } \\
9 \text { Negotiating second agreements } \\
6 \text { Inactive cases } \\
4 \text { Withdrawn } \\
2 \text { Yet to be determined } \\
37 \text { Total Agreements Imposed by the MLB } \\
8 \text { Decertifications } \\
7 \text { First agreements yet to expire } \\
6 \text { Negotiating the second agreement } \\
5 \text { Concluded second agreements } \\
\text { - } 8 \text { Further agreements negotiated/settled } \\
3 \text { Inactive cases }\end{array}$ \\
\hline $\begin{array}{l}\text { Haywood } \\
\text { (1992) }\end{array}$ & $\begin{array}{l}\text { Manitoba } \\
\text { and Ontario } \\
\text { 1982-1991 } \\
\text { (for } \\
\text { M anitoba) } \\
\text { 1986-1991 } \\
\text { (for Ontario) }\end{array}$ & & $\begin{array}{l}\text { Manitoba } \\
\text { 93 Total Applications } \\
48 \text { Agreements settled voluntarily (51.5\%) } \\
37 \text { Agreements imposed (39.8\%) } \\
3 \text { Applications withdrawn by parties (3.2\%) } \\
2 \text { Application yet to be determined (2.2\%) } \\
\text { Percentage of Cases ending with a CA: } 91.40 \% \\
\text { Ontario } \\
\text { 147 Total Applications } \\
48 \text { Directed to arbitration ( } 32.65 \%) \\
\text { - } 20 \text { Settled through private arbitration (41.7\%) } \\
\text { - } 16 \text { Voluntarily settled agreements (33.3\%) } \\
\text { - } 9 \text { Imposed agreements (18.8\%) } \\
\text { Percentage of Cases directed to arbitration } \\
\text { ending with a CA: } 93.75 \%\end{array}$ & \\
\hline
\end{tabular}




\begin{tabular}{|c|c|c|c|c|}
\hline \multicolumn{2}{|c|}{ Appendix 2: FCA Review } & \multicolumn{3}{|r|}{ GOALS } \\
\hline Author & \begin{tabular}{|l|} 
Province(s) \\
And years
\end{tabular} & End Work Stoppages & Secure a First Agreement & Foster Lasting Bargaining Relationships \\
\hline $\begin{array}{l}\text { Black and } \\
\text { Hosea } \\
\text { (1994) }\end{array}$ & $\begin{array}{l}\text { Manitoba } \\
\text { 1982-1991 }\end{array}$ & & $\begin{array}{l}90 \text { Total Applications } \\
47 \text { Voluntarily settled agreements (52.2\%) } \\
39 \text { Imposed agreements (43.3\%) } \\
3 \text { Withdrawn applications (3.3\%) } \\
1 \text { Refused by the M LB (1.1\%) } \\
\text { Percentage of Cases ending with a CA: } 95.56 \%\end{array}$ & $\begin{array}{l}90 \text { Total Applications } \\
59 \text { Agreements yet to expire (65.6\%) } \\
21 \text { Decertifications ( } 23.3 \% \text { ) } \\
\text { - } 12 \text { From imposed agreements (out of } 39 ; \\
30.7 \% \text { decertification rate for imposed) } \\
\text { - } 7 \text { From voluntary agreements (out of } 47 ; \\
14.9 \% \text { decertification rate for voluntary) } \\
6 \text { Business closures (6.7\%) } \\
4 \text { Inconclusive/Lacking information (4.4\%) } \\
\text { Find that those that access FCA have a } \\
\text { higher decertification rate than those who } \\
\text { do not but that the overall rate is less during } \\
\text { the period } 1983 \text { to } 1991 \text { than the previous } \\
\text { period } 1974 \text { to } 1982 \text { when no FCA provisions } \\
\text { existed. }\end{array}$ \\
\hline $\begin{array}{l}\text { O'Brien } \\
\text { (2001) }\end{array}$ & $\begin{array}{l}\begin{array}{l}\text { British } \\
\text { Columbia }\end{array} \\
1993-2000\end{array}$ & $\begin{array}{l}\text { 50 First contract work } \\
\text { stoppages } \\
31 \text { Accessed the FCA process } \\
\text { - } 16 \text { Applied at start of } \\
\text { stoppage. } \\
\text { ○ All } 16 \text { resulted in a } \\
\quad \text { contract } \\
\text { - } 15 \text { Stoppages took place } \\
\text { after the } \\
\text { application for FCA } \\
\text { O Only } 5 \text { resulted in a } \\
\text { contract }\end{array}$ & $\begin{array}{l}\text { 263 Total applications } \\
178 \text { Settled without direction to arbitration } \\
\text { (67.68\%) } \\
\text { - } 111 \text { Settlements through mediation } \\
\text { - } 67 \text { Settlements through mediator's } \\
\text { recommendations } \\
\circ 20 \text { Used voluntary arbitration } \\
85 \text { Not settled ( } 32.32 \%) \\
\text { - } 25 \text { Directions to arbitration } \\
\text { Percentage of Cases ending with a CA: } 77.19 \% \\
\text { (*Based on the assumption that those directed } \\
\text { to arbitration resulted in an agreement, an } \\
\text { assumption that may be incorrect.) }\end{array}$ & $\begin{array}{l}263 \text { Total applications } \\
66 \text { Decertifications ( } 25.1 \%) \\
\text { - } 23 \text { Took place during FCA process } \\
36 \text { Case sample } \\
16 \text { Agreements yet to expire } \\
13 \text { Cases concluded second agreements } \\
\text { - } 10 \text { Cases concluded further agreements } \\
\text { The author concludes that the evidence is } \\
\text { inconclusive. }\end{array}$ \\
\hline
\end{tabular}




\begin{tabular}{|c|c|c|c|c|}
\hline \multicolumn{2}{|c|}{ Appendix 2: FCA Review } & \multicolumn{3}{|r|}{ GOALS } \\
\hline Author & $\begin{array}{l}\text { Province(s) } \\
\text { And years }\end{array}$ & End Work Stoppages & Secure a First Agreement & Foster Lasting Bargaining Relationships \\
\hline $\begin{array}{l}\text { Marotte } \\
\text { and Paré } \\
(2002)\end{array}$ & $\begin{array}{l}\text { Quebec } \\
1993-2000\end{array}$ & & $\begin{array}{l}\text { 1031 Total applications } \\
\text { 541 Granted (52.5\%) } \\
\text { - Agreements imposed - } 43.1 \% \\
\text { - Voluntarily settled agreements - } 39.9 \% \\
\text { - Withdrawn applications - } 6.1 \% \\
\text { - Business closure - } 3.1 \% \\
\text { - Union decertification - } 2.6 \% \\
\text { - Still undergoing arbitration - } 2.5 \% \\
\text { - Refused to intervene - } 2.2 \% \\
\text { - Settled outside the FCA process - } 0.4 \% \\
\text { 487 Refused (47.2\%) } \\
\text { - Parties concluded an agreement - } 52.8 \% \\
\text { - Union decertified - } 18.9 \% \\
\text { - Business closure - } 7.0 \% \\
\text { - Withdrawn by the union - } 6.2 \% \\
\text { - Decision to use voluntary arbitration - } 6.2 \% \\
\text { - Withdrawn by the employer - } 0.4 \% \\
\text { - Unspecified - } 8.6 \% \\
\text { Percentage of Cases ending with a CA: } 68.5 \%\end{array}$ & $\begin{array}{l}218 \text { Total FCA cases resulting in an } \\
\text { agreement } \\
103 \text { Second agreements settled (47.2\%) } \\
\text { - } 54 \text { Further agreements settled ( } 24.8 \%) \\
\text { o Maximum of five successful rounds } \\
\text { The authors found that the average renewal } \\
\text { rate improved over time from } 20 \% \text { for } 1978 \text { - } \\
1983 \text { to } 25 \% \text { from } 1984-1989 \text { to over } 35 \% \\
\text { for } 1990-1998 \text {. }\end{array}$ \\
\hline $\begin{array}{l}\text { Murray } \\
\text { and } \\
\text { Cuillerier } \\
(2009)\end{array}$ & $\begin{array}{l}\text { Quebec } \\
\text { 1978-2008 }\end{array}$ & & $\begin{array}{l}\mathbf{1 2 3 9} \text { Total Applications } \\
\text { Cases resulting in first agreement - } 74.5 \% \\
\text { Cases granted access to FCA process and } \\
\text { resulting in a first agreement - } 86.4 \%\end{array}$ & \\
\hline $\begin{array}{l}\text { Johnson } \\
(2010)\end{array}$ & $\begin{array}{l}\text { Ten } \\
\text { Jurisdictions } \\
\text { 1976-2005 }\end{array}$ & $\begin{array}{l}\text { FCA statistically significant and } \\
\text { negative across all models. } \\
\text { FCA correlated with } 65 \% \\
\text { reduction in work stoppages in } \\
\text { Private and Quasi Public } \\
\text { Sectors and } 50 \% \text { reduction in } \\
\text { Private Sector. No effect on } \\
\text { work stoppage duration. }\end{array}$ & & \\
\hline
\end{tabular}




\begin{tabular}{|c|c|c|c|c|c|}
\hline \multicolumn{2}{|c|}{ Appendix 2: FCA Review } & \multicolumn{4}{|c|}{ GOALS } \\
\hline Author & $\begin{array}{l}\text { Province(s) } \\
\text { And years }\end{array}$ & End Work Stoppages & Secure a First Agreement & Foster Lasting Bargaining Relationships & Act as a Deterrent \\
\hline $\begin{array}{l}\text { Vipond } \\
(2010)\end{array}$ & $\begin{array}{l}\text { British } \\
\text { Columbia }\end{array}$ & & $\begin{array}{l}\text { 302 Case sample (out of a population of 407) } \\
\text { Concluded a first agreement - } 88.4 \% \\
\text { Success rate of concluding an agreement when: } \\
\text { - Accepting the mediator's recommendations - } \\
97.4 \% \\
\text { - Using voluntary arbitration - } 95.5 \% \\
\text { - Using mediation - } 88.5 \% \\
\text { - Directed to arbitration - } 85.7 \% \\
\text { - Directed to use self-help - } 74.3 \% \\
\text { Percentage of Cases ending with a CA: } 75.00 \% * \\
\text { (*Estimate made by the author of this study.) }\end{array}$ & $\begin{array}{l}\text { 302 Case sample (out of a population of } \\
\text { 407) } \\
\text { 164 Still in bargaining relationship (51.0\%) } \\
\text { - } 86 \text { from a mediated settlement (out of } \\
193 ; 44.6 \% \text { ) } \\
\text { - } 32 \text { from acceptance of the mediator's } \\
\text { recommendations (out of } 39 ; 82.1 \% \text { ) } \\
\text { - } 16 \text { from cases where parties allowed to } \\
\text { exercise self-help (out of } 36 ; 44.4 \% \text { ) } \\
\text { - } 11 \text { from arbitration after mediator's } \\
\text { recommendations refused by one party } \\
\text { (out of } 17 ; 64.7 \% \text { ) } \\
\text { - } 11 \text { from arbitration (out of } 28 ; 39.3 \% \text { ) } \\
\text { - } 8 \text { from voluntary arbitration (out of } 18 ; \\
44.4 \% \text { ) } \\
\text { 123 Decertifications ( } 38.0 \% \text { ) } \\
37 \text { Business closures (11.0\%) } \\
\text { 407 Total Cases } \\
136 \text { Decertifications ( } 33 \% \text { ) } \\
\text { The overall average relationship from the } \\
\text { resolution of the first agreement to the end } \\
\text { of the bargaining relationship (either } \\
\text { decertification or business closure) was } 35.8 \\
\text { months and that it was longest for the cases } \\
\text { that were resolved through mediation } \\
\text { (average of } 38.3 \text { months) than those that } \\
\text { were settled in either arbitration ( } 29.2 \\
\text { months) or a direction to exercise self-help } \\
\text { (32.2 months). Defines a lengthy bargaining } \\
\text { relationship as one that lasts longer than the } \\
12 \text { month freeze period following settlement } \\
\text { of the contract. }\end{array}$ & \\
\hline
\end{tabular}




\begin{tabular}{|c|c|c|c|c|}
\hline \multicolumn{2}{|c|}{ Appendix 2: FCA Review } & \multicolumn{3}{|c|}{ GOALS } \\
\hline Author & $\begin{array}{l}\text { Province(s) } \\
\text { And years }\end{array}$ & End Work Stoppages & Secure a First Agreement & Foster Lasting Bargaining Relationships \\
\hline $\begin{array}{l}\text { Slinn and } \\
\text { Hurd } \\
\text { (2011) }\end{array}$ & $\begin{array}{l}\text { British } \\
\text { Columbia, } \\
\text { Manitoba, } \\
\text { Ontario, } \\
\text { Quebec } \\
\text { 2001-2008 } \\
\text { (2001-2009 } \\
\text { for Ontario, } \\
2002-2008 \\
\text { for Quebec) }\end{array}$ & & $\begin{array}{l}\text { British Columbia } \\
116 \text { Total applications } \\
65 \text { Settled by the parties (56.0\%) } \\
\text { - } 10 \text { Accepted the mediator's recommendations } \\
12 \text { Directions to exercise self-help (10.3\%) } \\
10 \text { Settled through mediation/arbitration (8.6\%) } \\
8 \text { Parties agreed to accept mediation/ arbitration } \\
\text { or the mediator's recommendations (6.9\%) } \\
8 \text { Imposed agreements (6.9\%) } \\
6 \text { Applications withdrawn (5.2\%) } \\
3 \text { Union decertifications (2.6\%) } \\
2 \text { Business closures/ changed ownership (1.7\%) } \\
1 \text { Overturned due to invalid strike vote (0.9\%) } \\
\text { Percentage of Cases ending with a CA: 83.63\% } \\
\text { Manitoba } \\
\text { 47 Total applications } \\
21 \text { Voluntarily settled agreements (44.7\%) } \\
21 \text { Imposed agreements (44.7\%) } \\
5 \text { Applications withdrawn (10.6\%) } \\
\text { Percentage of Cases ending with a CA: 89.40\% } \\
\text { Ontario } \\
70 \text { Total Applications } \\
38 \text { Applications withdrawn (54.29\%) } \\
22 \text { Not granted (adjourned sine die, terminated } \\
\text { or closed for administrative purposes) (31.43\%) } \\
8 \text { Granted direction to arbitration (11.43\%) } \\
2 \text { Dismissed (2.86\%) } \\
\text { Quebec } \\
\text { 214 Total applications } \\
151 \text { Granted (70.6\%) } \\
\text { - } 80 \text { Agreements imposed (53.0\%) } \\
\text { - } 57 \text { Agreements settled voluntarily (37.7\%) } \\
\text { - } 8 \text { Decertifications/Union withdrawals (5.3\%) } \\
\text { - } 6 \text { Yet to finish arbitration (4.0\%) } \\
57 \text { Denied (26.6\%) } \\
\text { - } 38 \text { Agreements concluded (66.7\%) } \\
\text { - } 10 \text { Decertifications/Withdrawals (17.5\%) } \\
\text { - } 9 \text { Unspecified (15.8\%) } \\
\text { 8 Applications withdrawn (2.8\%) } \\
\text { Percentage of Cases ending with a CA: 81.78\% }\end{array}$ & $\begin{array}{l}\text { British Columbia } \\
65 \text { Cases producing settlement through FCA } \\
47 \text { Relationships still in existence ( } 72.3 \%) \\
\text { - } 10 \text { (out of } 10 \text { ) accepting mediator's } \\
\text { recommendations } \\
\text { - } 12 \text { (out of } 18 \text { ) for those directed to } \\
\text { mediation/arbitration or having an } \\
\text { agreement imposed } \\
\text { - } 9 \text { (out of } 12 \text { ) for direction to exercise self- } \\
\text { help } \\
13 \text { Decertifications ( } 20.0 \%) \\
5 \text { Business closures (7.7\%) } \\
108 \text { Total Cases } \\
33 \text { Decertification applications } \\
\text { - } 24 \text { Successful ( } 22.2 \%) \\
\text { Manitoba } \\
28 \text { Cases producing an agreement } \\
7 \text { (out of } 11 \text { cases in which the agreement } \\
\text { was imposed still active } \\
10 \text { (out of } 17 \text { ) cases in which the agreement } \\
\text { was settled still active } \\
\text { Ontario } \\
70 \text { Total applications } \\
15 \text { Decertifications ( } 22.9 \%) \\
\text { - } 1 \text { Case where agreement was imposed } \\
\text { - } 9 \text { Cases were application withdrawn } \\
\text { - } 5 \text { Cases closed due to administrative } \\
\text { reasons, sine die or terminated } \\
\text { - } 2 \text { Cases were dismissed } \\
8 \text { Imposed agreements during period } \\
4 \text { Still active } \\
1 \text { Decertification } \\
3 \text { Not enough information to determine }\end{array}$ \\
\hline
\end{tabular}


\begin{tabular}{l|l|l} 
& And years & \\
\hline Riddell & Ontario & Found that the first contract success rate was
\end{tabular}

(forthcom between 60 and 70 percent for all cases

the 60 and 70 percent for all cases

whether they accessed the FCA process or not.

He also found that the automatic type of FCA

was associated with a 10 to 12 percentage point

higher success rate than under the no-fault form

of FCA. 
Appendix 3 - Summary Statistics Table and Bivariate Correlation Table

\begin{tabular}{|c|c|c|c|c|c|c|}
\hline Variable & & Mean & Std. Deviation & Minimum & Maximum & Observations \\
\hline ID & $\begin{array}{l}\text { overall } \\
\text { between } \\
\text { within }\end{array}$ & 5 & $\begin{array}{l}2.585331 \\
2.738613 \\
0\end{array}$ & $\begin{array}{l}1 \\
1 \\
5\end{array}$ & $\begin{array}{l}9 \\
9 \\
5\end{array}$ & $\begin{array}{l}N=369 \\
n=9 \\
T=41\end{array}$ \\
\hline Year & $\begin{array}{l}\text { overall } \\
\text { between } \\
\text { within }\end{array}$ & 1990 & $\begin{array}{l}11.84822 \\
0 \\
11.84822\end{array}$ & $\begin{array}{l}1970 \\
1990 \\
1970\end{array}$ & $\begin{array}{l}2010 \\
1990 \\
2010\end{array}$ & $\begin{array}{l}N=369 \\
n=9 \\
T=41\end{array}$ \\
\hline $\begin{array}{l}\text { Log Decertifications/ } \\
\text { Union Workforce }\end{array}$ & $\begin{array}{l}\text { overall } \\
\text { between } \\
\text { within }\end{array}$ & -2.703446 & $\begin{array}{l}0.810634 \\
0.5183715 \\
0.6483517\end{array}$ & $\begin{array}{l}-4.756173 \\
-3.296971 \\
-4.795443\end{array}$ & $\begin{array}{l}0.0216112 \\
-1.819134 \\
-0.2520435\end{array}$ & $\begin{array}{l}\mathrm{N}=354 \\
\mathrm{n}=9 \\
\overline{\mathrm{T}}=39.3333\end{array}$ \\
\hline $\begin{array}{l}\text { Log Decertifications/ } \\
\text { Certifications }\end{array}$ & $\begin{array}{l}\text { overall } \\
\text { between } \\
\text { within }\end{array}$ & -2.040594 & $\begin{array}{l}0.8984797 \\
0.4600837 \\
0.7863391\end{array}$ & $\begin{array}{l}-5.030438 \\
-2.787357 \\
-4.850818\end{array}$ & $\begin{array}{l}0.9162908 \\
-1.361775 \\
0.5256174\end{array}$ & $\begin{array}{l}\mathrm{N}=354 \\
\mathrm{n}=9 \\
\bar{T}=39.3333\end{array}$ \\
\hline $\begin{array}{l}\text { First Contract } \\
\text { Arbitration }\end{array}$ & $\begin{array}{l}\text { overall } \\
\text { between } \\
\text { within }\end{array}$ & 0.4471545 & $\begin{array}{l}0.4978746 \\
0.3632018 \\
0.360974\end{array}$ & $\begin{array}{l}0 \\
0 \\
-0.4552846\end{array}$ & $\begin{array}{l}1 \\
0.902439 \\
1.056911\end{array}$ & $\begin{array}{l}N=369 \\
n=9 \\
T=41\end{array}$ \\
\hline Fault FCA & $\begin{array}{l}\text { overall } \\
\text { between } \\
\text { within }\end{array}$ & 0.2140921 & $\begin{array}{l}0.410748 \\
0.3264964 \\
0.2714792 \\
\end{array}$ & $\begin{array}{l}0 \\
0 \\
-0.5907859 \\
\end{array}$ & $\begin{array}{l}1 \\
0.804878 \\
1.189702 \\
\end{array}$ & $\begin{array}{l}\mathrm{N}=369 \\
\mathrm{n}=9 \\
\mathrm{~T}=41\end{array}$ \\
\hline No-Fault FCA & $\begin{array}{l}\text { overall } \\
\text { between } \\
\text { within }\end{array}$ & 0.0867209 & $\begin{array}{l}0.2818077 \\
0.1869919 \\
0.2196594\end{array}$ & $\begin{array}{l}0 \\
0 \\
-0.4498645\end{array}$ & $\begin{array}{l}1 \\
0.5365854 \\
0.8428184\end{array}$ & $\begin{array}{l}N=369 \\
n=9 \\
T=41\end{array}$ \\
\hline Automatic FCA & $\begin{array}{l}\text { overall } \\
\text { between } \\
\text { within }\end{array}$ & 0.097561 & $\begin{array}{l}0.297123 \\
0.2164419 \\
0.2157013\end{array}$ & $\begin{array}{l}0 \\
0 \\
-0.5609756\end{array}$ & $\begin{array}{l}1 \\
0.6585366 \\
1.02439\end{array}$ & $\begin{array}{l}N=369 \\
n=9 \\
T=41\end{array}$ \\
\hline $\begin{array}{l}\text { Mediation- } \\
\text { Arbitration FCA }\end{array}$ & $\begin{array}{l}\text { overall } \\
\text { between } \\
\text { within }\end{array}$ & 0.0487805 & $\begin{array}{l}0.2157013 \\
0.1463415 \\
0.1656473 \\
\end{array}$ & $\begin{array}{l}0 \\
0 \\
-0.3902439 \\
\end{array}$ & $\begin{array}{l}1 \\
0.4390244 \\
0.6097561 \\
\end{array}$ & $\begin{array}{l}N=369 \\
n=9 \\
T=41\end{array}$ \\
\hline $\begin{array}{l}\text { Mandatory } \\
\text { Representation Vote }\end{array}$ & $\begin{array}{l}\text { overall } \\
\text { between } \\
\text { within }\end{array}$ & 0.3089431 & $\begin{array}{l}0.462685 \\
0.2854805 \\
0.376081 \\
\end{array}$ & $\begin{array}{l}0 \\
0 \\
-0.5203252\end{array}$ & $\begin{array}{l}1 \\
0.8292683 \\
1.235772 \\
\end{array}$ & $\begin{array}{l}N=369 \\
n=9 \\
T=41\end{array}$ \\
\hline Conservative Govt. & $\begin{array}{l}\text { overall } \\
\text { between } \\
\text { within }\end{array}$ & 0.4634146 & $\begin{array}{l}0.4993368 \\
0.3301704 \\
0.3900947\end{array}$ & $\begin{array}{l}0 \\
0 \\
-0.4878049\end{array}$ & $\begin{array}{l}1 \\
0.9512195 \\
1.219512\end{array}$ & $\begin{array}{l}N=369 \\
n=9 \\
T=41\end{array}$ \\
\hline Anti-Union Govt. & $\begin{array}{l}\text { overall } \\
\text { between } \\
\text { within }\end{array}$ & 0.0650407 & $\begin{array}{l}0.2469324 \\
0.1027579 \\
0.2270774 \\
\end{array}$ & $\begin{array}{l}0 \\
0 \\
-0.2276423 \\
\end{array}$ & $\begin{array}{l}1 \\
0.2926829 \\
1.01626 \\
\end{array}$ & $\begin{array}{l}\mathrm{N}=369 \\
\mathrm{n}=9 \\
\mathrm{~T}=41\end{array}$ \\
\hline $\begin{array}{l}\text { ULPs/Union } \\
\text { Workforce }\end{array}$ & $\begin{array}{l}\text { overall } \\
\text { between } \\
\text { within }\end{array}$ & 0.5667259 & $\begin{array}{l}0.5595493 \\
0.3604667 \\
0.4485179\end{array}$ & $\begin{array}{l}0.0176056 \\
0.1788498 \\
-0.3793794\end{array}$ & $\begin{array}{l}6.614682 \\
1.248926 \\
5.932482\end{array}$ & $\begin{array}{l}\mathrm{N}=354 \\
\mathrm{n}=9 \\
\overline{\mathrm{T}}=39.3333\end{array}$ \\
\hline Unemployment Rate & $\begin{array}{l}\text { overall } \\
\text { between } \\
\text { within }\end{array}$ & 9.004065 & $\begin{array}{l}3.779624 \\
3.348421 \\
2.071791\end{array}$ & $\begin{array}{l}2.8 \\
5.64878 \\
3.660163\end{array}$ & $\begin{array}{l}20.2 \\
16.1439 \\
15.41626\end{array}$ & $\begin{array}{l}\mathrm{N}=369 \\
\mathrm{n}=9 \\
\mathrm{~T}=41\end{array}$ \\
\hline Employment Rate & $\begin{array}{l}\text { overall } \\
\text { between } \\
\text { within }\end{array}$ & 57.09213 & $\begin{array}{l}6.926039 \\
6.348869 \\
3.47033 \\
\end{array}$ & $\begin{array}{l}38.16833 \\
45.24298 \\
46.18496 \\
\end{array}$ & $\begin{array}{l}72 \\
66.03398 \\
64.25481 \\
\end{array}$ & $\begin{array}{l}N=369 \\
n=9 \\
T=41\end{array}$ \\
\hline CPI Rate & $\begin{array}{l}\text { overall } \\
\text { between } \\
\text { within }\end{array}$ & 71.68049 & $\begin{array}{l}30.36116 \\
0.65071 \\
30.35494\end{array}$ & $\begin{array}{l}20.3 \\
70.87561 \\
19.08049\end{array}$ & $\begin{array}{l}122.7 \\
72.9 \\
123.0293\end{array}$ & $\begin{array}{l}\mathrm{N}=369 \\
\mathrm{n}=9 \\
\mathrm{~T}=41\end{array}$ \\
\hline Union Density Rate & $\begin{array}{l}\text { overall } \\
\text { between } \\
\text { within }\end{array}$ & 33.62232 & $\begin{array}{l}6.887604 \\
5.49913 \\
4.526109\end{array}$ & $\begin{array}{l}16.96019 \\
24.64629 \\
12.34269\end{array}$ & $\begin{array}{l}57.6 \\
43.405 \\
47.81732\end{array}$ & $\begin{array}{l}N=369 \\
n=9 \\
T=41\end{array}$ \\
\hline
\end{tabular}




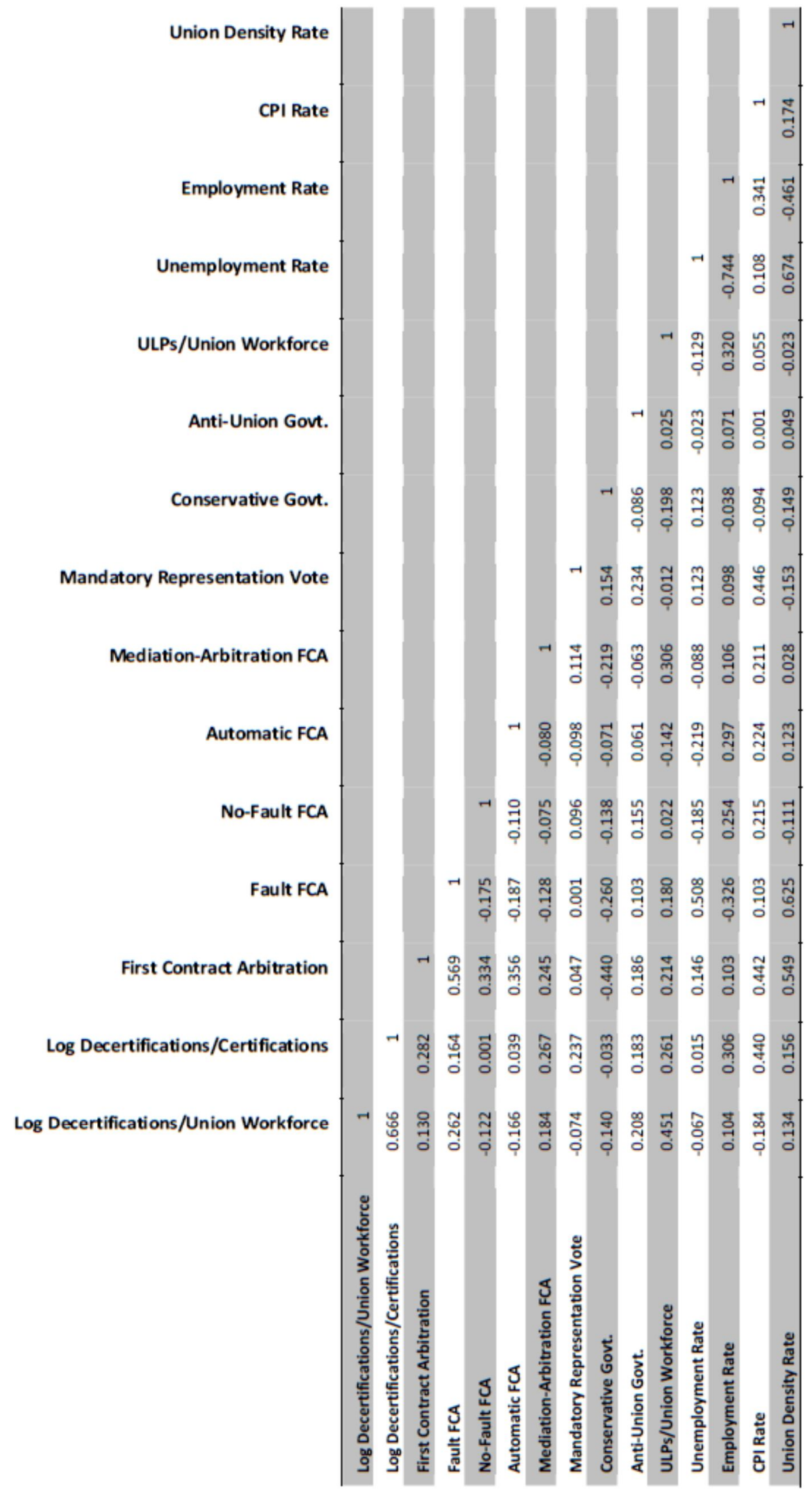




\section{Bibliography}

Anderson, John C., Charles A. O’Reilly, and Gloria Busman. 1980. "Union Decertification in the U.S.: 1947-1977.” Industrial Relations, Vol. 19, No. 1, pp. 100-107.

Akyeampong, Ernest B. 2004. "The union movement in transition." Perspectives on Labour and Income, Vol. 5, No. 8. http://www.statcan.gc.ca/pub/75-001-x/10804/7011-eng.htm.

Backhouse, Constance. 1980. "The fleck strike: A case study in the need for first contract arbitration." Osgoode Hall Law Journal, Vol. 18, No. 4, pp. 495-553.

Beck, Nathaniel. 2001. "Time-Series-Cross-Section Data: What Have We Learned in the Past Few Years?” Annual Review of Political Science, Vol. 4, pp. 271-293.

Beck, Nathaniel and Jonathan N. Katz. 1995. "What to do (and not to do) with Time-Series Cross-Section Data.” The American Political Science Review, Vol. 89, No. 3, pp. 634-647.

Bentham, Karen. 2002. "Employer Resistance to Union Certification: A Study of Eight Canadian Jurisdictions." Relations Industrielles/Industrial Relations, Vol. 57, No. 1, pp. 159-187.

Black, Errol and Craig Hosea. 1994. "First Contract Legislation in Manitoba: A model for the United States.” Labor Law Journal, Vol. 45, No. 1, pp. 33-40.

Bronfenbrenner, Kate. 1994. "Employer Behavior in Certification Elections and First Contract Campaigns: Implications for Labor Law Reform.” In Sheldon Friedman, Richard Hurd, and Rudolph Oswald, Eds. Restoring the Promise of American Labor Law, pp. 75-89. Ithaca, New York: ILR Press.

Bronfenbrenner, Kate. 1996. "Lasting Victories: Successful Union Strategies for Winning First Contracts." Proceedings of the Forty-Eight Annual Meeting of the Industrial Relations Research Association Series. San Francisco, California.

Bronfenbrenner, Kate. 2009. "No Holds Barred: The Intensification of Employer Opposition to Organizing." EPI Policy Briefing Paper \#235. Washington, D.C.: Economic Policy Institute.

Cameron, A. Colin and Pravin K. Trivedi. 2009. Microeconometrics Using Stata. College Station, Texas: Stata Press.

Cleveland, Deborah J. 1982. "First Agreement Arbitration in British Columbia: 1974-1979." Calgary, A.B.: University of Calgary. 
Cooke, William N. 1983. "Determinants of the Outcomes of Union Certification Elections." Industrial and Labor Relations Review, Vol. 36, No. 3, pp. 402-414.

Cooke, William N. 1985. "The Failure to Negotiate First Contracts: Determinants and Policy Implications." Industrial and Labor Relations Review, Vol. 38, No. 2, pp. 163-178.

Eisenbrey, Ross and Patrick Eagan-Van Meter. 2010. "Business Success and First Contract Arbitration.” EPI Policy Briefing Paper \#275. Washington D.C.: Economic Policy Institute.

Employee Free Choice Act. Bill H.R.1409.IH. Available at: http://thomas.loc.gov/cgibin/query/z?c111:H.R.1409:.

Ferguson, John-Paul. 2008. "The Eyes of the Needles: A Sequential Model of Union Organizing Drives, 1999-2004." Industrial and Labor Relations Review, Vol. 62, No. 1, pp. 3-21.

Forrest, Anne. 1986. "Bargaining Units and Bargaining Power." Relations

Industrielles/Industrial Relations, Vol. 41, No. 4, pp. 840-850.

Friedman, Sheldon and Robert Wozniak. 1996. "First Contract Arbitration: The Canadian Experience." Proceedings of the Forty-Eighth Annual Meeting of the Industrial Relations Research Association Series. San Francisco, CA. pp. 153-160.

Garrett, Geoffrey and Deborah Mitchell. 1999. "Globalization and the Welfare State." Unpublished Paper: Yale University.

Girard, Michelle and Yvan St-Onge. 1982. "Etude Sur L'arbitrage des Premieres Conventions Collectives." Gouvernement du Quebec: Ministère du Travail, Centre de Recherche et de Statistiques sur le Marché du Travail.

Godard, John. 2003. "Do Labor Laws Matter? The Density Decline and Convergence Thesis Revisited." Industrial Relations, Vol. 42, No. 3, pp. 458-492.

Greene, William H. 2003. Econometric Analysis. Upper Saddle River, N.J.: Prentice Hall. $5^{\text {th }}$ Ed.

Haywood, Lenard. 1993. "Experience with first agreement arbitration in Ontario and Manitoba, 1982-1992.” Ontario: Ministry of Labour, Office of Collective Bargaining Information. 
Hoh, Ronald. 2010. "Interest Arbitration under the Proposed Employee Free Choice Act: What We Can Learn From the American and Canadian Experiences." Dispute Resolution Journal, Vol. 64, No. 4, pp. 50-59.

Hurd, Richard W. 1996. "Union-Free Bargaining Strategies and First Contract Failures." Proceedings of the Forty-Eighth Annual Meeting of the Industrial Relations Research Association Series. San Francisco, CA. pp. 145-152.

Jain, Harish C. and S. Muthuchidambaram. 1996. "Labor Law Reform in Ontario: Evaluation of Bill 40." Proceedings of the Forty-Eight Annual Meeting of the Industrial Relations Research Association Series. San Francisco, California.

Johnson, Susan. 2002. "Card Check or Mandatory Representation Vote? How the Type of Union Recognition Procedure Affects Union Certification Success." The Economic Journal, Vol. 112, No. 479, pp. 344-361.

Johnson, Susan. 2004. "The Impact of Mandatory Votes on the Canada-U.S. Union Density Gap: A Note." Industrial Relations, Vol. 43, No. 2, pp. 356-363.

Johnson, Susan J.T. 2010. "First Contract Arbitration: Effects on Bargaining and Work Stoppages." Industrial and Labor Relations Review, Vol. 63, No. 4, pp. 585-605.

Korpesho, J.M.P. 1986. "First Contract Experience in Manitoba." Paper presented at the Proceedings of the $23^{\text {rd }}$ Annual Meeting of the Canadian Industrial Relations Association. University of Manitoba. Winnipeg, Manitoba, May 29-31, 1986, pp. 50-54.

Logan, John. 2002. "Consultants, Lawyers and the Union-Free Movement in the USA since the 1970s.” Industrial Relations, Vol. 33, No. 3, pp. 197-214.

Maddala, G.S. 1998. "Recent Developments in Dynamic Econometric Modelling : A Personal Viewpoint." Political Analysis, Vol. 7, No. 1, pp. 59-87.

Marotte, Josée and Francine Paré 2002. "L'arbitrage de première convention collective: Un portrait statistique, 1978-2001." Quebec: Ministère du Travail.

Martinello, Felice. 1996. "Correlates of Certification Application Success in British Columbia, Saskatchewan and Manitoba.” Relations Industrielles/Industrial Relations, Vol. 51, No. 3, pp. 544-562. 
Martinello, Felice. 2000. "Mr. Harris, Mr. Rae and Union Activity in Ontario." Canadian Public Policy/Analyse de Politiques, Vol. 26, No. 1, pp. 17-33.

Martinello, Felice. 2002. Certification and Decertification Activity in Canadian Jurisdictions. Kingston, Ontario: Industrial Relations Centre Press, Queen's University.

Martinello, Felice and Ronald Meng. 1992. "Effects of Labor Legislation and Industry Characteristics on Union Coverage in Canada." Industrial and Labor Relations Review, Vol. 46, No. 1, pp. 176-190.

McCormack, Judith. 1991. "First Contract Arbitration in Ontario: A Glance at Some of the Issues." Labour Arbitration Yearbook.

McDonald, Alistair Peter. 1987. "First Contract Arbitration in Canada: An Analysis of the Legislation in Five Labour Jurisdictions in Canada." School of Industrial Relations Research Essay Series, No. 17. Kingston, Ontario: Industrial Relations Centre Press, Queen's University.

Mitchell, Grant. 1992. "Private sector statutory interest arbitration: The Manitoba experience in the Canadian context - imposed first contracts and final offer selection." Canadian Journal of Administrative Law and Practice, Vol. 5, pp. 287-332.

Murray, Gregor and Joelle Cuillerier. 2009. "The Sky Is Not Falling: Unionization, Wal-Mart and First-Contract Arbitration in Canada." Just Labour: A Canadian Journal of Work and Society, Vol. 15, Nov., pp. 78-98

Muthuchidambaram, S. 1980. "Settlement of First Collective Agreement: An Examination of the Canada Labour Code Amendment." Relations Industrielles/Industrial Relations, Vol. 35, No. 3, pp. 387-409.

O’Brien, Jan. 2001. "First Collective Agreement Legislation: From Exceptional Remedy to Routine Solution.” Vancouver, B.C.: Simon Fraser University.

Ontario Labour Relations Act. http://www.elaws.gov.on.ca/html/statutes/english/elaws_statutes_95101_e.htm.

Patterson, Diane L. 1990. "First Contract Arbitration in Ontario." School of Industrial Relations Research Essay Series, No. 30. Kingston, Ontario: Industrial Relations Centre Press, Queen's University. 
Pavy, Gordon. 1994. "Winning NLRB Elections and Establishing Collective Bargaining Relationships." In Sheldon Friedman, Richard Hurd, and Rudolph Oswald, Eds. Restoring the Promise of American Labor Law, pp. 75-89. Ithaca, New York: ILR Press.

Riddell, Chris. 2001. "Union Suppression and Certification Success." The Canadian Journal of Economics, Vol. 34, No. 2, pp. 396-410.

Riddell, Chris. 2004. "Union Certification Success under Voting versus Card-Check Procedures: Evidence from British Columbia, 1978-1998." Industrial and Labor Relations Review, Vol. 57, No. 4, pp. 493-517.

Riddell, Chris. Forthcoming. "Labor law reform, unionization and reaching a first collective agreement: Empirical evidence from Ontario."

Rose, Joseph B. 2006. "Collective Bargaining Performance of Newly Certified Unions in Canada: Process and Outcomes." In Gregor Gall, Ed. Union Recognition: Organising and Bargaining Outcomes, pp. 198-214. New York: Routledge.

Sexton, Jean. 1987a. "First Contract Arbitration in Canada." Labor Law Journal, Vol. 38, No. 8, pp. 508-514.

Sexton, Jean. 1987b. "L'arbitrage de première convention collective au Québec : 1978-1984." Relations Industrielles/Industrial Relations, Vol. 42, No. 2, pp. 272-291.

Slinn, Sara and Richard W. Hurd. 2010. "First Contract Arbitration and the Employee Free Choice Act: Multi-Jurisdictional Evidence from Canada." Advances in Industrial and Labor Relations, Vol. 18, pp. 41-86.

Solomon, Norman A. 1984. "The Negotiation of First Agreements in Ontario: An Empirical Study." Relations Industrielles/Industrial Relations, Vol. 39, No. 1, pp. 23-35.

Solomon, Norman A. 1985. "The Negotiation of First Agreements under the Canada Labour Code." Relations Industrielles/Industrial Relations, Vol. 40, No. 3, pp. 458-472.

Taras, Daphne Gottlieb. 1997. "Collective Bargaining Regulation in Canada and the United States: Divergent Cultures, Divergent Outcomes.” In Bruce Kaufman, Ed. Government Regulation of the Employment Relation, Madison, WI: Industrial Relations Research Association, pp. 295-341. 
Vipond, Melanie. 2010. "First Contract Arbitration: Evidence From British Columbia, Canada of the Significance of Mediator's Non-Binding Recommendations." Available at:

http://works.bepress.com/melanie_vipond/1

Voos, Paula B. 1997. "The Potential Impact of Labor and Employment Legislation on Arbitration.” In James L. Stern and Joyce M. Najita, Eds. Labor Arbitration Under Fire, Ithaca, NY: Cornell University Press, pp. 208-230.

Walker, Julian. 1987. "First Agreement Disputes and Public Policy in Canada." School of Industrial Relations Research Essay Series, No. 12. Kingston, Ontario: Industrial Relations Centre Press, Queen's University.

Weiler, Paul. 1980. Reconcilable Differences: New Directions in Canadian Labour Law. Toronto, Ontario: The Carswell Company Limited.

Weiler, Paul. 1984. "Striking a New Balance: Freedom of Contract and the Prospects for Union Representation." Harvard Law Review, Vol. 98, No. 2, pp. 351-420 